Portland State University

PDXScholar

Fall 11-4-2015

\title{
Design and Synthesis of Novel Chloroquine-based Antimalarials
}

Kevin Vincent Murphy

Portland State University

Follow this and additional works at: https://pdxscholar.library.pdx.edu/open_access_etds

Part of the Chemistry Commons, and the Medicinal and Pharmaceutical Chemistry Commons Let us know how access to this document benefits you.

\section{Recommended Citation}

Murphy, Kevin Vincent, "Design and Synthesis of Novel Chloroquine-based Antimalarials" (2015).

Dissertations and Theses. Paper 2623.

https://doi.org/10.15760/etd.2619

This Thesis is brought to you for free and open access. It has been accepted for inclusion in Dissertations and Theses by an authorized administrator of PDXScholar. Please contact us if we can make this document more accessible: pdxscholar@pdx.edu. 
Design and Synthesis of Novel Chloroquine-based Antimalarials

by

Kevin Vincent Murphy

A thesis submitted in partial fulfillment of the requirements for the degree of

Master of Science

in

Chemistry

Thesis Committee:

David Peyton, Chair

Albert Benight

Robert Strongin

Portland State University

2015 


\begin{abstract}
$\underline{\text { Abstract }}$
Malaria is an infectious, often fatal disease that afflicts nearly 200 million people every year. The disease, characterized by recurring and extreme flu-like symptoms, is caused by the protozoan parasite Plasmodium falciparum. Victims usually contract the disease through a mosquito vector. Chloroquine is a chemotherapeutic that was introduced in the 1940s. For many years the drug was the foremost treatment of malaria, being effective and producing few side effects. Unfortunately, tolerance to chloroquine developed when the parasite evolved a resistance mechanism. Newer drugs have been developed and implemented, but these medicines also show a decreasing effect with continued administration. It is imperative that a new pipeline of drugs be developed in order to combat the disease and anticipated resistance. Reversed chloroquines are a new class of multiple-ligand compounds that are active against chloroquine-sensitive and chloroquine-resistance malaria species. This thesis describes research targeted at the modification of lead reversed chloroquine molecules to discover new and effective moieties, as well as to improve pharmacokinetic-related properties. An especial emphasis of this project is the addition of a sulfonamide functional group to a reversed chloroquine. Preliminary evidence indicates that this is a promising direction for this line of research. Brief discussions of some reversed chloroquine characterization studies are included in appendices.
\end{abstract}




\section{$\underline{\text { Acknowledgments }}$}

The passage to becoming a scientist was an unexpected journey. Dr. David Peyton, my advisor, has been a constant support of this fledgling chemist, beginning with permitting me to join the ranks of chemistry as a member of his lab, and then granting me the freedom to explore its varied branches, even too often at the cost of immediate results. I only hope I can someday repay you, Dr. Peyton! I thank my family for nurturing my passion for all things intellectual. Finally, I think my dear wife, Amara, for her loving patience throughout this long, winding journey of mine, and for gently encouraging me to see this project through to the end, even when the going got rough - and it did. The cliché could not be more true: I couldn't have done it without you! 


\section{$\underline{\text { Table of Contents }}$}

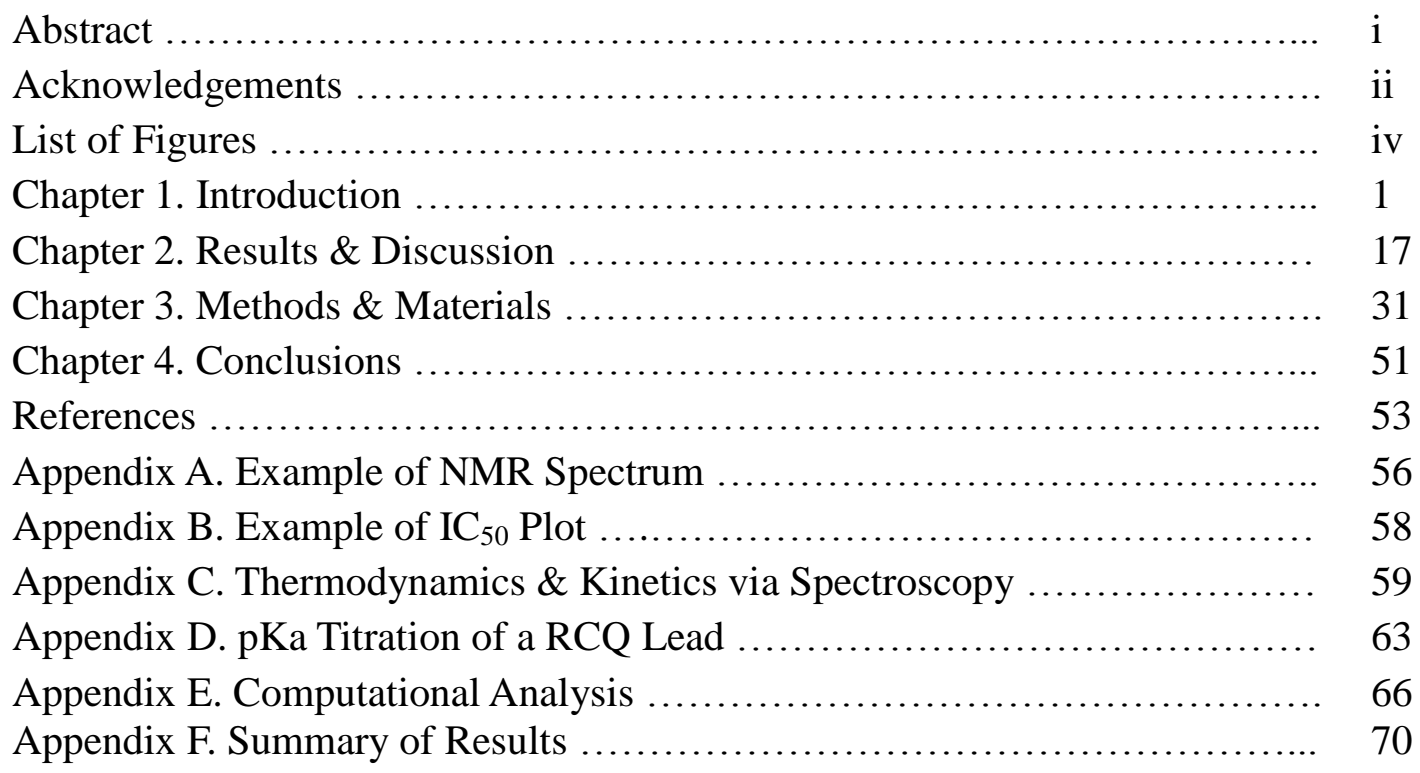




\section{$\underline{\text { List of Figures }}$}

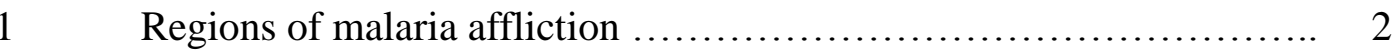

$2 \quad$ The female Anopheles mosquito ................................ 3

3 The Plasmodium parasite ...................................... 4

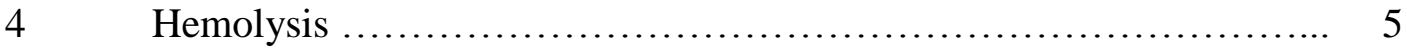

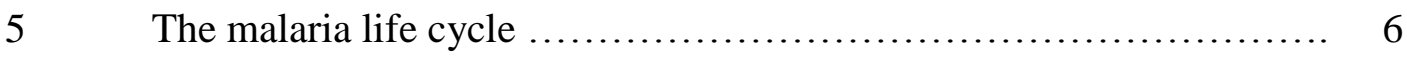

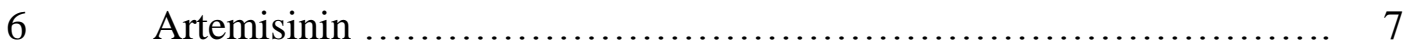

$7 \quad$ Quinine ..................................................... 8

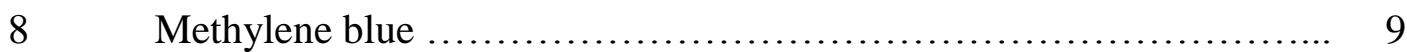

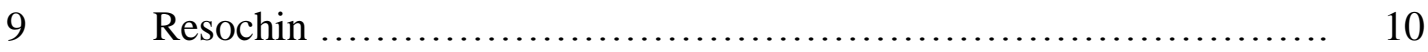

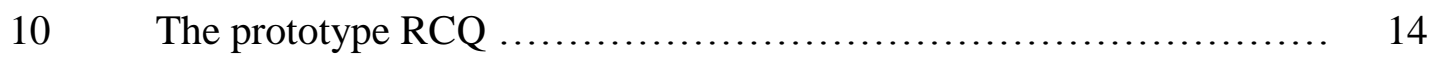

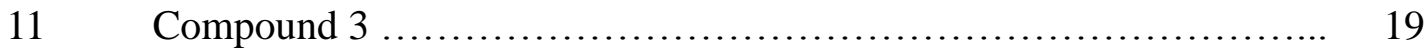

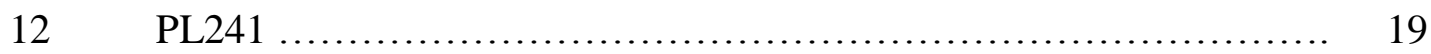

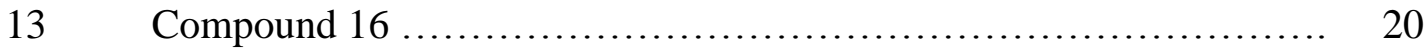

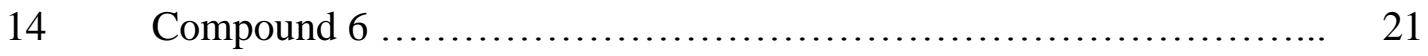

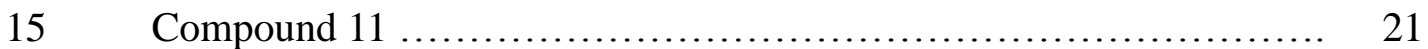

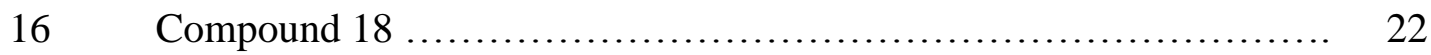

17 Proposed reaction scheme for synthesis of a 7-sulfonamide-RCQ ..... 23

18 Proposed reaction scheme 1 for synthesis of a sulfonamide in linker ... 24

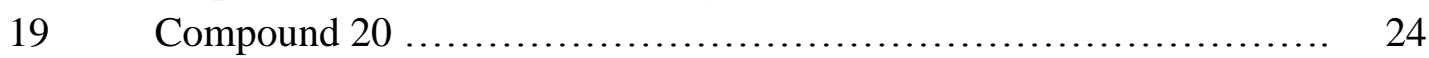

20 Proposed reaction scheme 2 for synthesis of a sulfonamide in linker ... 25

21 Primaquine ............................................. 26

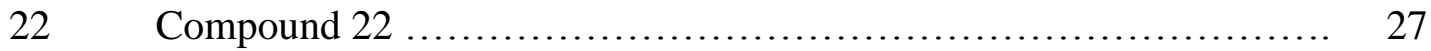

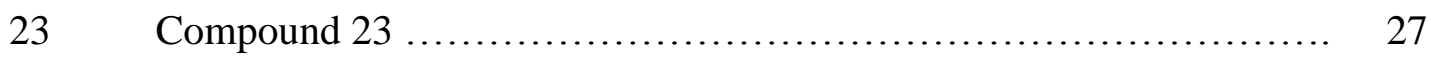

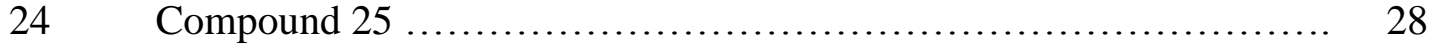

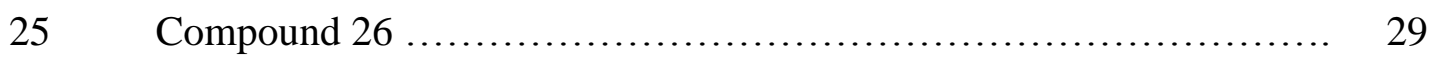

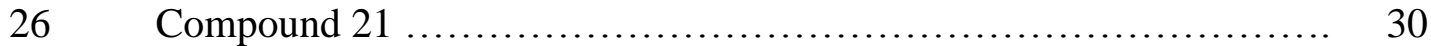

27 Reaction Scheme 1 ........................................ 33

28 Reaction Scheme 2 ....................................... 35

29 Reaction Scheme 3 ......................................... 38

$30 \quad$ Reaction Scheme 4 .......................................... 41

31 Reaction Scheme 5 ........................................ 43

32 Reaction Scheme 6 .......................................... 45

33 Reaction Scheme 7 .......................................... 46

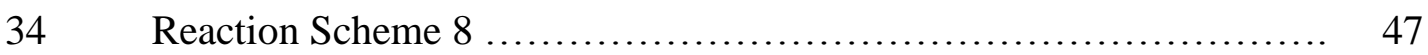

$35 \quad$ Reaction Scheme 9 ............................................. 59

$36 \quad$ Reaction Scheme 10 ......................................... 50 


\section{Chapter 1. Introduction:}

Mal'aria, translated from the Latin "bad air", is an old, lethal disease. Its origins precede recorded history (Lie et al, 2014). Today, in the $21^{\text {st }}$ century, the disease continues to wreak devastation. The World Health Organization reported that, in 2013 alone, nearly 200 million clinical cases of malaria had occurred, and that 600,000 people had died of it.

How can it be that, in today's modern age of advanced technology and medicine, such scourges persist? The answer lies in economics (President's Malaria Initiative Strategy, 2015 Annual Report). Medical treatment demands resources. The majority of deaths occur in the most destitute regions of sub-Saharan Africa, where medicine often cannot be afforded (W HO, 2013). More devastating still, the vast majority of these deaths are children less than five years of age. A vicious cycle of impoverishment and disease is perpetuated with the terrible drain on a nation's productivity and economy that malaria inflicts.

Financial deprivation is not a necessary condition of transmission. Approximately 1500 cases of malaria are diagnosed in the United States each year (Linscott, 2011). Unsurprisingly, many of these victims are travelers to those parts of the world afflicted with the disease. Regions of malaria epidemic extend beyond sub-Saharan Africa to include South Asia, South America, and India. Endemicity is generally a function of climatic factors, with heightened prevalence in areas of greater temperature, humidity, and rainfall (Mbaso \& Ndlovu, 2012). Malaria tends to be found in tropical and subtropical regions (see Figure 1). 


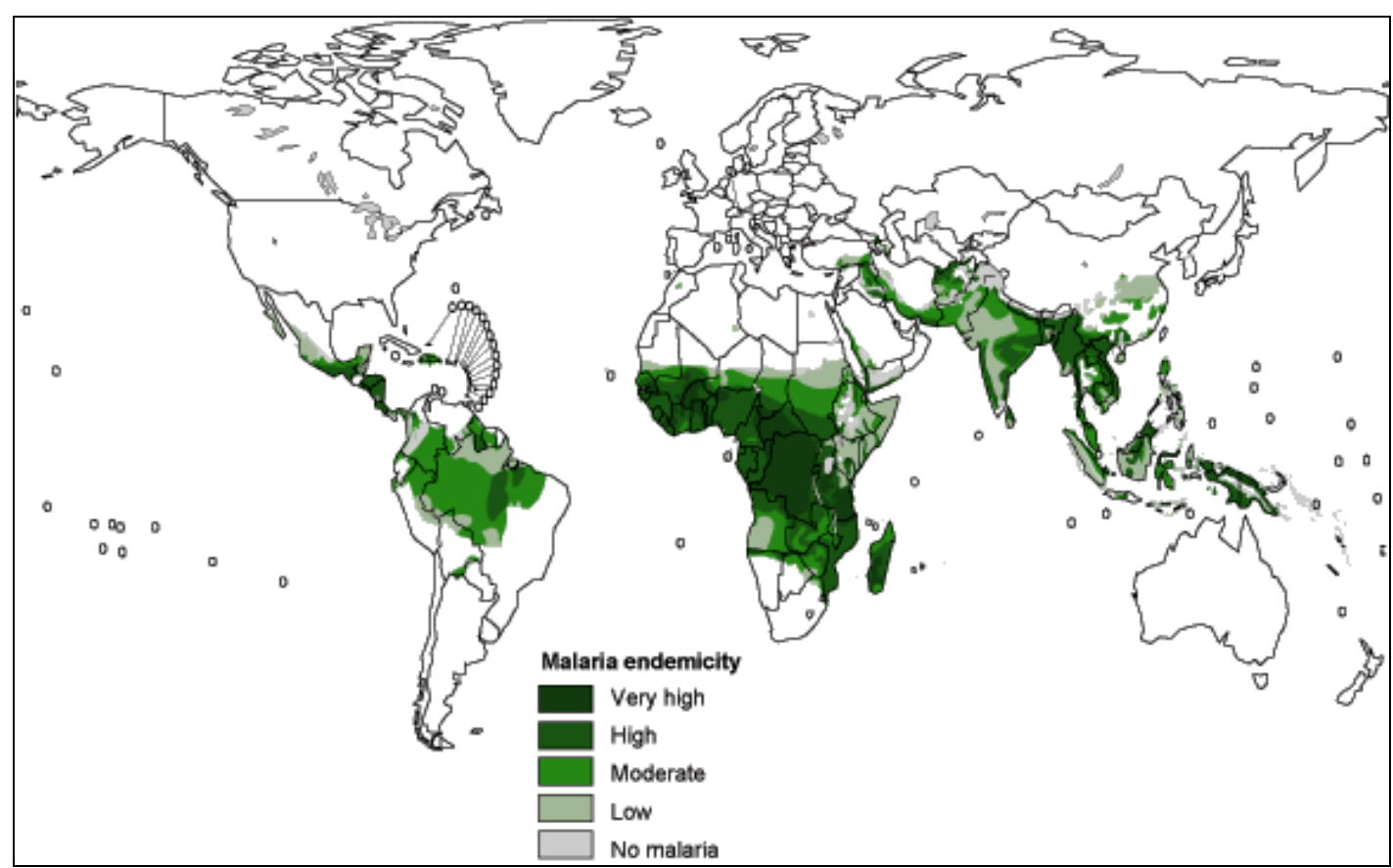

Figure 1. Regions of complaint of malaria (WHO, 2013).

The victim of malaria suffers flu-like symptoms, including high fever, shaking chills, back pain, nausea, and vomiting. In spite of its name, malaria does not entail airborne transmission. It is however, transmitted by airborne insects, namely the infective female Anopholes mosquito (Hall \& Fauci, 2009) (see Figure 2). 


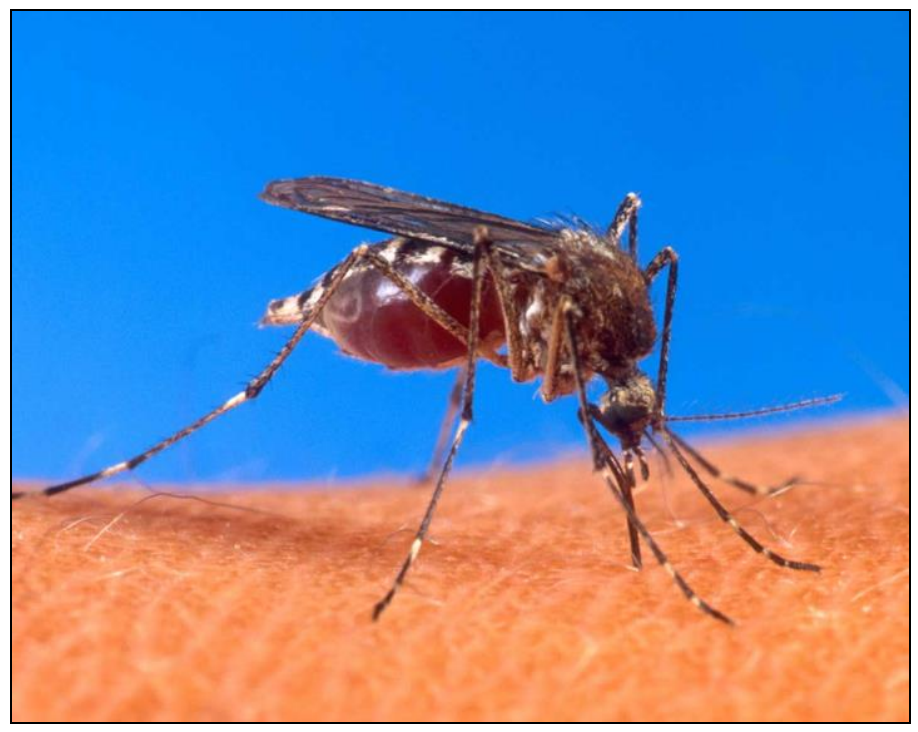

Figure 2. The female Anopholes mosquito enjoying a blood meal. (source:

http://www.windows2universe.org/-teacher_resources/online_courses/health/images/mosquito_cdc_sm.jpg)

The infected mosquito carries a single-celled Plasmodium organism, the pathogenic parasite of malaria, in its midgut. In the midgut the eukaryote asexually reproduces. Over the course of a week, the parasite infection, in the form of diploid sporozoites migrates to the salivary glands of its host (Sherman, 1998). The proboscis of the mosquito is now a conduit of disease, and the anthrophilic hematophage charges the weapon unto its hapless victim during a blood meal.

One might ask how a mosquito becomes infected in the first place. It does so simply by engaging in normal feeding, having taken up the parasite-infested blood of its meal (Sherman, 1998). The general life cycle of the malaria parasite is complex, but worthy of some added discussion for the illumination it provides the pathology and treatment of the disease.

Upon injection of Plasmodium into the blood of the victim, the sporozoites are passaged to the liver and invade the cells of this tissue (Sherman, 1998). (See Figure 3.) 
Over the course of one to two weeks, the sporozoites undergo several rounds of division to bear thousands of haploid merozoites per cell of the liver. Not all of species of sporozites necessarily undergo immediate division: $P$. vivax and $P$. ovale may remain dormant for weeks or months. The latent division of these initially inactive sporozoites accounts for the relapse of illness that is often observed in malarial patients.

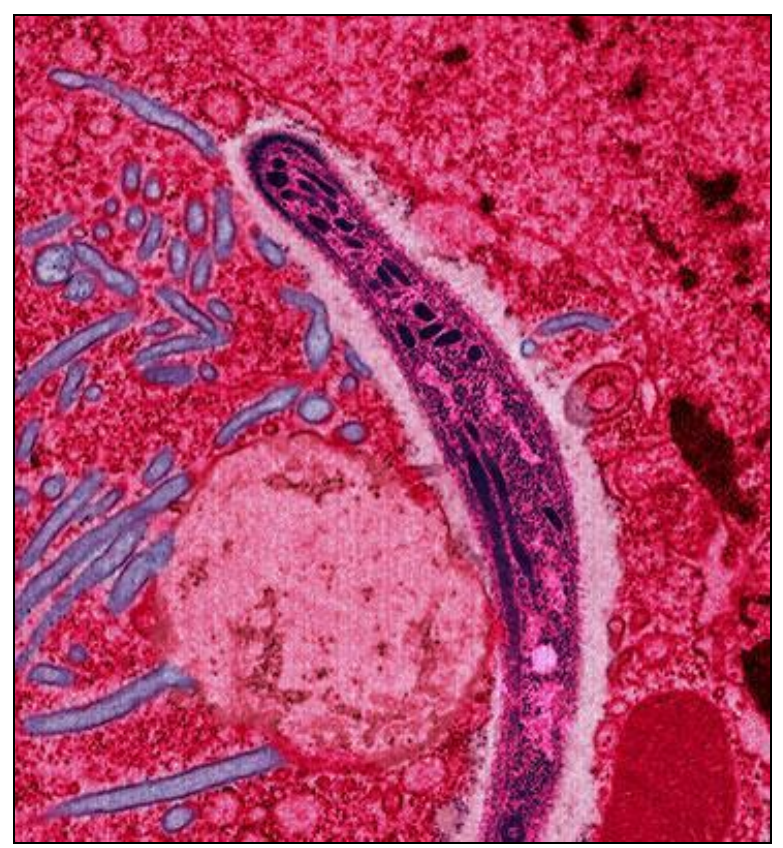

Figure 3. The Plasmodium sporozoite. (source: http://blogs.discovermagazine.com/notrocketscience/files/2012/07/Plasmodium1.jpg)

Freshly formed merozoites slip the liver and are unleashed upon the bloodstream (Sherman, 1998). The red blood cells are infected, asexual replication ensues, and yet more merozoites are produced therein. The proliferation of merozoites break free from the erythrocytes during hemolysis, the rupturing of red blood cells, and infect more blood cells over several days. Thousands of erythrocytes of the bloodstream are thereby infected. 
It is this stage of the parasite's cycle that causes the symptoms of malaria, and warrants a brief digression. The manifestations of malaria include anemia due to hemolysis (Wilson et al, 2010). Consequently, hemoglobin is detectable in the urine. There may be abnormalities in blood coagulation and low blood pressure caused by cardiovascular collapse. Acute kidney failure and metabolic acidosis can occur, often in association with hypoglycemia. Neurological affliction can induce abnormal behavior, impairments in consciousness, seizures, and coma (Hashemi, Callon, \& Kumar, 2015).

Returning to the parasites' cycle, the asexual multiplication phase is ended, and the merozoites develop into the sexually reproducing male and female gametocytes (Sherman, 1998). Released from the red blood cells, these gametocytes circulate the bloodstream and can be taken up by a feeding mosquito. In the gut of the mosquito, the human blood cells rupture, spilling the gametocytes, where they mature into gametes.

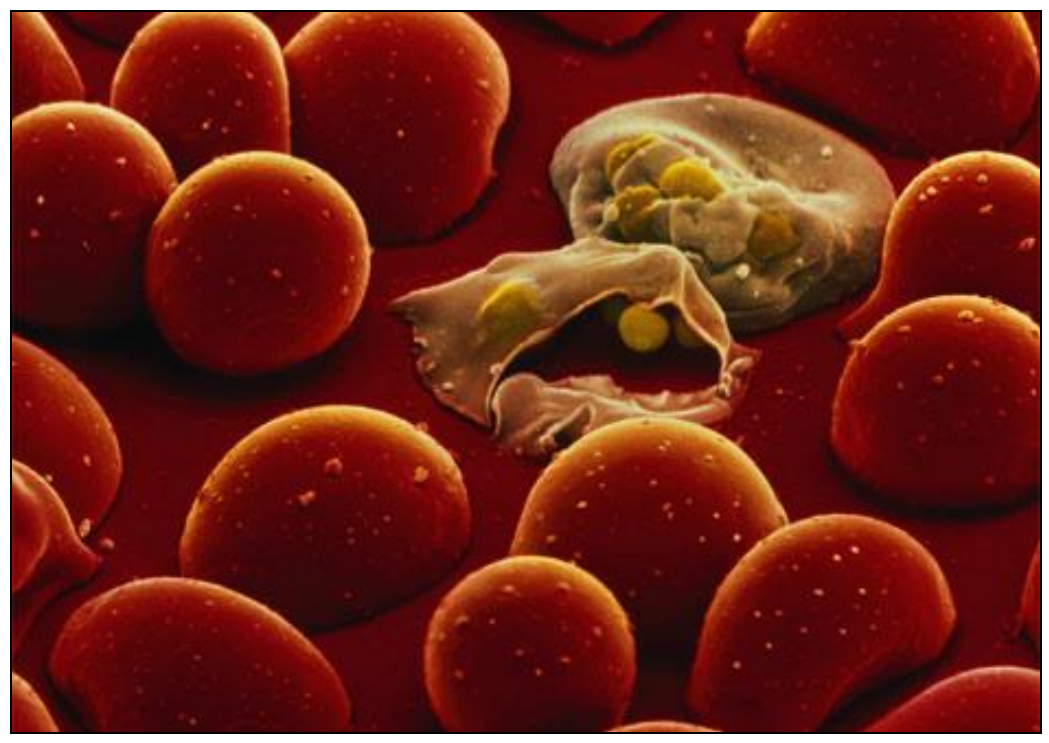

Figure 4. Ruptured red blood cells due to infection by the malaria parasite. (Source: http://images.sciencetimes.com/data/images/full/6242/malaria.jpg) 
Male and female gametes fuse to form diploid zygotes, which undergo further development before burrowing into the wall of the mosquito's midgut as oocytes (Sherman, 1998). Over about two weeks, the division of oocytes produce sporozoites. The cycle is begun anew. It is summarized in Figure 5.

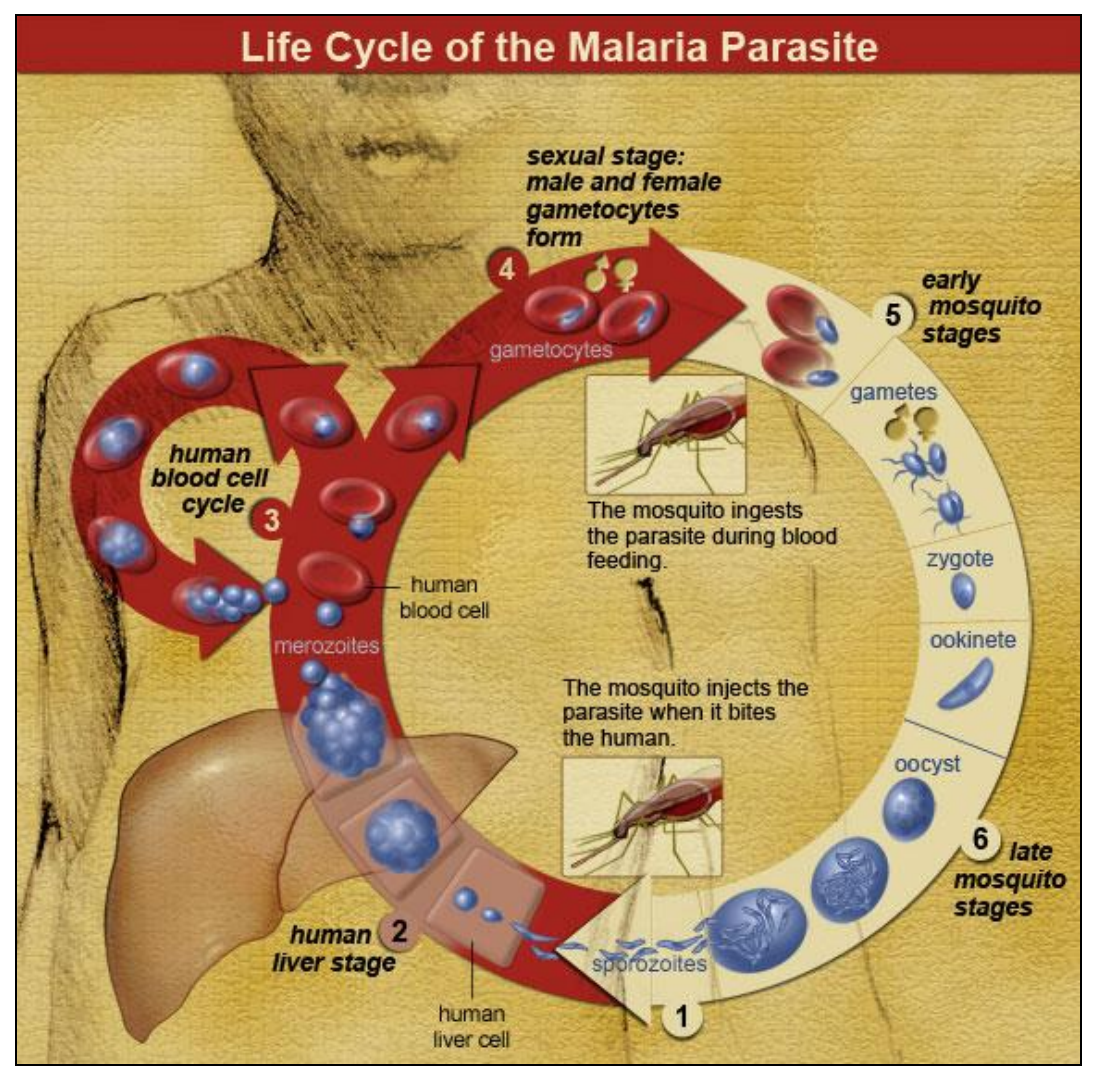

Figure 5. The life cycle of the malaria parasite (source: National Institute of Health 2015 website, http://www.niaid.nih.gov/SiteCollectionImages/topics/malaria/lifecycleWeb.jpg).

Plasmodium is the genus that encompasses the four species of the parasite that infect humans; these include Plasmodium falciparum, P. vivax, P. ovale, P. knowles, and P. malariae. The first of these, P. falciparum, is the most dangerous (Khan et al, 2010), the most likely to induce severe cases of illness in humans, and is the primary target of medicines discussed here. 
Evidence of recognition of the symptoms of malaria can be found in texts of five millennia ago, having been described in ancient Chinese medical writings (Moss, Shaw, \& Morrow, 2013). In ancient Greece, as described in writings of the fourth century BCE, malaria brought several city-state populations to ruin (Bynum, 2008). Hippocrates, the Greek physician of this era, noted the principal symptoms. A Sakskrit medical treatise attributed the symptoms of malarial fever to insect bites (Hviid, 2000). Writers in ancient Rome described zones of pestilence; that people were dying of fevers in these zones; and that these fevers could be attributed to the region's swamps (Sallares \& Gomzi, 1999).

The treatment of malaria is also addressed in the early periods of recorded history. In the fourth century $\mathrm{CE}$, the antipyretic properties of what is now typically referred to as wormwood were described by Ge Hong of the East Ying Dynasty (Moss, Shaw, \& Morrow, 2013). The active ingredient of wormwood, known as artemisinin, was isolated by Chinese scientists just forty years ago. Derivatives of this extract, collectively known as the artemisinins, are employed today throughout the world as a potent treatment of malaria. (See Figure 6.)

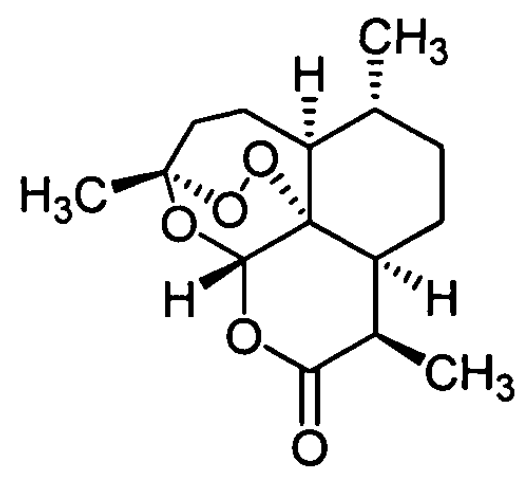

Figure 6. The chemical structure of artemisinin. 
Members of the Jesuit missions inaugurated by the Spanish Empire first arrived in the Americas in the $15^{\text {th }}$ century. These missionaries learned from indigenous tribes of a medicinal bark used for the treatment of fevers (Moss, Shaw, \& Morrow, 2013). One of the medicines from the bark is now known as the antimalarial quinine; it is one of the most effective antimalarial drugs available today. (See Figure 7a.) Mefloquine is a synthetic analog of quinine developed in the 1970s by the U.S. military, and remains an especially important form of malaria treatment and prevention (Figure 7b).

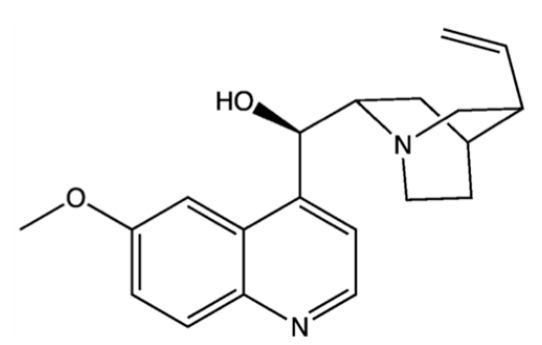

(a)

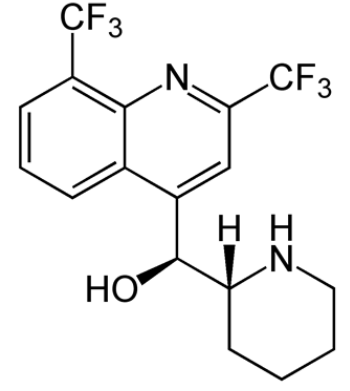

(b)

Figure 7. The chemical structure of quinine (a) and mefloquine (b).

The class of antimalarials of primary interest in this thesis have their origins in Germany in the late $19^{\text {th }}$ century (Meshnick \& Dobson, 2001). The scientist Paul Ehrlich observed that the chemical dye known as methylene blue (figure 8) was a particularly effective stain of malaria parasites. He reasoned that the molecule might be toxic to this microorganism. Based on this hypothesis, Ehrlich treated two human malarial patients with methylene blue. They were both cured. This discovery was momentous not only for the therapeutic effect with respect to malaria, but also that it was the first time a synthetic chemical had ever been used as a drug. 


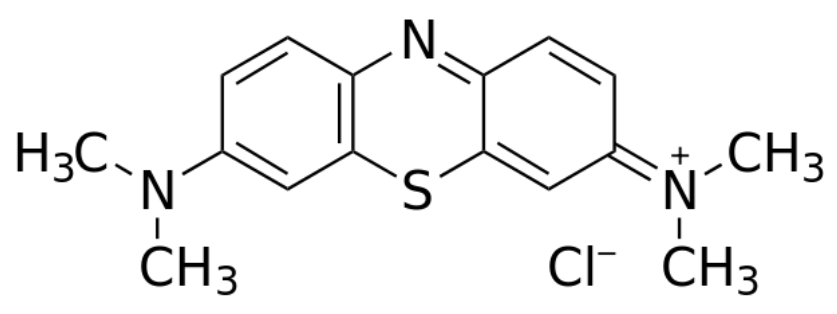

Figure 8. The chemical structure of methylene blue.

In the first quarter of the $20^{\text {th }}$ century, the Germany-based Bayer Industries was a leading manufacturer of dyes that had begun morphing into a prominent pharmaceutical company (Meshnick \& Dobson, 2001). On the basis of Paul Ehrlich's work, Bayer Industries had assembled a team of chemists and biologists to develop antimalarial drugs, with methylene blue serving as a prototype. An important drug to be produced in these efforts was plasmoquine, an 8-aminoquinoline effective against the $P$. vivax species.

In 1934, one chemist in Bayer's laboratories, Hans Andersag, synthesized the molecule (RS)-N'-(7-chloroquinolin-4-yl)-N,N-diethyl-pentane-1,4-diamine (see Figure 9). Andersag dubbed this molecule resochin (Krafts Hempelmann, \& Skórska-Stania, 2012). Resochin showed great promise as an antimalarial, but little came of it immediately for it was thought to be too toxic. Six research groups throughout the world spent over ten years contesting the drug's efficacy and safety. Meanwhile and through World War II, Bayer's plasmoquine was adopted globally to treat malaria (Mays, 2000). By 1946, World War II had ended, and clinical trials of resochin were finally completed in the United States. These showed unequivocally that chloroquine, as it had come to be known in lieu of resochin, was the superior treatment of malaria to all other drugs. It also 
soon become clear that chloroquine was not only a potent treatment, but an effective prophylactic as well (Mays, 2000).

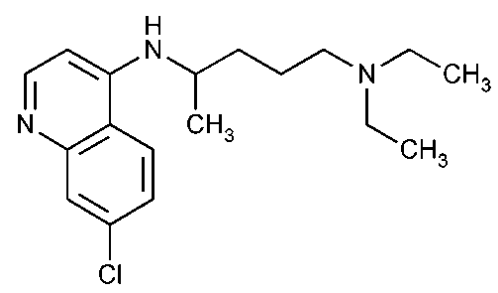

Figure 9. Bayer chemist Hans Andersag's "resochin".

Considerable scientific effort has been exerted to understand chloroquine's mechanism of action. One can begin to understand the current scientific knowledge by considering the nutrient supply of Plasmodium. In the erythrocyte of the human host's blood stream, the parasite consumes hemoglobin. The hemoglobin is digested in the eukaryote's digestive vacuole (DV) to obtain vital amino acids (Sinton \& Ghosh, 1934). In the process of digestion, iron protoporphyrin IX (heme), a prosthetic group of the larger macromolecule, is released into the DV (Pishchany, 2012). In sufficient accumulation, this monomeric heme is toxic to the parasite (Roepe, 2009). Plasmodium lacks the enzyme that catabolizes heme, and would thus be predicted to be suffocated by its own digestion products. But the parasite's DV has a $\mathrm{pH}$ estimated to be between 4.6 and 5.2 (Roepe, 2009). Heme precipitates at $\mathrm{pH}$ values below 5.4 to form the biocrystal known as hemozoin, which is deposited as harmless black granules in the DV of the parasite. This insoluble crystal is also known as malaria pigment.

Drugs such as chloroquine are believed to inhibit the formation of hemozoin. Chloroquine binds heme monomers and mu-oxo dimers predominantly via $\pi-\pi$ 
interactions, and effectively foils its "polymerization" into hemozoin (Egan, 2008). The parasite is poisoned.

The matter of how chloroquine comes arrives upon its target to begin with is a function, at least in part, of acid-base chemistry (Egan, 2008). The pKa of the quinoline nitrogen of chloroquine is 8.5 , meaning it is about $10 \%$ deprotonated at physiological $\mathrm{pH}$. This decreases to $0.2 \%$ at a $\mathrm{DV} \mathrm{pH}$ of 4.6. Because the deprotonated form is more membrane-permeable than the protonated form, a quantitative trapping of the compound in the DV results. This character of chloroquine is believed to account for much of its antimalarial activity, because these drug concentrations in the acidic food vacuole of the parasite interfere with essential processes, as described earlier. Some estimates proffer a 6,000-fold greater concentration of CQ in the DV to the cytoplasm (Kuhn et al, 2007). Much of this introduction has been devoted to a discussion of the efficacy of chloroquine and its mechanism of action. If it is so effective a drug, why are new drugs that are based on, but distinct from, chloroquine even necessary? In fact, the efficacy of chloroquine as an antimalarial has been flagging for six decades. The reason for this is that Plasmodium has evolved a resistance mechanism to the drug. Resistant strains have appeared throughout East and West Africa, Southeast Asia, and South America (WHO, 2013). They effectively neutralize the drug via a mechanism that drains chloroquine away from the digestive vacuole (Martin et al, 2009). Research points to, as a possible causal factor, mutations of transmembrane proteins of the digestive vacuole, including sets of critical mutations in the P. falciparum chloroquine resistance transport (PfCRT) gene. The mutated protein, but not the wild-type transporter, transports chloroquine when expressed in Xenopus oocytes (Wellems, 2001). Thus, PfCRT is thought to mediate chloroquine 
leak from its site of action in the digestive vacuole. The normal function of the PfCRT protein may include the regulation of DNA, particularly vis-à-vis histone acetylation . K76T may be the mutation of PfCRT responsible for chloroquine resistance (Wellems, 2001). Cationic molecules like chloroquine may engage in a pivotal electrostatic interaction with this amino acid, which is near the amino terminal of the first transmembrane helix. The alteration of the native charged lysine residue to the non-polar threonine may form the basis for resistance by inducing an unfavorable electrostatic interaction (Peyton, 2012).

Alternatives to classical chloroquine chemotherapy must be made available. One approach that has been the focus of intense development and research effort concerns the possible treatment of malaria by vaccine. The parasite's ability to evade the immune system by constantly altering its polymorphic surface proteins has made the development of an effective vaccine difficult (Ferreira et al, 2004). But one experimental vaccine, known as RTS,S/AS01, has become an advanced candidate (RTS,S Clinical Trials Partnership, 2015). A Phase III trial of RTS,S/AS01 began in 2009. It included children aged 5-17 months at first dose, and another group of children aged $6-12$ weeks at first dose. Both groups received three doses of the vaccine at one month intervals. The results were published in April, 2015 (RTS,S Clinical Trials Partnership). Broadly, it was found that RTS,S/AS01 protected approximately a third of children from malaria over four years. While a much higher percentage of prevention had been anticipated, it should also be considered that, given that there are about 200 million cases of malaria each year, this $\sim 33 \%$ level of efficacy potentially translates into millions of cases of malaria in children being prevented. 
Yet this program's modest success is far from being grounds for the forfeit of research in small molecule medicines. The World Health Organization describes that a possible vaccine must be considered as a supplement to, and not a replacement for, existing preventive, diagnostic, and treatment measures, including insecticidal nets and drug therapies. Moreover, it is theoretically possible for any microbe to develop resistance to a vaccine.

Thus there remains a pressing need for a pipeline of drugs, in anticipation of ineffective treatments and a continual evolution of resistance mechanisms. This impetus is the launching pad of this lab's research, and this thesis.

A desirable solution to the problem of malaria drug resistance is to retain the properties of a drug that permit its effect, while reversing the mechanism that is responsible for resistance. Agents of this latter property have been termed "chemosensitizers", in reference to th e re-sensitization of a target to the treatment. They have also been termed "reversal agents" (RA), in reference to the reversal of the resistance mechanism (Peyton, 2012); the terms can be used interchangeably. With regards to the malaria mechanism, a reversal agent suppresses drug efflux and thereby resensitizes the parasite to the antimalarial piece by the accumulation of drug in the DV.

One has, then, an antimalarial fragment to consider, as well a RA fragment. These fragments could be co-administered as distinct agents. One of several molecules that has been shown to have effect as a malaria RA is the antipsychotic imipramine (Adam et al, 2004). The administration of imipramine permitted the accumulation of chloroquine in the DV of chloroquine-resistant strains. 
Alternatively to co-administration, the antimalarial molecule and reversal agent could be covalently linked to ensure a constant delivery of both fragments to the target. This hybrid-drug approach was first investigated in the laboratory of David Peyton (2012). The resultant class of molecules, incorporating a chemical-efflux inhibitor coupled to the classical antimalarial chloroquine, were termed reversed chloroquines (RCQ). The first published structure (2006) and prototype RCQ, shown in Figure 10, exhibited greater antimalarial effect in an in vitro pharmacology test than chloroquine in both chloroquine-resistant and chloroquine-sensitive strains.

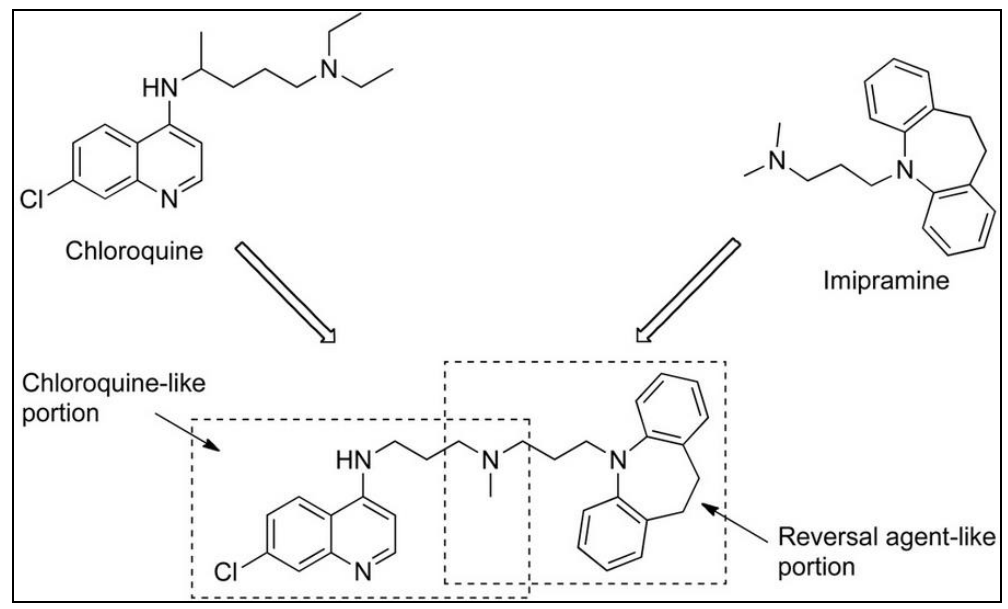

Figure 10. The first reported reversed chloroquine (Burgess et al, 2006).

The goal of this drug design program has stemmed from this prototype. For example, in the second generation of RCQ molecules, efforts were made to reduce the tricyclic nature of the RA impipramine (Peyton, 2012), which was known to have central nervous system effects.

Much research effort in the lab has been devoted to gaining a deep structureactivity relationship of reversed chloroquines. For example, it was found that varying the 
linker between chloroquine and the reversal agent, of a length between two and 4 carbons, produced little difference (Andrews et al, 2010). Additionally, it was found that having a proton on the 4-amino moiety of the quinoiline ring (i.e., a secondary rather than a tertiary amine) was beneficial.

Other efforts have emphasized the optimization of the structure so as to enhance pharmacokinetic parameters. The clogP value of the prototype RCQ in Figure 10 was very high, with a value of 9 , indicating an exceedingly lipophilic molecule. Modifications have succeeded in bringing this value down to values of 7 and less, increasing the hydrophilicity of the molecule, but there is room for improvement.

Still other efforts have explored chemical moieties that might alter or enhance binding mechanisms. For example, it has been found that an alternative RA to imipramine or other diphenyl moiety is another quinoline ring, wherein one quinoline serves as the drug, and the other quinoline serves as the RA. Indeed, these bisquinolines have an important history in the development of antimalarials (Raynes, 1999).

The present thesis has elements of the three drug design considerations described: SAR, efficacy, and pharmacokinetics. Still, the chemical synthesis efforts, which constitute the bulk of the work in this project, have been largely targeted toward: 1) an exploration of unique moieties that garner maximal efficacy, primarily in the variation of the reversal agent and the chain linking the antimalarial and the RA, and 2) subtle alterations of an established RCQ that garner expected improved pharmacokinetics.

Key aspects of classical chloroquine's success included its economy of production: it is inexpensive and simple to manufacture. The preservation of these two features remains a primary objective in the current drug development paradigm. In order 
for a drug to be a viable therapy in poorer nations, where it is most needed, it must be inexpensive to produce. RCQs are of great interest because they are generally inexpensive to produce. Because of the uniqueness of the side structures, there may be little cross-resistance to other strains. There is a flexibility of design (Peyton, 2012), which is good for maintaining a pipeline against malaria resistance, and the flexibility to improve pharmakcokinetic parameters.

The driving hypothesis of this research is that reversed chloroquines are a medically and economically viable antimalarial. On the basis of established successes, the research of this thesis has entailed the design and synthesis of analogs of leading reversed chloroquine candidates. A foremost effort has been in improving predicted pharmacokinetic parameters, namely the reduction of clog $\mathrm{P}$ values.

The appendices give the results of some related studies: In Appendix III, a spectroscopic analysis of select RCQ's behavior in aqueous solution in the presence of heme is described. In Appendix IV, a pH titration analysis of a lead RCQ candidate is detailed. In appendix V, some computational analysis of quinoline-based drugs is offered. 


\section{Chapter 2. Results \& Discussion:}

Reversed chloroquines (RCQs) are a class of molecules designed to re-sensitize chloroquine-resistant strains of malaria to classical chloroquine-like molecules. This is achieved by the covalent coupling of the chloroquine-like molecule to a chemosensitizer. The driving hypothesis is that RCQs are a medically and economically viable antimalarial with sufficient design flexibility to maintain a pipeline of drugs in the face of evolving resistance. Specific research goals include modification of the structure to maximize efficacy as well as to enhance pharmacokinetic properties.

There appears to be a striking degree of flexibility in the reversal agent (RA) (Peyton, 2012). The question as to the modifiability of the antimalarial fraction prompted the initial efforts of this thesis. Whereas classical chloroquine and the leading reversed chloroquine candidates feature a 4-amino substitution of the quinoline ring, some antimalarial quinolines include substitutions elsewhere - namely, the 8-position substitution as present in primaquine, discussed in the introduction. The first antimalarial modification of this thesis work was synthesized with 3-aminoquinoline as starting material. The aliphatic linker was bound via the formation of an amido linkage, and the linker's terminal halogen substituted with an established reversal agent, diphenylmethylpiperazine. With lithium aluminum hydride the amide was reduced to an amine to yield $\mathrm{N}-\{3$-[4-(diphenylmethyl)piperazin-1-yl]propyl\}quinolin-3-amine (3) (see Figure 11).

Compound $\mathbf{3}$ was subjected to the primary antimalarial potency in vitro test. The method is detailed elsewhere (Andrews et al, 2010), but is briefly described here: The D6 chloroquine-sensitive $\left(\mathrm{CQ}^{\mathrm{S}}\right)$ and $\mathrm{Dd} 2$ chloroquine-resistant $\left(\mathrm{CQ}^{\mathrm{R}}\right)$ strains of $P$. falciparum 
were maintained in cell culture. These cells were added to 96-well microplates; to this cell mixture was added concentrations of drug ranging from 0 to $10^{-4} \mathrm{M}$. After $72 \mathrm{~h}$ of incubation, the SYBR Green I-based fluorescence assay yielded fluorescence readings plotted against drug concentration, which permitted the calculation of $\mathrm{IC}_{50}$ values via nonlinear regression. In this context, $\mathrm{IC}_{50}$ ("inhibitory concentration $50 \%$ ") is a measure of the concentration of drug required to suppress the growth of parasite cells by $50 \%$. The smaller is the $\mathrm{IC}_{50}$ value, the more potent is the drug. An example of an $\mathrm{IC}_{50}$ plot is shown in Appendix II.

Chloroquine has an $\mathrm{IC}_{50}$ of $6.9 \mathrm{nM}$ in the chloroquine sensitive $\left(\mathrm{CQ}^{\mathrm{S}}\right)$ strain of $P$. falciparum (D6). It is much less potent in the chloroquine-resistance $\left(\mathrm{CQ}^{\mathrm{R}}\right)$ strain, $\mathrm{Dd}$, with an $\mathrm{IC}_{50}$ value of $102 \mathrm{nM}$. By contrast, the first reversed chloroquine, featuring imipramine as the chemosensitizer, exhibits $\mathrm{IC}_{50}$ values of between 3 and $5 \mathrm{nM}$ in both parasite strains. Compound 3 (Figure 11) proved considerably less potent as an antimalarial, with an $\mathrm{IC}_{50}$ of $282 \mathrm{nM}$ in the $\mathrm{CQ}^{\mathrm{S}}$ strain and $507 \mathrm{nM}$ in $\mathrm{CQ}^{\mathrm{R}}$. This corroborated the hypothesis that not all quinoline substitutions are created equal. It is worth noting that $\mathbf{3}$ also lacks a chlorine in the 7-position, and previous research in the laboratory (Liebman, 2014) suggests that this substitution is often important for maximizing potency. 


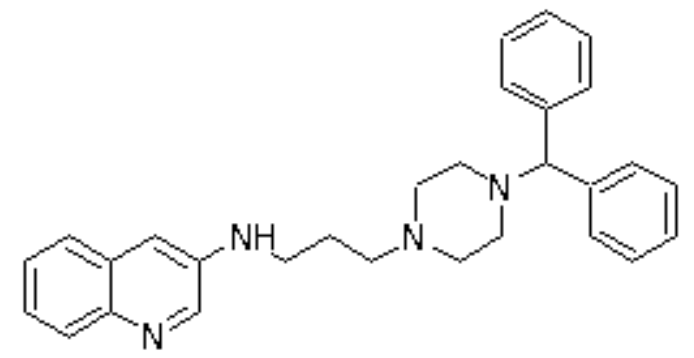

Figure 11. Compound $3 \mathrm{~N}$-\{3-[4-(diphenylmethyl)piperazin-1-yl]propyl $\}$ quinolin-3-amine. $\mathrm{MW}=436.6 \mathrm{~g}$ $\mathrm{mol}^{-1}$. Formula $=\mathrm{C}_{29} \mathrm{H}_{32} \mathrm{~N}_{4} \cdot \operatorname{clog} \mathrm{P}=5.32 . \mathrm{CQ}^{\mathrm{S}} \mathrm{IC}_{50}=282 \mathrm{nM}$. $\mathrm{CQ}^{\mathrm{R}} \mathrm{IC}_{50}=507 \mathrm{nM}$.

As efforts to determine the most effective reversal agent continued, research in the lab uncovered that the pharmacophore of the chemosensitizer could extend from the need for two distinct aromatic structures, to one featuring a fusion of the two, in the form of a quinoline ring. Indeed, this led the lab to appreciate a class of drugs that had been developed previously, known as bisquinolines, as functionally serving as another kind of reversed chloroquine. The following such bisquinoline developed in this lab as a new kind of reversed chloroquine, dubbed PL241 (figure 12), has proven remarkably potent in the in vitro pharmacology test (Liebman, 2014).<smiles>Clc1ccc2c(NCCCN3CCC(Nc4ccnc5cc(Cl)ccc45)CC3)ccnc2c1</smiles>

Figure 12. Compound PL241. MW $=$ 480.4. Formula $=\mathrm{C}_{26} \mathrm{H}_{27} \mathrm{Cl}_{2} \mathrm{~N}_{5} \cdot \operatorname{clog} \mathrm{P}=7.00 . \mathrm{CQ}^{\mathrm{S}} \mathrm{IC}_{50}<2.5 \mathrm{nM}$. $\mathrm{CQ}^{\mathrm{R}} \mathrm{IC}_{50}<2.5 \mathrm{nM}$. 
It was of interest to see whether the removal of a single methylene within the alipathic linker, reducing the number of freely rotatable bonds and the molecular weight, and thereby the clogP, would prove equally potent. Synthesis began with 4,7dichloroquinoline reagents, and the target molecule was completed with four steps and an overall yield of 21\%. In keeping with its 3-carbon precursor, 16 (figure 13) exhibited very high potency in both $\mathrm{CQ}^{\mathrm{S}}$ and $\mathrm{CQ}^{\mathrm{R}}$, with $\mathrm{IC}_{50}$ values of less than $2.5 \mathrm{nM}$.<smiles>Clc1ccc2c(NCCN3CCC(Nc4ccnc5cc(Cl)ccc45)CC3)ccnc2c1</smiles>

Figure 13. Compound 16. 7-chloro-N-(2-\{4-[(7-chloroquinolin-4-yl)amino]piperidin-1-yl $\}$ ethyl)quinolin-4-amine. $\mathrm{MW}=466.4 \mathrm{~g} \mathrm{~mol}^{-1}$. Formula $=\mathrm{C}_{25} \mathrm{H}_{25} \mathrm{Cl}_{2} \mathrm{~N}_{5} \cdot \operatorname{clog} \mathrm{P}=6.72 . \mathrm{CQ}^{\mathrm{S}} \mathrm{IC}_{50}<2.5 \mathrm{nM}$. $\mathrm{CQ}^{\mathrm{R}} \mathrm{IC}_{50}<2.5 \mathrm{nM}$.

In addition to the 3-position substitution of the quinoline ring described earlier, linking at the 2-position was also a substitution of interest. Now employing the use of another bisquinoline as a reversal agent, rather than the imipramine-like moiety of earlier studies, 2-chloroquinoline was reacted with 3-aminopropanol to produce a 2-amino substation and a terminal alcohol. The alcohol was converted to a mesylate to improve its leaving capacity, and was substituted with a reversal agent featuring 4-amino-piperidine at the 4-position of the quinoline ring. The target molecule 6 (figure 14) was thus synthesized in four steps. In the pharmacological assay, $\mathbf{6}$ showed effectiveness about 10- 
fold less than $\mathrm{CQ}$ in $\mathrm{CQ}^{\mathrm{S}}$, but considerably less potency against $\mathrm{CQ}^{\mathrm{R}}$, with an $\mathrm{IC}_{50}$ of just $0.5 \mu \mathrm{M}$. As with $\mathbf{3}$, this may be a consequence of the absence of a chlorine. However, this would not be entirely consistent with earlier studies which suggest that, all other factors being held constant, the presence of a chlorine on at least one of the two quinoline rings was sufficient for producing an effect nearing that of the di-chloro structures.

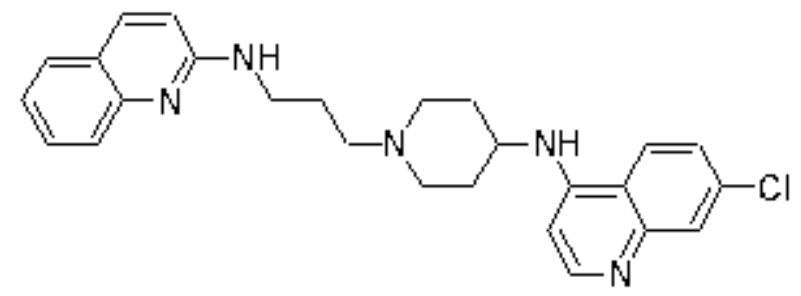

Figure 14. Compound 6. 7-Chloro-N-(1-\{3-[(quinolin-2-yl)amino]propyl $\}$ piperidin-4-yl)quinolin-4-amine. $\mathrm{MW}=446.0 \mathrm{~g} \mathrm{~mol}^{-1}$. Formula $=\mathrm{C}_{26} \mathrm{H}_{28} \mathrm{ClN}_{5} . \operatorname{clog} \mathrm{P}=6.18 . \mathrm{CQ}^{\mathrm{S}} \mathrm{IC}_{50}=69 \mathrm{nM} . \mathrm{CQ}^{\mathrm{R}} \mathrm{IC}_{50}=540 \mathrm{nM}$.

The "mirror" of $\mathbf{6}$ was also synthesized, 11 (figure 15), in which the 4-aminopiperadyl moiety extends from the 2-position of one quinoline ring, and the aliphatic nitrogen extends from the 4-position of the other quinoline. Its synthesis entailed a reaction scheme similar to that of $\mathbf{6 . 1 1}$ is as yet untested.<smiles>Clc1ccc2c(NCCCN3CCC(Nc4ccc5ccccc5n4)CC3)ccnc2c1</smiles>

Figure 15. Compound 11. 7-chloro-N-(3-\{4-[(quinolin-2-yl)amino]piperidin-1-yl $\}$ propyl)quinolin-4-amine. $\mathrm{MW}=446.0 \mathrm{~g} \mathrm{~mol}^{-1}$. Formula $=\mathrm{C}_{26} \mathrm{H}_{28} \mathrm{ClN}_{5} \cdot \operatorname{clog} \mathrm{P}=5.80 . \mathrm{IC}_{50}=\mathrm{TBD}$.

In the interest of continuing the bisquinoline project, a scheme was developed whereby a large number of bisquinoline molecules could be readily synthesized. Both primary starting materials, 4,7-dichloroquinoline and 1,4-bis(3-aminopropyl)piperazine, 
are inexpensive and readily available. The reaction is fairly rapid and easily executed: 4,7-dichloroquinoline is mixed with a large excess of the latter in organic solvent, and does not require extreme or inert conditions. Unfortunately, the product proved to have very poor solubility, making its use a starting material generally impossible. One target molecule of this scheme was successful, however, yielding an asymmetric 2-substituted bisquinoline, 18 (figure 16).

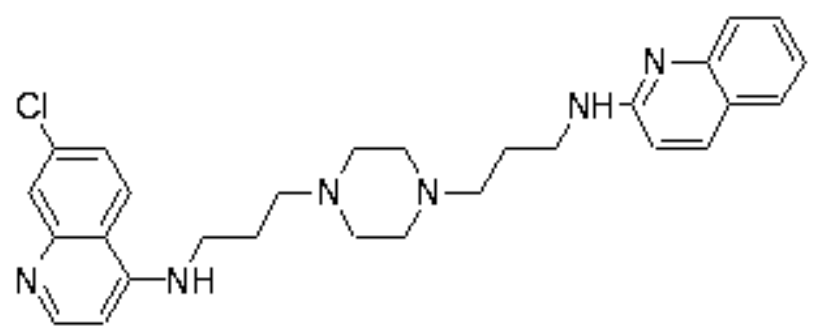

Figure 16. Compound 18. N-[3-(4-\{3-[(6-chloronaphthalen-1-yl)amino]propyl $\}$ piperazin1-yl)propyl]quinolin-2-amine. $\mathrm{MW}=488.1 \mathrm{~g} \mathrm{~mol}^{-1}$. Formula $=\mathrm{C}_{29} \mathrm{H}_{34} \mathrm{ClN}_{5} \cdot \operatorname{clogP}=5.90$.

Modification of the work-up procedure of $\mathbf{1 8}$ may ameliorate the solubility difficulties, as may the use of 2-carbon aliphatic chains instead of 3 . This latter method would also reduce the molecular weight and lower the clogP value. It is interesting to note that the precursor to $\mathbf{1 8}$, compound $\mathbf{1 7}$ (see reaction scheme 5), shows marked potency, with $\mathrm{CQ}^{\mathrm{R}} \mathrm{IC}_{50}=3.4 \mathrm{nM}$, and $\mathrm{CQ}^{\mathrm{S}} \mathrm{IC}_{50}<2.5 \mathrm{nM}$.

A long-standing goal of the research group has been to incorporate into the reversed chloroquine design a sulfonamide moiety. The purpose of this is two-fold: 1) though several molecules of the reversed chloroquine design exhibit considerable potency, many have high clogP values that may prove problematic for human pharmacokinetics, and 2) sulfonamides have a long-standing history of use as medicinal 
agents. The so-called "sulfa drugs" are antimicrobial agents. The presence of a sulfonamide moiety in a reversed chloroquine may confer some complementary effect that bolsters the drug's effect. A scheme was construed to produce a sulfonamide analog of PL241, and is shown in Figure 17.

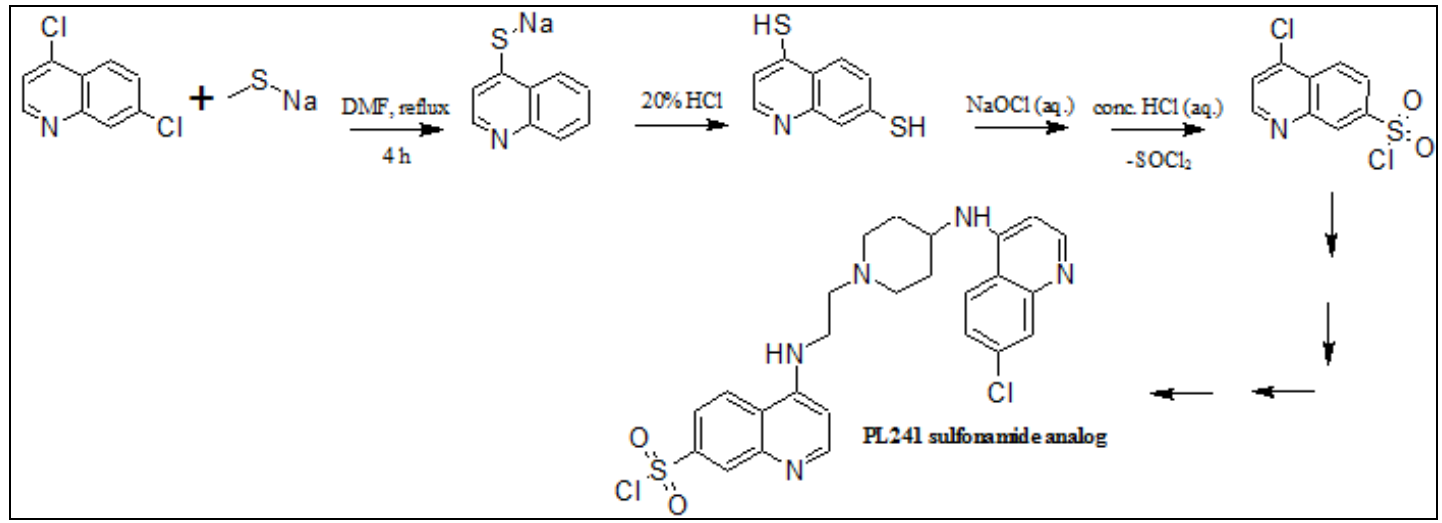

Figure 17. Reaction scheme based on (Marciniec \& Maslankiewicz, 2009) for the synthesis of a sulfonamide-based RCQ.

The synthesis of a starting material was based on Marciniec \& Maslankiewicz (2009). Unfortunately, their synthesis could not be replicated, with the thiol favoring the reduction to thiomethyl groups at the third and fourth step, rather than the sought oxidation. Therefore, an alternative analog and scheme was devised. 


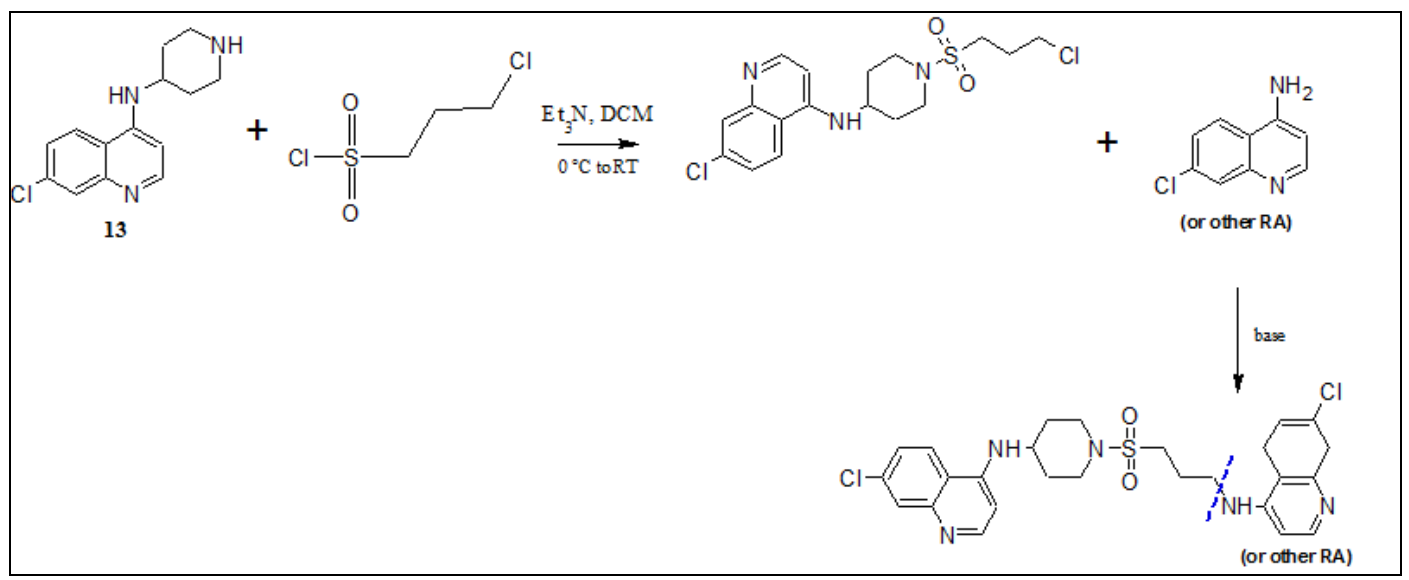

Figure 18. Initial scheme designed to produce a RCQ with a sulfonamide moiety.

The step featuring the substation of the leaving halogen of the sulfonyl chloride group by the nucleophilic amine was successful on a small scale, $0.50 \mathrm{~g}$. Only one of several efforts to couple varying chemosensitizers at the leaving halogen was successful. Compound 20 (figure 19) was manufactured with 6\% yield.<smiles>O=S(=O)(CCCN1CCN(c2ccccn2)CC1)N1CCC(Nc2ccnc3cc(Cl)ccc23)CC1</smiles>

Figure 19. Compound 20. (7-chloro-N-(1-\{3-[4-(pyridin-2-yl)piperazin-1-yl]propanesulfonyl $\}$ piperidin-4-yl)-quinolin-4-amine ). $\mathrm{MW}=529.1 \mathrm{~g} \mathrm{~mol}^{-1}$. Formula $=\mathrm{C}_{26} \mathrm{H}_{33} \mathrm{ClN}_{6} \mathrm{O}_{2} \mathrm{~S} . \operatorname{clog} \mathrm{P}=4.14 . \mathrm{CQ}^{\mathrm{S}}$ $\mathrm{IC}_{50}<2.5 \mathrm{nM}$. CQ $\mathrm{IC}_{50}<2.5 \mathrm{nM}$.

Compound $\mathbf{2 0}$ is distinguished from the most reversed chloroquines by featuring a single aromatic ring, rather than two distinct or fused aromatic rings. Yet its performance on the pharmacological assay lends considerable credence to the sulfonamide design. With $\mathrm{IC}_{50}$ values less than $2.5 \mathrm{mM}$ against $\mathrm{CQ}^{\mathrm{S}}$ and $\mathrm{CQ}^{\mathrm{R}}$ strains, its potency was the 
measured equivalent of PL241 and PL241's 2-carbon analog. This serves as an impetus for continued efforts at the sulfonamide design. In such an effort, a more complex scheme involving several additional steps was designed. Although this method is longer, it was hoped that it would give larger overall yields.

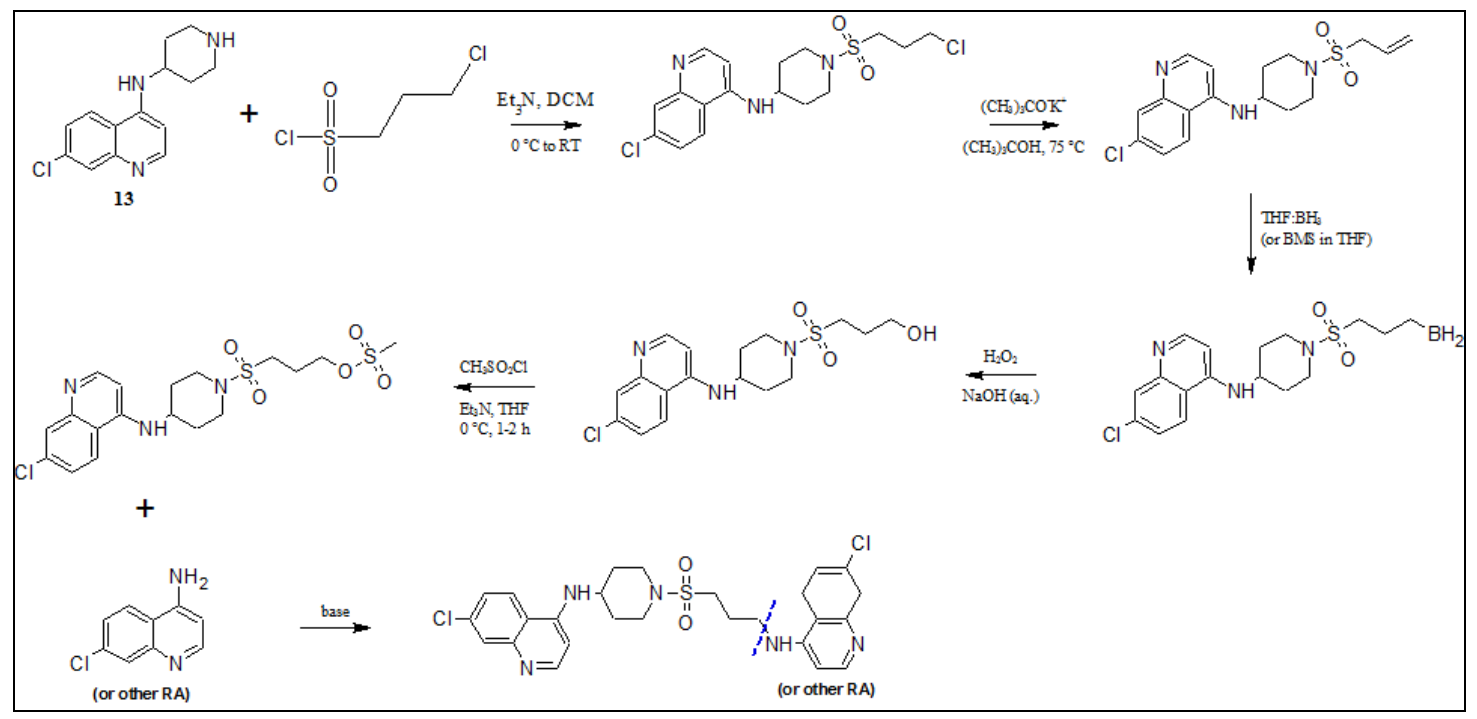

Figure 20. Proposed reaction scheme for synthesis of a RCQ with a sulfonamide moiety within the linker.

It was attempted to scale up the first reaction of this scheme, to provide starting material for the several subsequent steps. The reaction failed, producing a host of inseparable side products that could not be successfully removed by either chromatography or recrystallization to give a useful yield. However, as the following dehydrohalogenation step applied to the small-scale products was successful (although not shown in Materials \& Methods), it may well be worth attempting to alter the reaction conditions to produce this starting material on a large scale.

Encouraged by the reaction's small-scale (if not large-scale) success, sulfonamidecontaining reversed chloroquine reagents that could be synthesized in one final step with 
suitable starting materials were chosen as targets. A particularly intriguing such starting material was quinonyl-8-sulfonyl-chloride. As described previously, substitution at the 8position has an established basis in malaria treatments in the form of primaquine (figure 21).

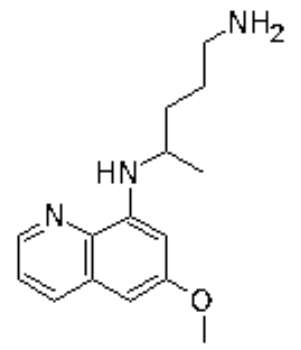

Figure 21. Primaquine, a member of the 8-aminoquinoline group of drugs.

Primaquine is a member of the 8-aminoquinoline group of drugs that includes tafenoquine and pamaquine. Primaquine is mainly used to treat $P$. vivax or $P$. ovale malaria, specifically to clear the dormant liver forms of these parasites once the parasite has been eliminated from the bloodstream. If primaquine is not administered to patients with proven P. vivax or P. ovale infection, a very high likelihood of relapse exists for weeks or months (sometimes years). The interaction between primaquine and quinine or chloroquine is thought to reduce relapse. Thus, a hybrid molecule of these two classical antimalarials could be a promising treatment.

7-chloro-N-[3-(piperazin-1-yl)propyl]quinolin-4-amine (PL34, figure 22) is a starting material that had previously been synthesized in the lab, and afforded an aliphatic linker as well as a protonatable nitrogen, which previous studies of this lab showed may play an important role in binding heme (Gunsaru, 2010). PL34 was purified by column chromatography, and then dissolved in dichloromethane with quinonyl-8-sulfonyl- 
chloride; triethylamine served as the reaction base. Compound 22 (figure 23) was successfully synthesized via a rapid nucleophilic substitution reaction, and readily purified by recrystallization in DCM and hexanes.

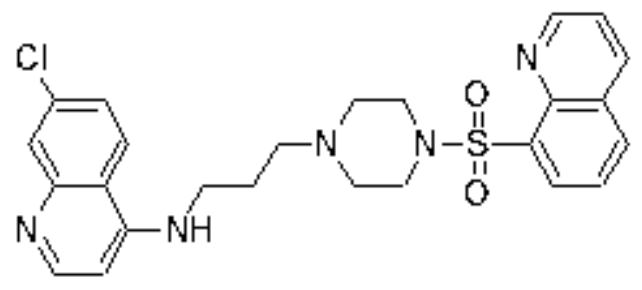

Figure 22. Compound 22. (7-chloro-N-\{3-[4-(quinoline-8-sulfonyl)piperazin-1-yl]propyl $\}$ quinolin-4-amine). $\mathrm{MW}=496.0 \mathrm{~g} \mathrm{~mol}^{-1}$. Formula $=\mathrm{C}_{26} \mathrm{H}_{33} \mathrm{ClN}_{6} \mathrm{O}_{2} \mathrm{~S} . \operatorname{clogP}=3.74 . \mathrm{CQ}^{\mathrm{S} / \mathrm{R}}>250 \mathrm{nM}$.

PL34 was similarly coupled with 3-(trifluoromethyl)benzylsulfonyl chloride to yield 23 (figure 23), which has yet to be pharmacologically tested.

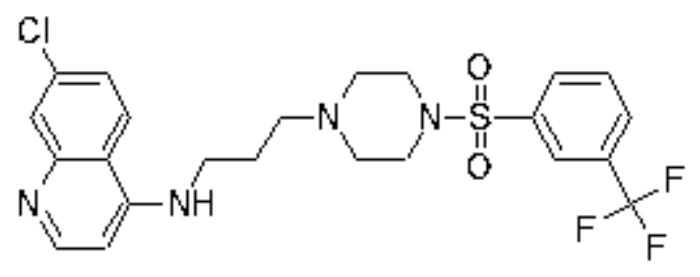

Figure 23. Compound 23. (7-chloro-N-\{3-[4-(quinoline-8-sulfonyl)piperazin-1-yl]propyl $\}$ quinolin-4-amine). $\mathrm{MW}=513.0 \mathrm{~g} \mathrm{~mol}^{-1}$. Formula $=\mathrm{C}_{23} \mathrm{H}_{24} \mathrm{ClF}_{3} \mathrm{~N}_{4} \mathrm{O}_{2} \mathrm{~S} . \operatorname{clogP}=4.66 . \mathrm{CQ}^{\mathrm{S}} \mathrm{IC}_{50}=79 \mathrm{nM}$; $\mathrm{CQ}^{\mathrm{R}} \mathrm{IC}_{50}=211 \mathrm{nM}$.

It is well established in the medicinal chemistry literature that the substitution of hydrogen atoms with fluorine atoms at a site of metabolic oxidation in a drug candidate (such as an aromatic structure) may prevent such metabolism from taking place. Because the fluorine atom is similar in size to the hydrogen atom the overall topology of the molecule is essentially unchanged, leaving the desired biological activity unaffected and improving the drug's half-life. Moreover, trifluoromethyl groups are bioisosteres for 
chlorine atoms (Patrick, 1995). As chlorine has proven an important substituent in the RCQ, as described earlier, this could be an interesting substitution.

In the pharmacophore of the reversal agent first described by Bhatacharjee (2001), it was suggested a protonatable nitrogen might an important feature to chemosensitization. Consistent with this hypothesis, it was found within this thesis's set of experiments that the amide equivalent of $\mathbf{3}$ had no pharmacological effect (i.e., $\mathrm{IC}_{50}>$ $2500 \mathrm{nM}$ ), where its amine counterpart, 3 proper, did suppress parasite growth substantially, if not potently (see the results and discussion of $\mathbf{3}$ above). As a further test of this hypothesis, molecules $\mathbf{2 5}$ and $\mathbf{2 6}$ were synthesized as equivalents to $\mathbf{2 2}$, but lacking the piperazine moiety, and hence lacking the protonatable nitrogen. 25 and $\mathbf{2 6}$ differ only by the former featuring a 2-carbon linker, where $\mathbf{2 6}$ features a 3-carbon linker. Additionally, a rigid piperazine bound to the 4 position of the chloroquinoline ring and 8sulfonyl of the reversal agent was synthesized by coupling 7-chloro-4-piperazylquinoline with quinonyl-8-sulfonyl-chloride via nucleophilic substitution. (See Figure 26, compound 21.)

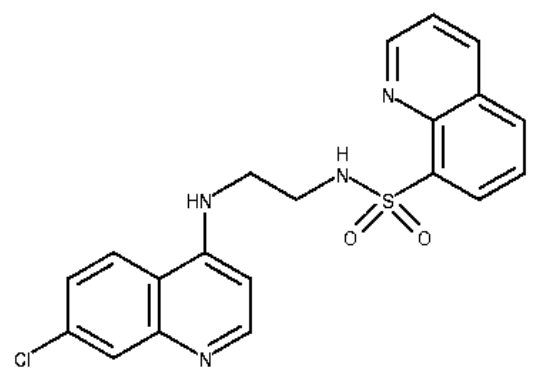

Figure 24. Compound 25. 7-chloro-N-\{2-[4-(quinoline-8-sulfonyl)piperazin-1-yl]ethyl $\}$ quinolin-4-amine). $\mathrm{MW}=415.0 \mathrm{~g} \mathrm{~mol}^{-1}$. Formula $=\mathrm{C}_{20} \mathrm{H}_{17} \mathrm{ClN}_{4} \mathrm{O}_{2} \mathrm{~S}$. clogP $=3.53$. CQ $\mathrm{IC}_{50}=79 \mathrm{nM} ; \mathrm{CQ}^{\mathrm{R}} \mathrm{IC}_{50}=225 \mathrm{nM}$. 


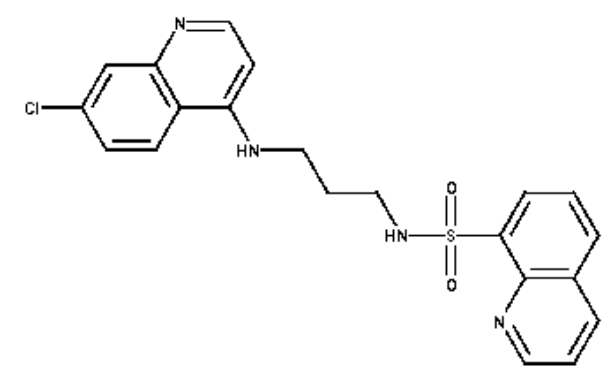

Figure 25. Compound 26. (7-chloro-N-\{3-[4-(quinoline-8-sulfonyl)piperazin-1-yl]propyl $\}$ quinolin-4-amine). $\mathrm{MW}=427.0 \mathrm{~g} \mathrm{~mol}^{-1}$. Formula $=\mathrm{C}_{21} \mathrm{H}_{19} \mathrm{ClN}_{4} \mathrm{O}_{2} \mathrm{~S} \cdot \operatorname{clog} \mathrm{P}=3.61 . \mathrm{CQ}^{\mathrm{S} / \mathrm{R}}=$ unk.

Inconsistent with the hypothesis that a protonatable nitrogen in the aliphatic linker is required for antimalarial effect, compound $\mathbf{2 2}$ showed no effect against either $\mathrm{CQ}^{\mathrm{S}}$ or $\mathrm{CQ}^{\mathrm{R}}$ (for both, $\mathrm{IC}_{50}>250 \mathrm{nM}$ ). By contrast, its analog lacking the protonable nitrogen, 25, showed modest potency $\left(\mathrm{CQ}^{\mathrm{S}} \mathrm{IC}_{50}=79 \mathrm{nM} ; \mathrm{CQ}^{\mathrm{R}} \mathrm{IC}_{50}=226 \mathrm{nM}\right)$. The 3-carbon linker analog of $\mathbf{2 5}$, compound $\mathbf{2 6}$ (figure 25), has yet to be tested. Interestingly, compound $\mathbf{2 3}$ featuring a protonatable nitrogen, as well as the less typical reversal agent consisting of a phenyl ring featuring a trifluoromethyl substituent, demonstrated good potency $\left(\mathrm{CQ}^{\mathrm{S}} \mathrm{IC}_{50}=21 \mathrm{nM} ; \mathrm{CQ}^{\mathrm{R}} \mathrm{IC}_{50}=211 \mathrm{nM}\right)$. This is consistent with the finding that the mono-aromatic reversal agent in the earlier synthesized antimalarial, may show great promise when coupled with a sulfonamide moiety, regardless of the structure of the linker. It will be an interesting SAR to determine whether the presence of this trifluoromethyl-phenyl reversal agent, and the absence of a protontable nitrogen, still shows effect. This would help parse the individual influence of the reversal agent and the function of the protonatable nitrogen in the aliphatic linker. Molecular modeling would also aid in this analysis to visualize specific interactions between the target and heme. Finally, the relatively rigid molecule $\mathbf{2 1}$ (figure 26), also lacking a protonatable nitrogen, 
showed very good effect, particularly against the chloroquine-resistance strain of $\left(\mathrm{CQ}^{\mathrm{S}}\right.$ $\left.\mathrm{IC}_{50}=21 \mathrm{nM} ; \mathrm{CQ}^{\mathrm{R}} \mathrm{IC}_{50}=10 \mathrm{nM}\right)$. This is consistent with the test results of 22; indeed, the two molecules are distinguished only by an additional aliphatic bridge between the amine moieties to form a heterocyclic linker.

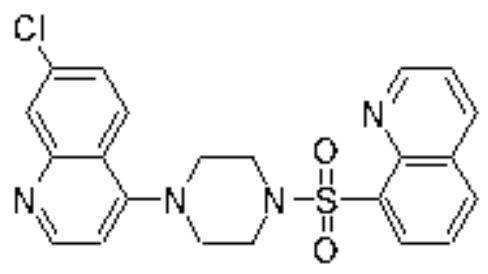

Figure 26. Compound 21. (8-\{[4-(6-chloronaphthalen-1-yl)piperazin-1-yl] sulfonyl $\}$ quinoline). $\mathrm{MW}=$ $437.8 \mathrm{~g} \mathrm{~mol}^{-1}$. Formula $=\mathrm{C}_{23} \mathrm{H}_{20} \mathrm{ClN}_{3} \mathrm{O}_{2} \mathrm{~S} \cdot \operatorname{clog} \mathrm{P}=4.61 . \mathrm{CQ}^{\mathrm{S}} \mathrm{IC}_{50}=21 \mathrm{nM} ; \mathrm{CQ}^{\mathrm{R}} \mathrm{IC}_{50}=10 \mathrm{nM}$.

A table summarizing these results, and corresponding thesis compounds with Peyton Lab (PL) database entries, is presented in Appendix F. 


\section{Chapter 3. Methods \& Materials:}

All the required chemicals were purchased from Sigma-Aldrich Chemical Company (USA) and TCI America. Precoated aluminum or silica sheets were used for thin-layer chromatography (TLC) and spots were visualized under UV light. Proton NMR spectra were recorded on a Bruker Avance II $400 \mathrm{MHz}$ spectrometer using solvents as indicated and trimethylsilane (TMS) as an internal standard. Splitting patterns are designated as follows: s, singlet; d, doublet; dd, doublet of doublets; t, triplet; m, multiplet. Chemical shift values are given in ppm. An example of an NMR spectrum appears in Appendix A.

\subsubsection{3-chloro-N-(7-chloroquinolin-3-yl)propanamide (1):}

A solution of $3.0 \mathrm{~g}(0.021 \mathrm{~mol})$ 7-chloroquinolin-3-amine and $3.35 \mathrm{~mL}(0.032 \mathrm{~mol})$ triethylamine in $30 \mathrm{~mL}$ dichloromethane was cooled to $0^{\circ} \mathrm{C} .2 .10 \mathrm{~mL}(0.022 \mathrm{~mol})$ chloroprionyl chloride was added dropwise while ensuring that reaction temperature remained below $10{ }^{\circ} \mathrm{C}$. The solution stirred for $1 \mathrm{~h}$. On reaction completion (TLC) the reaction solution was washed with $30 \mathrm{~mL}$ saturated sodium bicarbonate. The aqueous layer was washed with 3 x $30 \mathrm{~mL}$ portions of dichloromethane. The organic layers were pooled and dried over magnesium sulfate. The solvent was evaporated under vacuum to leave a crude dull white solid extract. Yield $86 \%$ (dull white solid). ${ }^{1} \mathrm{H}$ NMR (MeOD) $\delta$ (ppm): $3.77(2 \mathrm{H}, \mathrm{t}, \mathrm{J}=6.348), 2.78(2 \mathrm{H}, \mathrm{t}, \mathrm{J}=6.35), 8.06(1 \mathrm{H}, \mathrm{d}, \mathrm{J}=2.04), 7.86(1 \mathrm{H}, \mathrm{s})$, $7.72(1 \mathrm{H}, \mathrm{d}, \mathrm{J}=2.04), 7.51(1 \mathrm{H}, \mathrm{dd}, \mathrm{J}=6.35$ and 2.04$), 7.69(1 \mathrm{H}, \mathrm{dd}, \mathrm{J}=6.35$ and 2.04$)$. 


\subsubsection{3-[4-(diphenylmethyl)piperazin-1-yl]-N-(quinolin-3-yl)propanamide (2):}

$4.0 \mathrm{~g}(0.021 \mathrm{~mol})$ of 1 was mixed with $2.3 \mathrm{~g}(0.023 \mathrm{~mol})$ of diphenylmethylpiperazine in $30 \mathrm{~mL}$ anhydrous acetonitrile. $1.65 \mathrm{~g}(0.033 \mathrm{~mol})$ of anhydrous potassium carbonate and several grains of catalytic KI were added to the solution. The solution was let reflux overnight. Upon reaction completion (TLC), the reaction product was concentrated via rotary evaporation. The resultant slurry was taken into $60 \mathrm{~mL} \mathrm{H}_{2} \mathrm{O}$ and $30 \mathrm{~mL}$ ethyl acetate. The aqueous layer was extracted with $2 \times 20 \mathrm{~mL}$ ethyl acetate. The organic layer was washed with $30 \mathrm{~mL}$ sodium bicarbonate, followed by $30 \mathrm{~mL}$ brine. The organic layer was dried over magnesium sulfate, and the solvent evaporated under heat and vacuum to yield a yellow oil. This crude extract was subjected to silica column chromatography with ethyl acetate as the mobile phase. Yield $69 \%$ (yellow solid). ${ }^{1} \mathrm{H}$ NMR $\left(\mathrm{CDCl}_{3}\right) \delta(\mathrm{ppm})$ : $2.45(2 \mathrm{H}, \mathrm{t}, \mathrm{J}=2.67), 2.92(2 \mathrm{H}, \mathrm{t}, \mathrm{J}=2.67), 8.06(1 \mathrm{H}, \mathrm{dd}, \mathrm{J}=5.45, \mathrm{~J}=1.50), 7.86(1 \mathrm{H}, \mathrm{s})$, $2.56(4 \mathrm{H}, \mathrm{m}), 2.51(4 \mathrm{H}, \mathrm{m}), 7.71(1 \mathrm{H}, \mathrm{d}, \mathrm{J}=7.75), 2.45(2 \mathrm{H}, \mathrm{t}, \mathrm{J}=2.67), 8.02(1 \mathrm{H}, \mathrm{d}$, $\mathrm{J}=5.450), 7.51(1 \mathrm{H}, \mathrm{dd}, \mathrm{J}=6.96, \mathrm{~J}=1.63),, 7.67(1 \mathrm{H}, \mathrm{dd}, \mathrm{J}=6.96, \mathrm{~J}=1.513), 5.45(1 \mathrm{H}, \mathrm{s})$, $7.41(4 \mathrm{H}, \mathrm{dd}, \mathrm{J}=5.34, \mathrm{~J}=1.36), 7.30$ (4H, dd, J=5.34, J=1.36).

\subsubsection{N-\{3-[4-(diphenylmethyl)piperazin-1-yl]propyl\}quinolin-3-amine (3):}

Under nitrogen, a flask was charged with $0.50 \mathrm{~g}$ oven-dried $2.20 \mathrm{~mL}$ tetrahydrofuran solvent was added. The mixture was put on ice and let cool to $0{ }^{\circ} \mathrm{C} .2 .1 \mathrm{~mL}$ of LiAlH4 in THF was added dropwise, inducing a salient red color change. The reaction was let warm to room temperature overnight. The reaction, returned to ice, was quenched with aqueous citric via dropping funnel. This was followed by the addition of sodium bicarbonate. The crude reaction mixture was worked up with an additional $150 \mathrm{~mL}$ sodium bicarbonate and $50 \mathrm{~mL}$ dichloromethane pulled through Celite filtration aid. The organic layer was 
evaporated under vacuum to yield crude extract. The crude product was subjected to silica column chromatography with ethyl acetate as the mobile phase. Yield $60 \% .{ }^{1} \mathrm{H}$ $\operatorname{NMR}\left(\mathrm{CDCl}_{3}\right) \delta(\mathrm{ppm}): 2.45(2 \mathrm{H}, \mathrm{t}, \mathrm{J}=2.67), 2.92(2 \mathrm{H}, \mathrm{t}, \mathrm{J}=2.67), 8.04(1 \mathrm{H}, \mathrm{dd}, \mathrm{J}=5.45$, $\mathrm{J}=1.50), 7.81(1 \mathrm{H}, \mathrm{s}), 2.56(4 \mathrm{H}, \mathrm{m}), 2.51(4 \mathrm{H}, \mathrm{m}), 7.69(1 \mathrm{H}, \mathrm{d}, \mathrm{J}=7.75), 2.45(2 \mathrm{H}, \mathrm{t}, \mathrm{J}=$ 2.67), $7.99(1 \mathrm{H}, \mathrm{d}, \mathrm{J}=5.45), 7.48(1 \mathrm{H}, \mathrm{dd}, \mathrm{J}=6.96, \mathrm{~J}=1.63),, 7.57(1 \mathrm{H}, \mathrm{dd}, \mathrm{J}=6.96$, $\mathrm{J}=1.513), 5.45(1 \mathrm{H}, \mathrm{s}), 7.41(4 \mathrm{H}, \mathrm{dd}, \mathrm{J}=5.34, \mathrm{~J}=1.36), 7.30(4 \mathrm{H}, \mathrm{dd}, \mathrm{J}=5.34, \mathrm{~J}=1.36)$.<smiles></smiles>

Figure 27. Reaction Scheme 1. (a) 1.5 eq. Et3N, DCM, $0{ }^{\circ} \mathrm{C}$, 1 h. (b) 1.5 eq. $\mathrm{K}_{2} \mathrm{CO}_{3}$, $\mathrm{KI}$ (cat.), acetonitrile, reflux. (c) THF, $0{ }^{\circ} \mathrm{C}$ to rt, 10 eq. $\mathrm{LiAlH} 4$, overnight; citric acid for reaction quench, on ice.

\subsubsection{3-(quinolin-2-ylamino)propan-1-ol (4):}

$3.0 \mathrm{~g}$ 2-chloroquinoline was reacted with 10 eq 3 -aminopropanol, neat. The mixture was heated in a Carius vessel to $90{ }^{\circ} \mathrm{C}$ for $20 \mathrm{~h}$. Upon reaction completion, the solution was poured into $20 \mathrm{~mL}$ water, and let stir for $20 \mathrm{~min}$. The solid was collected by vacuum 
filtration to yield a pure white solid that was let air dry for $3 \mathrm{~d}$. Yield: $98 \%$. Yield $60 \%$. ${ }^{1} \mathrm{H}$ NMR (MeOD) $\delta$ (ppm): 3.35 (2H, t, J=4.77), $1.87(2 \mathrm{H}, \mathrm{m}), 3.34$ (2H, t, J=6.64), 7.40 $(1 \mathrm{H}, \mathrm{t}, \mathrm{J}=8.98), 8.26(1 \mathrm{H}, \mathrm{d}, \mathrm{J}=6.34), 7.61(1 \mathrm{H}, \mathrm{d}, \mathrm{J}=7.61), 7.91(1 \mathrm{H}, \mathrm{d}, \mathrm{J}=8.01), 7.64$ $(1 \mathrm{H}, \mathrm{t}, \mathrm{J}=7.66), 7.40(1 \mathrm{H}, \mathrm{d}, \mathrm{J}=8.02)$.

\subsubsection{3-(quinolin-2-ylamino)propyl methanesulfonate (5):}

$3.5 \mathrm{~g} 4$ was dissolved in $30 \mathrm{~mL}$ tetrahydrofuran. $0.75 \mathrm{~mL}$ triethylamine ws added. The mixture was cooled to $0{ }^{\circ} \mathrm{C} .0 .67 \mathrm{~mL}$ methanesulfonylchloride was added dropwise. The reaction proceed for $2 \mathrm{~h}$, and was monitored by TLC. Upon completion, the reaction was added to $30 \mathrm{~mL}$ ethyl acetate and $30 \mathrm{~mL}$ saturated sodium bicarbonate. The organic layer was washed with $3 \times 30 \mathrm{~mL}$ sodium bicarbonate, and the aqueous layer was washed with $2 \times 20 \mathrm{~mL}$ ethyl acetate. The organic layers were pooled and the solvent was evaporated under heat and vacuum to yield a tan solid. Yield 87\%. ${ }^{1} \mathrm{H}$ NMR $\left(\mathrm{CDCl}_{3}\right) \delta(\mathrm{ppm}): 3.67$ $(2 \mathrm{H}, \mathrm{t}, \mathrm{J}=4.87), 1.87(2 \mathrm{H}, \mathrm{m}), 3.34(2 \mathrm{H}, \mathrm{t}, \mathrm{J}=6.64), 7.40(1 \mathrm{H}, \mathrm{t}, \mathrm{J}=8.98), 8.26(1 \mathrm{H}, \mathrm{d}, \mathrm{J}=$ 6.34), $7.61(1 \mathrm{H}, \mathrm{d}, \mathrm{J}=7.61), 7.91(1 \mathrm{H}, \mathrm{d}, \mathrm{J}=8.01), 7.64(1 \mathrm{H}, \mathrm{t}, \mathrm{J}=7.66), 7.40(1 \mathrm{H}, \mathrm{d}$, $\mathrm{J}=8.02)$.

\subsubsection{7-Chloro-N-(1-\{3-[(quinolin-2-yl)amino]propyl\}piperidin-4-yl)quinolin-4-amine}

(6):

$0.40 \mathrm{~g} 5$ was mixed with $0.37 \mathrm{~g}$ 7-chloro-N-(piperidin-4-yl)quinolin-4-amine in $10 \mathrm{~mL}$ anhydrous acetonitrile. $0.30 \mathrm{~g}$ anhydrous potassium carbonate and several grains of catalytic KI were added to the mixture. The reaction was heated to reflux and proceeded for $20 \mathrm{~h}$. Upon reaction completion (TLC), the mixture was subjected to rotary evaporation. The resultant slurry was added to $40 \mathrm{~mL}$ water and $20 \mathrm{~mL}$ ethyl acetate. The aqueous layer was extracted of product with 2 x $10 \mathrm{~mL}$ ethyl acetate. The organic layer 
was washed with $15 \mathrm{~mL}$ saturated sodium bicarbonate, then $20 \mathrm{~mL}$ brine. The organic layer was dried over magnesium sulfate, and the solvent was evaporated under heat and vacuum. The crude product was purified via alumina column chromatography on a gradient of $100 \% \mathrm{EA} \rightarrow 90 \% \mathrm{EA} / 10 \% \mathrm{MeOH}$. Yield $70 \% .{ }^{1} \mathrm{H} \mathrm{NMR}\left(\mathrm{CDCl}_{3}\right) \delta(\mathrm{ppm})$ : $7.80(1 \mathrm{H}, \mathrm{s}), 7.31(1 \mathrm{H}, \mathrm{dd}, \mathrm{J}=8.263, \mathrm{~J}=1.903), 8.10(1 \mathrm{H}, \mathrm{d}, \mathrm{J}=8.263), 8.53(1 \mathrm{H}, \mathrm{d}, \mathrm{J}=5.11)$, $6.75(1 \mathrm{H}, \mathrm{dd}, \mathrm{J}=5.108, \mathrm{~J}=0.446), 3.81(4 \mathrm{H}, \mathrm{m}), 2.65(2 \mathrm{H}, \mathrm{t}, \mathrm{J}=8.505), 2.38(2 \mathrm{H}, \mathrm{t}, \mathrm{J}=8.47)$, $1.81(2 \mathrm{H}, \mathrm{m}), 3.36(4 \mathrm{H}, \mathrm{m}), 7.42(1 \mathrm{H}, \mathrm{dd}, \mathrm{J}=8.98), 8.24(1 \mathrm{H}, \mathrm{d}, \mathrm{J}=8.98), 7.61(1 \mathrm{H}, \mathrm{d}$, $\mathrm{J}=7.661), 7.91(1 \mathrm{H}, \mathrm{d}, \mathrm{J}=8.007), 7.64(1 \mathrm{H}, \mathrm{d}, \mathrm{J}=7.66), 7.40(1 \mathrm{H}, \mathrm{d}, \mathrm{J}=8.01)$.

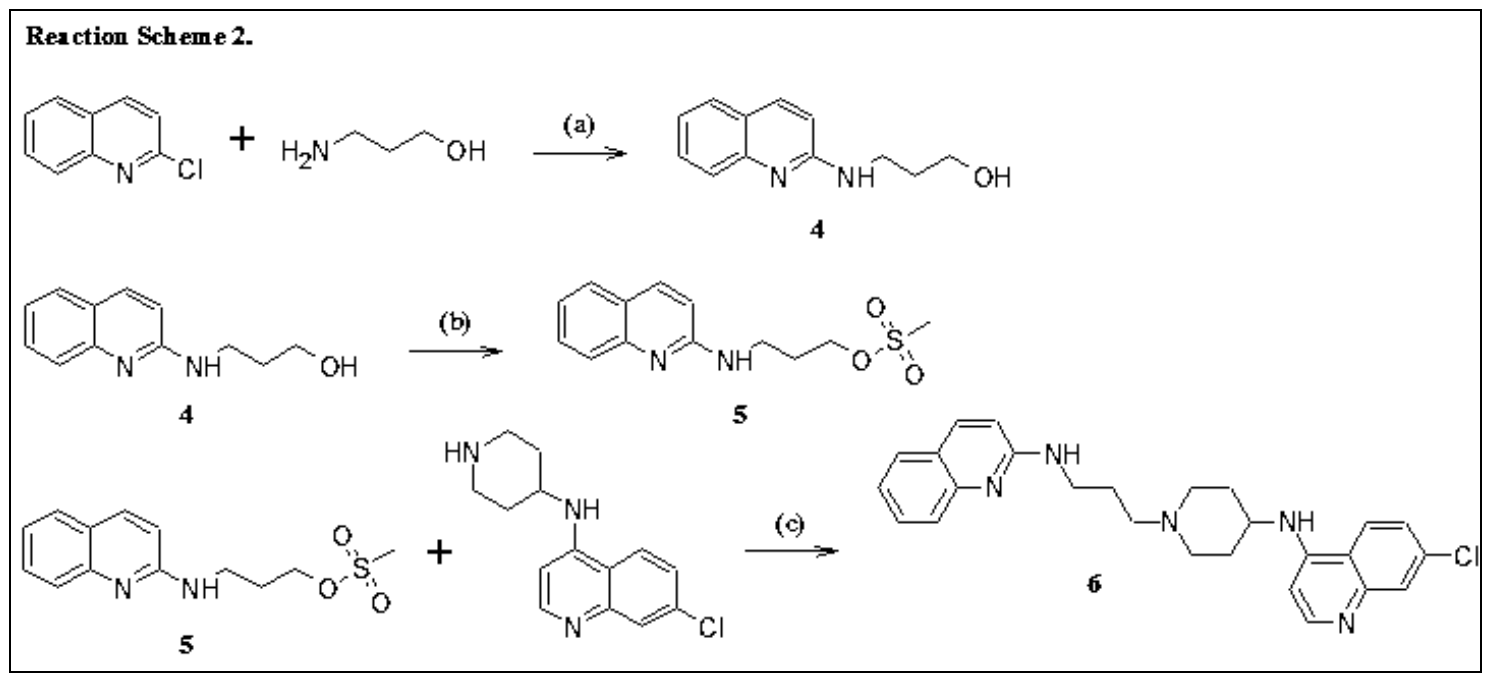

Figure 28. Reaction Scheme 2. (a) 10 eq. 3 -aminopropanol, neat. (b) 1.5 eq. $\mathrm{Et}_{3} \mathrm{~N}$, THF; (c) 1.5 eq. $\mathrm{K}_{2} \mathrm{CO}_{3}$, KI (cat.), acetonitrile, reflux.

\subsubsection{Ethyl 4-(quinolin-2-ylamino)piperidine-1-carboxylate (7):}

A Carius vessel was charged with $1.0 \mathrm{~g}$ 2-chloroquinoline, $1.05 \mathrm{~mL}$ 4-amino-piperidine1-carboxylate, and $3.45 \mathrm{~g}$ phenol. Upon heating to $100{ }^{\circ} \mathrm{C}$, the phenol dissolved and served as a solvent for the other reagents. The reaction proceeded for $5 \mathrm{~d}$. Upon reaction completion (TLC), the warm mixture was poured into $25 \mathrm{~mL}$ ethyl acetate. This organic mixture was washed with $6 \times 10 \mathrm{~mL} 10 \% \mathrm{NaOH}$ (aq.), followed by $3 \times 10 \mathrm{~mL}$ brine 
washes. The solvent of the organic layer was evaporated under heat and vacuum to yield a salmon-colored waxy solid. The solid was let air dry, and subjected directly to the following reaction prior to purification or analysis.

\subsubsection{N-(piperidin-4-yl)quinolin-2-amine (8):}

$0.79 \mathrm{~g}$ of solid 7 was dissolved in $20 \mathrm{~mL}$ ethanol. To achieve a 10 molar equivalence of $\mathrm{NaOH}$ (aq.), $10.6 \mathrm{~mL}$ of $10 \% \mathrm{NaOH}$ (aq.) was added. The mixture was heated at reflux overnight. Upon reaction completion, the ethanol solvent was evaporated under heat and vacuum. The residue was taken into $25 \mathrm{~mL}$ chloroform and $25 \mathrm{~mL}$ water. An emulsion formed, and the separatory funnel let stand overnight until the emulsion disappeared. The aqueous layer was washed with $3 \times 10 \mathrm{~mL}$ chloroform. All organic layers were pooled and dried with magnesium sulfate, followed by evaporation of the solvent under vacuum and heat. This yielded a caramel colored solid that was let air dry overnight. The solid was recrystallized with $15 \mathrm{~mL}$ ethyl acetate. Yield 55\%. ${ }^{1} \mathrm{H}$ NMR (MeOD) $\delta(\mathrm{ppm}): 7.43$ $(5,1 \mathrm{H}, \mathrm{d}, \mathrm{J}=8.984), 7.618(1 \mathrm{H}, \mathrm{dd}, \mathrm{J}=7.659, \mathrm{~J}=1.316), 3.91(8,1 \mathrm{H}, \mathrm{dd}, \mathrm{J}=10.22, \mathrm{~J}=3.250)$, $8.24(9,1 \mathrm{H}, \mathrm{dd}, \mathrm{J}=8.98, \mathrm{~J}=1.574), 7.91(1 \mathrm{H}, \mathrm{dd}, \mathrm{J}=8.01, \mathrm{~J}=1.627), 7.64(1 \mathrm{H}, \mathrm{dd}, \mathrm{J}=7.524$, $\mathrm{J}=1.627), 1.80(4 \mathrm{H}, \mathrm{m}), 7.40(1 \mathrm{H}, \mathrm{dd}, \mathrm{J}=8.008, \mathrm{~J}=1.316), 3.111(4 \mathrm{H}, \mathrm{m})$.

\subsubsection{3-[(7-chloroquinolin-4-yl)aminolpropan-1-ol (9):}

$3.0 \mathrm{~g}$ 4,7-dichloroquinoline was reacted with $11 \mathrm{~mL} 3$-aminopropanol, neat. The mixture was heated in a Carius vessel to $90{ }^{\circ} \mathrm{C}$ for $20 \mathrm{~h}$. Upon reaction completion, the solution was poured into $20 \mathrm{~mL}$ water, and let stir for $20 \mathrm{~min}$. The solid was collected by vacuum filtration to yield a pure white solid that was let air dry for $3 \mathrm{~d}$. Yield: $98 \%$. Yield $60 \%$.

${ }^{1} \mathrm{H}$ NMR (MeOD) $\delta(\mathrm{ppm}): 7.74(1 \mathrm{H}, \mathrm{s}), 7.30(1 \mathrm{H}, \mathrm{d}, \mathrm{J}=8.26), 8.10(1 \mathrm{H}, \mathrm{d}, \mathrm{J}=8.26), 8.52$ $(1 \mathrm{H}, \mathrm{s}), 6.74(1 \mathrm{H}, \mathrm{s}), 3.42(2 \mathrm{H}, \mathrm{d}, \mathrm{J}=6.869), 1.88(2 \mathrm{H}, \mathrm{t}, \mathrm{J}=6.87), 3.32(2 \mathrm{H}, \mathrm{d}, \mathrm{J}=5.36)$. 


\subsubsection{3-[(7-chloroquinolin-4-yl)aminolpropyl methanesulfonate (10):}

$3.5 \mathrm{~g} 9$ was dissolved in $30 \mathrm{~mL}$ tetrahydrofuran. $1.5 \mathrm{~mol} \mathrm{eq}$. triethylamine was added. The mixture was cooled to $0{ }^{\circ} \mathrm{C} .0 .75 \mathrm{~mL}$ methanesulfonylchloride was added dropwise. The reaction proceed for $2 \mathrm{~h}$, and was monitored by TLC. Upon completion, the reaction was added to $30 \mathrm{~mL}$ ethyl acetate and $30 \mathrm{~mL}$ saturated sodium bicarbonate. The organic layer was washed with $3 \times 30 \mathrm{~mL}$ sodium bicarbonate, and the aqueous layer was washed with $2 \times 20 \mathrm{~mL}$ ethyl acetate. The organic layers were pooled and the solvent was evaporated under heat and vacuum to yield a tan solid. Yield $87 \% .{ }^{1} \mathrm{H}$ NMR $\left(\mathrm{CDCl}_{3}\right) \delta(\mathrm{ppm}): 7.84$ $(1 \mathrm{H}, \mathrm{s}), 7.40(1 \mathrm{H}, \mathrm{d}, \mathrm{J}=8.26), 8.17(1 \mathrm{H}, \mathrm{d}, \mathrm{J}=8.26), 8.59(1 \mathrm{H}, \mathrm{s}), 6.79(1 \mathrm{H}, \mathrm{s}), 3.45(2 \mathrm{H}, \mathrm{d}$, $\mathrm{J}=6.869), 1.91(2 \mathrm{H}, \mathrm{t}, \mathrm{J}=6.87), 3.35(2 \mathrm{H}, \mathrm{d}, \mathrm{J}=5.362)$.

\subsubsection{7-chloro-N-(3-\{4-[(quinolin-2-yl)amino]piperidin-1-yl\}propyl)quinolin-4-amine}

(11):

$0.50 \mathrm{~g} 8$ was mixed with $0.37 \mathrm{~g} 10$ in $10 \mathrm{~mL}$ anyhdrous acetonitrile. $0.30 \mathrm{~g}$ anhydrous potassium carbonate and several grains of catalytic KI were added to the mixture. The reaction was heated to reflux and proceeded for $20 \mathrm{~h}$. Upon reaction completion (TLC), the mixture was subjected to rotary evaporation. The resultant slurry was added to $40 \mathrm{~mL}$ water and $20 \mathrm{~mL}$ ethyl acetate. The aqueous layer was extracted of product with $2 \times 10$ mL ethyl acetate. The organic layer was washed with $15 \mathrm{~mL}$ saturated sodium bicarbonate, then $20 \mathrm{~mL}$ brine. The organic layer was dried over magnesium sulfate, and the solvent was evaporated under heat and vacuum. The crude product was purified via alumina column chromatpgrahy on a gradient of $100 \% \mathrm{EA} \rightarrow 90 \% \mathrm{EA}, 10 \% \mathrm{MeOH}$. Yield 70\%. ${ }^{1} \mathrm{H}$ NMR (MeOD) $\delta$ (ppm): $7.80(1 \mathrm{H}, \mathrm{s}), 7.31$ (1H, dd, J=8.263, J=1.903), 
$8.10(1 \mathrm{H}, \mathrm{d}, \mathrm{J}=8.263), 8.53(1 \mathrm{H}, \mathrm{d}, \mathrm{J}=5.11), 6.75(1 \mathrm{H}, \mathrm{dd}, \mathrm{J}=5.108, \mathrm{~J}=0.446), 3.81(4 \mathrm{H}$, m), $2.65(2 \mathrm{H}, \mathrm{t}, \mathrm{J}=8.505), 2.38(2 \mathrm{H}, \mathrm{t}, \mathrm{J}=8.47), 1.81(2 \mathrm{H}, \mathrm{m}), 3.36(4 \mathrm{H}, \mathrm{m}), 7.42(1 \mathrm{H}, \mathrm{dd}$, $\mathrm{J}=8.98), 8.24(1 \mathrm{H}, \mathrm{d}, \mathrm{J}=8.98), 7.61(1 \mathrm{H}, \mathrm{d}, \mathrm{J}=7.661), 7.91(1 \mathrm{H}, \mathrm{d}, \mathrm{J}=8.007), 7.64(1 \mathrm{H}, \mathrm{d}$, $\mathrm{J}=7.66), 7.40(1 \mathrm{H}, \mathrm{d}, \mathrm{J}=8.01)$.

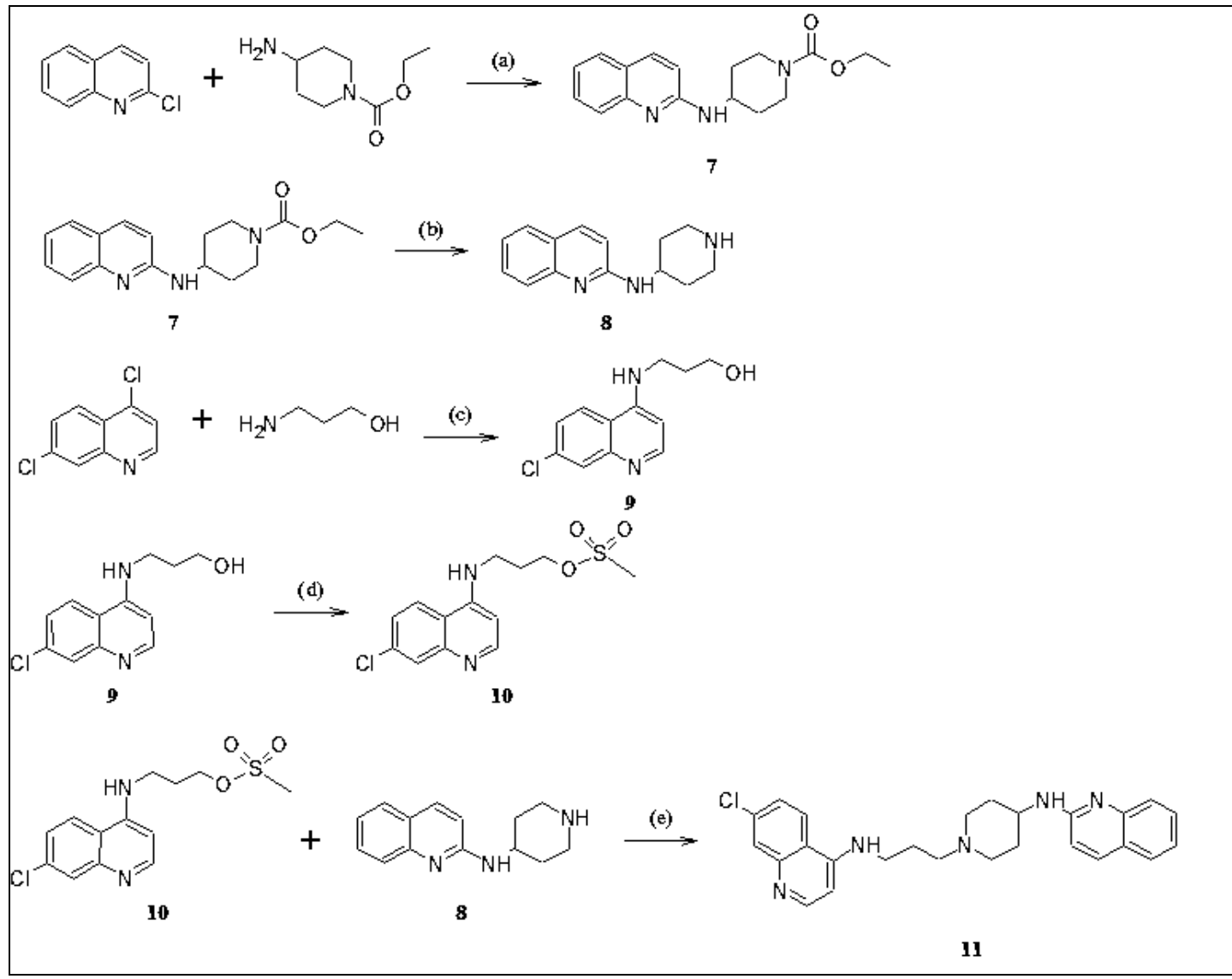

Figure 29. Reaction Scheme 3. (a) 6 eq. phenol, $100{ }^{\circ} \mathrm{C}$, 5d; (b) 10 eq. $\mathrm{NaOH}$ (aq.), EtOH, reflux; (c) 10 eq. 3-aminopropanol, neat; (d) 1.5 eq. $\mathrm{Et}_{3} \mathrm{~N}$, THF; (e) 1.5 eq. $\mathrm{K}_{2} \mathrm{CO}_{3}$, $\mathrm{KI}$ (cat.), acetonitrile, reflux.

\subsubsection{2. ethyl 4-[(7-chloroquinolin-4-yl)amino]piperidine-1-carboxylate (12):}

A Carius vessel was charged with $1.0 \mathrm{~g}$ 4,7-dichloroquinoline, $1.05 \mathrm{~mL}$ 4-aminopiperidine-1-carboxylate, and $3.45 \mathrm{~g}$ phenol. Upon heating to $100{ }^{\circ} \mathrm{C}$, the phenol dissolved and served as a solvent for the other reagents. The reaction proceeded for $5 \mathrm{~d}$. Upon reaction completion (TLC), the warm mixture was poured into $25 \mathrm{~mL}$ ethyl acetate. 
This organic mixture was washed with $6 \times 10 \mathrm{~mL} \mathrm{10 \%} \mathrm{NaOH}$ (aq.), followed by $3 \times 10$ $\mathrm{mL}$ brine washes. The solvent of the organic layer was evaporated under heat and vacuum to yield a salmon-colored waxy solid. The solid was let air dry, and subjected immediately to the following reaction prior to purification or analysis.

\subsubsection{7-chloro-N-(piperidin-4-yl)quinolin-4-amine (13):}

$0.79 \mathrm{~g}$ of solid 7 was dissolved in $20 \mathrm{~mL}$ ethanol. To achieve a 10 molar equivalence of $\mathrm{NaOH}$ (aq.), $10.6 \mathrm{~mL}$ of $10 \% \mathrm{NaOH}$ (aq.) was added. The mixture was heated at reflux overnight. Upon reaction completion, the ethanol solvent was evaporated under heat and vacuum. The residue was taken into $25 \mathrm{~mL}$ chloroform and $25 \mathrm{~mL}$ water. An emulsion formed, and the separatory funnel let stand overnight until the emulsion disappeared. The aqueous layer was washed with $3 \times 10 \mathrm{~mL}$ chloroform. All organic layers were pooled and dried with magnesium sulfate, followed by evaporation of the solvent under vacuum and heat. This yielded a caramel colored solid that was let air dry overnight. The solid was recrsyallized with $15 \mathrm{~mL}$ ethyl acetate. Yield $55 \% .{ }^{1} \mathrm{H}$ NMR $\left(\mathrm{CDCl}_{3}\right) \delta(\mathrm{ppm}): 7.43$ $(5,1 \mathrm{H}, \mathrm{d}, \mathrm{J}=8.984), 7.618(1 \mathrm{H}, \mathrm{dd}, \mathrm{J}=7.659, \mathrm{~J}=1.316), 3.91(8,1 \mathrm{H}, \mathrm{dd}, \mathrm{J}=10.22, \mathrm{~J}=3.250)$, $8.24(9,1 \mathrm{H}, \mathrm{dd}, \mathrm{J}=8.98, \mathrm{~J}=1.574), 7.91(1 \mathrm{H}, \mathrm{dd}, \mathrm{J}=8.01, \mathrm{~J}=1.627), 7.64(1 \mathrm{H}, \mathrm{dd}, \mathrm{J}=7.524$, $\mathrm{J}=1.627), 1.80(4 \mathrm{H}, \mathrm{m}), 7.40(1 \mathrm{H}, \mathrm{dd}, \mathrm{J}=8.008, \mathrm{~J}=1.316), 3.111(4 \mathrm{H}, \mathrm{m})$.

\subsubsection{2-[(7-chloroquinolin-4-yl)amino]ethanol (14):}

$3.0 \mathrm{~g}$ 4,7-dichloroquinoline was reacted with 113 -aminopropanol, neat. The mixture was heated in a Carius vessel to $90^{\circ} \mathrm{C}$ for $20 \mathrm{~h}$. Upon reaction completion, the solution was poured into $20 \mathrm{~mL}$ water, and let stir for $20 \mathrm{~min}$. The solid was collected by vacuum filtration to yield a pure white solid that was let air dry for $3 \mathrm{~d}$. Yield: $98 \%$. Yield $60 \%$. ${ }^{1} \mathrm{H}$ NMR (MeOD) $\delta(\mathrm{ppm}): 7.75(1 \mathrm{H}, \mathrm{s}), 7.30(1 \mathrm{H}, \mathrm{dd}, \mathrm{J}=8.25, \mathrm{~J}=1.90), 8.10(1 \mathrm{H}, \mathrm{d}$, 
$\mathrm{J}=8.25), 8.52(1 \mathrm{H}, \mathrm{d}, \mathrm{J}=4.58), 6.74(1 \mathrm{H}, \mathrm{d}, \mathrm{J}=4.58), 3.68(2 \mathrm{H}, \mathrm{t}, \mathrm{J}=6.24), 3.32(2 \mathrm{H}, \mathrm{t}$, $\mathrm{J}=6.25)$.

\subsubsection{3-[(7-chloroquinolin-4-yl)aminolpropyl methanesulfonate (15):}

$3.5 \mathrm{~g} 9$ was dissolved in $30 \mathrm{~mL}$ tetrahydrofuran. $2.45 \mathrm{~mL}$ triethylamine was added. The mixture was cooled to $0{ }^{\circ} \mathrm{C} .0 .72 \mathrm{~mL}$ methanesulfonylchloride was added dropwise. The reaction proceed for $2 \mathrm{~h}$, and monitored by TLC. Upon completion, the reaction was added to $30 \mathrm{~mL}$ ethyl acetate and $30 \mathrm{~mL}$ saturated sodium bicarbonate. The organic layer was washed with $3 \times 30 \mathrm{~mL}$ sodium bicarbonate, and the aqueous layer was washed with $2 \times 20 \mathrm{~mL}$ ethyl acetate. The organic layers were pooled and the solvent was evaporated under heat and vacuum to yield a tan solid. Yield 87\%. ${ }^{1} \mathrm{H}$ NMR (MeOD) $\delta$ (ppm): 7.82 $(1 \mathrm{H}, \mathrm{s}), 7.44(1 \mathrm{H}, \mathrm{dd}, \mathrm{J}=8.25, \mathrm{~J}=1.90), 8.13(1 \mathrm{H}, \mathrm{d}, \mathrm{J}=8.22), 8.60(1 \mathrm{H}, \mathrm{d}, \mathrm{J}=4.53), 6.77$ $(1 \mathrm{H}, \mathrm{d}, \mathrm{J}=4.58), 3.98(2 \mathrm{H}, \mathrm{t}, \mathrm{J}=7.14), 3.12(2 \mathrm{H}, \mathrm{t}, \mathrm{J}=6.55)$.

\subsubsection{7-chloro-N-\{2-[4-(7-chloroquinolin-4-yl)piperidin-1-yl]ethyl\}quinolin-4-amine} (16):

$0.50 \mathrm{~g} 13$ was mixed with $0.37 \mathrm{~g} 15 \mathrm{in} 10 \mathrm{~mL}$ anhydrous acetonitrile. $0.24 \mathrm{~g}$ anhydrous potassium carbonate and several grains of catalytic KI were added to the mixture. The reaction was heated to reflux and proceeded for $20 \mathrm{~h}$. Upon reaction completion (TLC), the mixture was subjected to rotary evaporation. The resultant slurry was added to $40 \mathrm{~mL}$ water and $20 \mathrm{~mL}$ ethyl acetate. The aqueous layer was extracted of product with $2 \times 10$ mL ethyl acetate. The organic layer was washed with $15 \mathrm{~mL}$ saturated sodium bicarbonate, then $20 \mathrm{~mL}$ brine. The organic layer was dried over magnesium sulfate, and the solvent was evaporated under heat and vacuum. The crude product was purified via alumina column chromatpgrahy on a gradient of $100 \% \mathrm{EA} \rightarrow 90 \% \mathrm{EA}, 10 \% \mathrm{MeOH}$. 
Yield 70\%. ${ }^{1} \mathrm{H}$ NMR (MeOD) $\delta$ (ppm): $7.80(1 \mathrm{H}, \mathrm{s}), 7.31$ (1H, dd, J=8.263, J=1.903), $8.10(1 \mathrm{H}, \mathrm{d}, \mathrm{J}=8.263), 8.53(1 \mathrm{H}, \mathrm{d}, \mathrm{J}=5.11), 6.75(1 \mathrm{H}, \mathrm{dd}, \mathrm{J}=5.108, \mathrm{~J}=0.446), 3.81(4 \mathrm{H}$, m), $2.65(2 \mathrm{H}, \mathrm{t}, \mathrm{J}=8.505), 2.38(2 \mathrm{H}, \mathrm{t}, \mathrm{J}=8.47), 1.81(2 \mathrm{H}, \mathrm{m}), 3.36(4 \mathrm{H}, \mathrm{m}), 7.42(1 \mathrm{H}, \mathrm{dd}$, $\mathrm{J}=8.98), 8.24(1 \mathrm{H}, \mathrm{d}, \mathrm{J}=8.98), 7.61(1 \mathrm{H}, \mathrm{d}, \mathrm{J}=7.661), 7.91(1 \mathrm{H}, \mathrm{d}, \mathrm{J}=8.01), 7.64(1 \mathrm{H}, \mathrm{d}$, $\mathrm{J}=7.66), 7.40(1 \mathrm{H}, \mathrm{d}, \mathrm{J}=8.01)$.

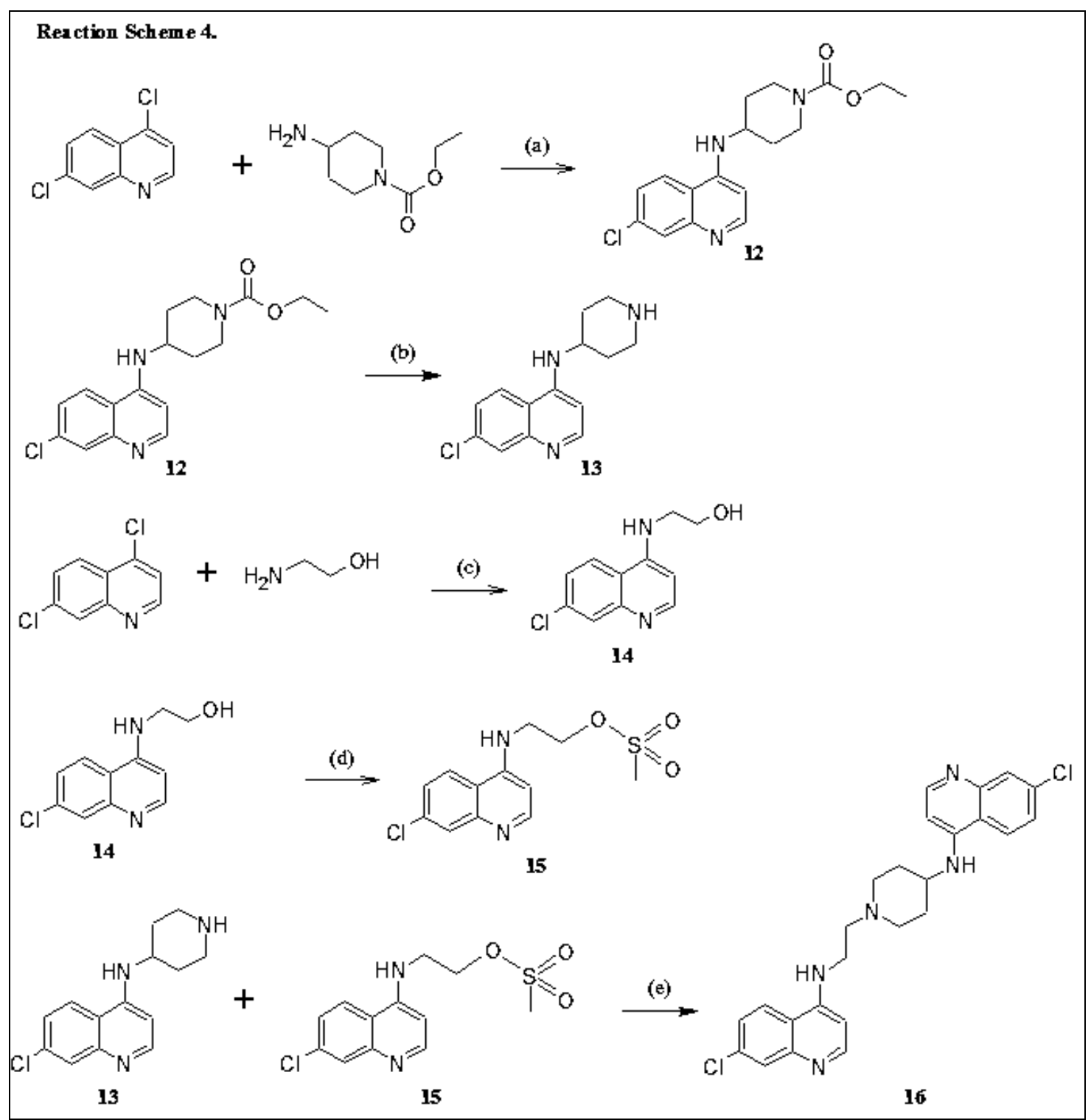

Figure 30. Reaction Scheme 4. (a) 6 eq. phenol, $100^{\circ} \mathrm{C}$, 5d; (b) 10 eq. $\mathrm{NaOH}$ (aq.), EtOH, reflux; (c) 10 eq. 3-aminopropanol, neat; (d) 1.5 eq. $\mathrm{Et}_{3} \mathrm{~N}$, THF; (e) 1.5 eq. $\mathrm{K}_{2} \mathrm{CO}_{3}$, $\mathrm{KI}$ (cat.), acetonitrile, reflux. 
3.2.17. N-\{3-[4-(3-aminopropyl)piperazin-1-yl]propyl\}-6-chloronaphthalen-1-amine (17):

$1.0 \mathrm{~g}$ of recrystallized 4,7-dichloroquinoline was dissolved in $20 \mathrm{~mL} n$-butnaol. To this was added $3.15 \mathrm{~mL}$ (3 molar equivalents) of 1,4-bis(3-aminopropyl)piperazine. The mixture was heated to reflux. Upon completion of the reaction (TLC), the solvent was evaporated under heat and vacuum. The resultant yellow, waxy solid was added to $50 \mathrm{~mL}$ water and stirred with mild heat for $1 \mathrm{~h}$. The solid suspension was then vacuum filtered to leave a light yellow solid. Yield 73\%. 1H NMR (DMSO) $\delta(\mathrm{ppm}): 7.80(1 \mathrm{H}, \mathrm{s}), 7.31(1 \mathrm{H}$, dd, J=8.263, J=1.903), $8.10(1 \mathrm{H}, \mathrm{d}, \mathrm{J}=8.26), 8.53(1 \mathrm{H}, \mathrm{d}, \mathrm{J}=5.11), 6.75(1 \mathrm{H}, \mathrm{d}, \mathrm{J}=5.108)$, $3.303(4 \mathrm{H}, \mathrm{t}, \mathrm{J}=6.75), 3.17(4 \mathrm{H}, \mathrm{t}, \mathrm{J}=6.55), 2.52(2 \mathrm{H}, \mathrm{t}, \mathrm{J}=2.67), 1.52(2 \mathrm{H}, \mathrm{m}), 2.62(2 \mathrm{H}$, $\mathrm{t}, \mathrm{J}=6.94), 3.61(2 \mathrm{H}, \mathrm{t}, \mathrm{J}=2.67), 2.13(2 \mathrm{H}, \mathrm{m}), 2.78(2 \mathrm{H}, \mathrm{t}, \mathrm{J}=6.83)$.

\subsubsection{N-[3-(4-\{3-[(6-chloronaphthalen-1-yl)amino]propyl\} piperazin-1-yl)-} propyllquinolin-2-amine (18):

Under nitrogen, a flask was charged with $0.67 \mathrm{~g} \mathrm{17}, 0.33 \mathrm{~g}$ 2-chloroquinoline, and 0.96 mL DIEA. The reagents were suspended in $15 \mathrm{~mL}$ anhydrous dichloromethane via syringe. The mixture stirred for $3 \mathrm{~h}$ at room temperature; upon discerning poor solubility of $\mathbf{1 7}, 10 \mathrm{~mL}$ of methanol was added. The mixture was heated to $100{ }^{\circ} \mathrm{C}$, and the materials soon dissolved. Over approximately $1 \mathrm{~h}$, an orange-yellow color appeared. The reaction was left to reflux overnight. The solution was poured into $50 \mathrm{~mL}$ sodium bicarbonate and $50 \mathrm{~mL}$ chloroform. The organic layer was washed with $3 \times 50 \mathrm{~mL}$ sodium bicarbonate. The aqueous layer was washed with $2 \times 25 \mathrm{~mL}$ chloroform. The organic layers were pooled, and the solvent was evaporated under heat and vacuum to 
leave a crude dark yellow solid. The crude extract was subjected to alumina basic column chromatography over a gradient of $100 \%$ ethyl acetate $\rightarrow 80 \%$ ethyl acetate / $20 \%$ methanol. This process yielded a pure light yellow solid. Yield $10 \% .{ }^{1} \mathrm{H}$ NMR $\left(\mathrm{CDCl}_{3}\right) \delta$ (ppm):

$7.80(2 \mathrm{H}, \mathrm{s}), 7.31(2 \mathrm{H}, \mathrm{dd}, \mathrm{J}=8.263, \mathrm{~J}=1.903), 8.10(2 \mathrm{H}, \mathrm{d}, \mathrm{J}=8.26), 8.53(2 \mathrm{H}, \mathrm{d}, \mathrm{J}=5.11)$, $6.75(2 \mathrm{H}, \mathrm{d}, \mathrm{J}=5.108), 3.40(8 \mathrm{H}, \mathrm{t}, \mathrm{J}=6.75), 2.52(4 \mathrm{H}, \mathrm{t}, \mathrm{J}=2.65), 1.52(4 \mathrm{H}, \mathrm{m}), 2.73(4 \mathrm{H}$, $\mathrm{t}, \mathrm{J}=6.94)$.

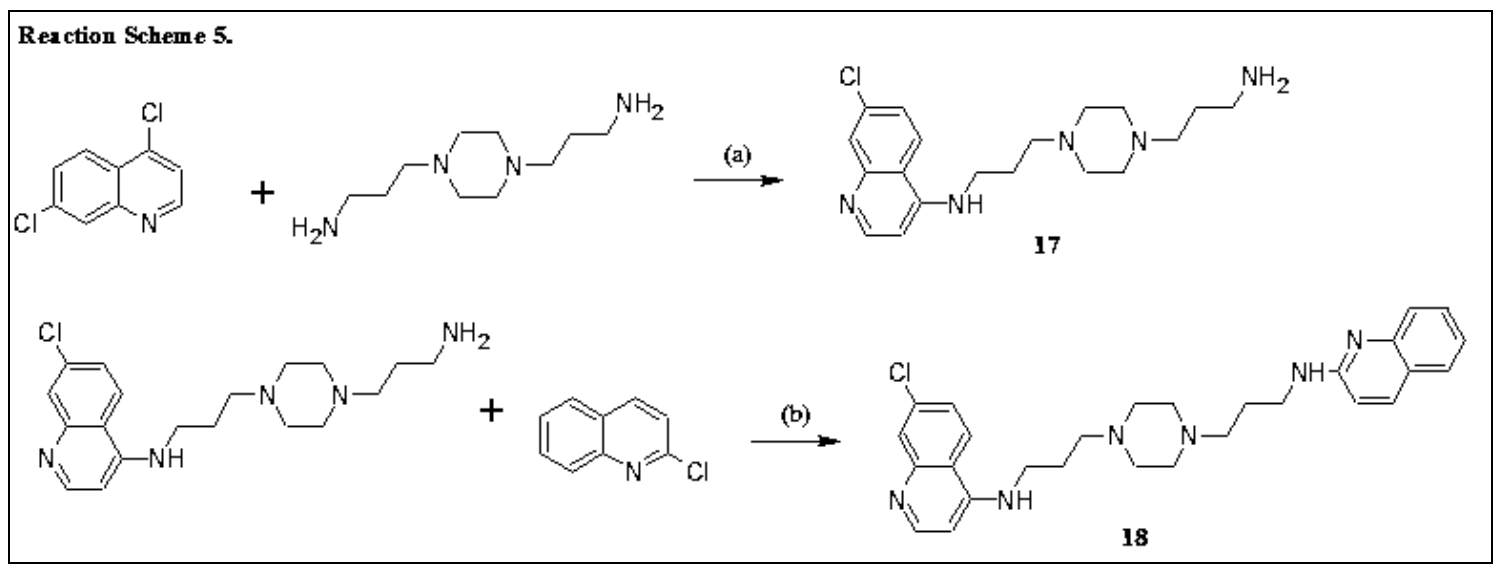

Figure 31. Reaction Scheme 5. (a) excess diamino-piperazine reagent, n-butanol, reflux. (b) 1.5 eq. $\mathrm{K}_{2} \mathrm{CO}_{3}$, KI (cat.), acetonitrile, reflux.

3.2.19. 7-chloro-N-\{1-[(3-chloropropyl)sulfonyl]piperidin-4-yl\}quinolin-4-amine (19):

To a stirred solution of 7-chloro-4-piperazin-1-yl-quinoline (2) $(1.0 \mathrm{~g}, 1 \mathrm{mmol})$ in $30 \mathrm{~mL}$ of DCM at $0{ }^{\circ} \mathrm{C}$ was added triethylamine $(0.12 \mathrm{~mL}, 1.26 \mathrm{mmol})$. A dropwise addition of 3-chloropropanesulfonyl chloride proceeded, with a correspondent change in solution color from white to yellow. The reaction was let warm to room temperature and continued for $18 \mathrm{~h}$. On reaction completion, the reaction mix was diluted diluted with 30 $\mathrm{mL}$ water and $30 \mathrm{~mL} \mathrm{DCM}$ and partitioned in separating funnel, where the organic layer was washed with water $(3 \times 20 \mathrm{~mL})$ before being separated and dried over sodium sulfate 
to yield compound 19 in which was recrystallized in DCM: hexane to yield pure product in $90 \%$ yield. ${ }^{1} \mathrm{H}$ NMR $\left(\mathrm{CDCl}_{3}\right) \delta(\mathrm{ppm}): 7.80(1 \mathrm{H}, \mathrm{s}), 7.30(1 \mathrm{H}, \mathrm{d}, \mathrm{J}=8.264), 8.10(1 \mathrm{H}$, d), $8.526(1 \mathrm{H}, \mathrm{d}, \mathrm{J}=5.12), 6.75(1 \mathrm{H}, \mathrm{d}, \mathrm{J}=5.12), 3.89(1 \mathrm{H}, \mathrm{dt}, \mathrm{J}=10.250, \mathrm{~J}=2.660), 1.69$ (4H, m) $3.20(4 \mathrm{H}, \mathrm{m}), 3.62(2 \mathrm{H}, \mathrm{t}, \mathrm{J}=14.881), 3.44(2 \mathrm{H}, \mathrm{t}, \mathrm{J}=6.49), 2.24(2 \mathrm{H}, \mathrm{t})$.

3.2.20. 7-chloro-N-(1-\{3-[4-(pyridin-2-yl)piperazin-1-yl]propanesulfonyl\}piperidin-4-yl)-quinolin-4-amine (20):

Under nitrogen, $0.25 \mathrm{~g}$ of solid $\mathbf{1 9}$ was dissolved in anhydrous acetonitrile, and mixed with anhydrous potassium bicarbonate. $0.2 \mathrm{~g}$ 1-(2-pyridyl)piperazine was added. The mixture was heated to reflux, and stirred for $3 \mathrm{~d}$. The solvent was evaporated under heat and vacuum, and then added to $50 \mathrm{~mL}$ chloroform and $50 \mathrm{ml}$ water for liquid-liquid extraction. After three washes of the organic layer with water, the organic layer was rotary evaporated. The crude extract was subjected to alumina basic column chromatography silica with 95\% ethyl acetate and 5\% methanol. Yield 22\%. ${ }^{1} \mathrm{H}$ NMR $\left(\mathrm{CDCl}_{3}\right) \delta(\mathrm{ppm}): 7.34(1 \mathrm{H}, \mathrm{d}, \mathrm{J}=6.67), 7.65(\mathrm{t}, \mathrm{J}=10.67), 7.44(1 \mathrm{H}, \mathrm{d}, \mathrm{J}=6.67), 6.98$ $(1 \mathrm{H}, \mathrm{t}, \mathrm{J}=8.87), 7.80(1 \mathrm{H}, \mathrm{s}), 7.30(1 \mathrm{H}, \mathrm{d}, \mathrm{J}=8.264), 8.10(1 \mathrm{H}, \mathrm{d}), 8.526(1 \mathrm{H}, \mathrm{d}, \mathrm{J}=5.12)$, $6.75(1 \mathrm{H}, \mathrm{d}, \mathrm{J}=5.12), 3.89(1 \mathrm{H}, \mathrm{dt}, \mathrm{J}=10.250, \mathrm{~J}=2.660), 1.69(4 \mathrm{H}, \mathrm{m}) 3.20(4 \mathrm{H}, \mathrm{m}), 3.62$ $(2 \mathrm{H}, \mathrm{t}, \mathrm{J}=14.88), 3.44(2 \mathrm{H}, \mathrm{t}, \mathrm{J}=6.49), 2.24(2 \mathrm{H}, \mathrm{t}), 3.27(4 \mathrm{H}, \mathrm{m}), 3.14(4 \mathrm{H}, \mathrm{m})$. 


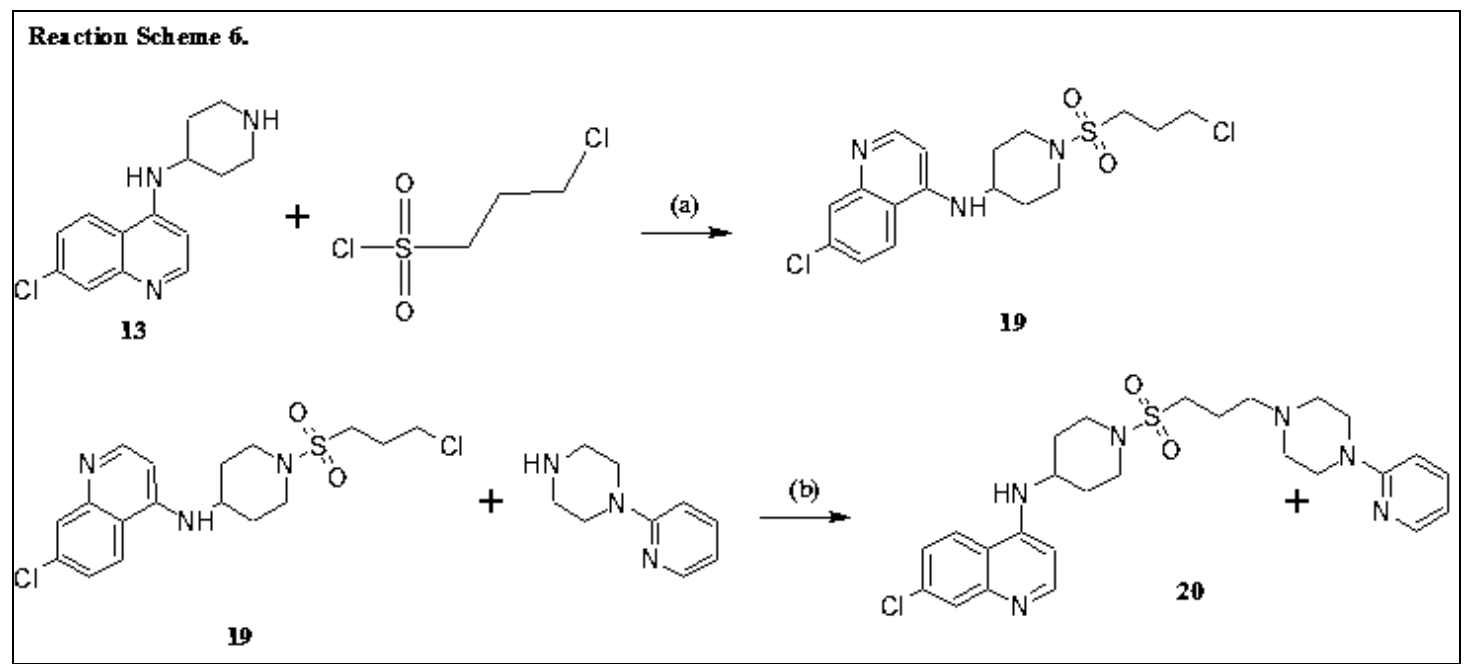

Figure 32. Reaction Scheme 6. (a) 1.25 eq $\mathrm{Et}_{3} \mathrm{~N}, \mathrm{DCM}, 0{ }^{\circ} \mathrm{C}$. (b) $\mathrm{K}_{2} \mathrm{CO}_{3}$, reflux, acetonitrile, $3 \mathrm{~d}$.

\subsubsection{7-Chloro-4-piperazin-1-yl-quinoline (20):}

To a stirred solution of 4,7-dichloroquinoline (10 g, $50.5 \mathrm{mmol})$ in $150 \mathrm{~mL})$ ethanol was added piperazine $(30.44 \mathrm{~g}, 353.5 \mathrm{mmol})$, the resulting solution was then refluxed for 12 h. On reaction completion (TLC) the reaction was concentrated under vacuum to give a crude solid mixture which was taken up in $200 \mathrm{~mL}$ DCM and washed with saturated sodium bicarbonate solution until no piperazine was seen in the organic layer (TLC). The combined organic extracts were dried over anhydrous sodium sulfate and concentrated to give a crude product which was purified by recrystallization in 30\% DCM:hexane as a white powder $(9.7 \mathrm{~g}, 77.6 \%)$ of compound. ${ }^{1} \mathrm{H}$ NMR (MeOD) $\delta(\mathrm{ppm}): 7.81(1 \mathrm{H}, \mathrm{s}), 7.31$ $(1 \mathrm{H}, \mathrm{d}, \mathrm{J}=8.269), 8.09(6,1 \mathrm{H}, \mathrm{d}, \mathrm{J}=8.27),, 8.51(1 \mathrm{H}, \mathrm{d}), 6.756(1 \mathrm{H}, \mathrm{d}, \mathrm{J}=5.15), 3.09(4 \mathrm{H}$, $\mathrm{m}), 2.81(4 \mathrm{H}, \mathrm{m})$.

\subsubsection{7-chloro-4-[4-(quinolin-8-ylsulfonyl)piperazin-1-yl]quinoline (21):}

To a stirred solution of 7-chloro-4-piperazin-1-yl-quinoline (2) $(0.25 \mathrm{~g}, 1 \mathrm{mmol})$ in $8-10$ $\mathrm{mL}$ of $\mathrm{DCM}$ at $0{ }^{\circ} \mathrm{C}$ was added triethylamine $(0.12 \mathrm{~mL}, 1.26 \mathrm{mmol}) .0 .19 \mathrm{~g}$ of quinonyl- 
8-sulfonyl chloride was added portionwise. The reaction was let warm to room temperature and stirred overnight. On reaction completion (TLC) $20 \mathrm{~mL}$ dichloromethane and $20 \mathrm{~mL}$ were added, and then poured into a separatory for liquid-liquid extraction. The organic layer was washed with 3 x $20 \mathrm{~mL}$ water. The organic extracts were dried over anhydrous sodium sulfate and concentrated to give a crude product which was purified by recrystallization in $15 \%$ DCM / 85\% hexane as a white powder $(0.3 \mathrm{~g}, 72 \%)$ of compound. ${ }^{1} \mathrm{H}$ NMR $\left(\mathrm{CDCl}_{3}\right) \delta(\mathrm{ppm}): 8.22(1 \mathrm{H}, \mathrm{d}, \mathrm{J}=8.44), 7.71(1 \mathrm{H}, \mathrm{d}, \mathrm{J}=8.23), 8.94$ $(1 \mathrm{H}, \mathrm{d}, \mathrm{J}=4.72), 8.19(1 \mathrm{H}, \mathrm{d}, \mathrm{J}=8.529), 8.13(\mathrm{~d}, \mathrm{~J}=8.23), 7.65(1 \mathrm{H}, \mathrm{t}, \mathrm{J}=8.529), 7.81(1 \mathrm{H}$, s), $7.31(1 \mathrm{H}, \mathrm{d}, \mathrm{J}=8.269), 8.09$ (6, 1H, d, J=8.27, ), $8.51(1 \mathrm{H}, \mathrm{d}), 6.756(1 \mathrm{H}, \mathrm{d}, \mathrm{J}=5.15)$, $3.09(4 \mathrm{H}, \mathrm{m}), 2.81(4 \mathrm{H}, \mathrm{m})$.

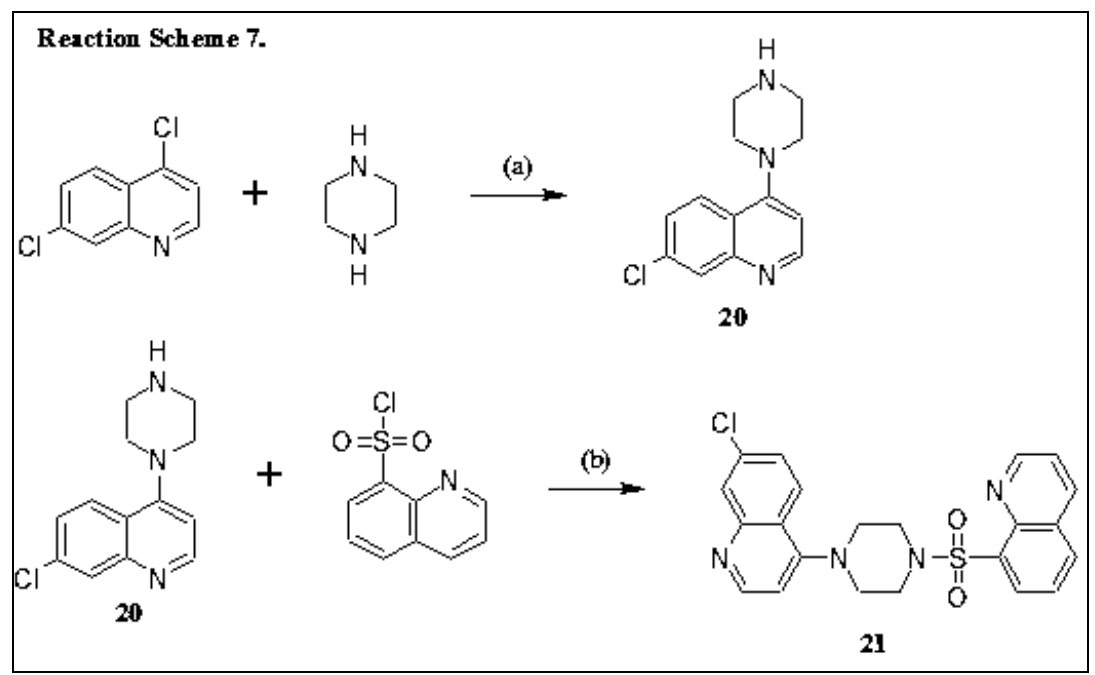

Figure 33. Reaction Scheme 7. (a) EtOH, reflux 12 h. (b) 1.25 eq Et 3 N, DCM, $0{ }^{\circ} \mathrm{C}$.

3.2.22. 7-chloro-N-\{3-[4-(quinoline-8-sulfonyl)piperazin-1-yl]propyl\}quinolin-4-amine (22):

Previously prepared 7-chloro-N-[3-(piperazin-1-yl)propyl]quinolin-4-amine was purified by alumina basic column chromatography with ethyl acetate as the mobile phase. To a 
stirred solution of 7-chloro-N-[3-(piperazin-1-yl)propyl]quinolin-4-amine $(0.25 \mathrm{~g}, 1$ mmol $)$ in $8-10 \mathrm{~mL}$ of $\mathrm{DCM}$ at $0{ }^{\circ} \mathrm{C}$ was added triethylamine $(0.12 \mathrm{~mL}, 1.26 \mathrm{mmol})$. $0.19 \mathrm{~g}$ of quinonyl-8-sulfonyl chloride was added portionwise. The reaction was let warm to room temperature and stirred overnight. On reaction completion (TLC) $20 \mathrm{~mL}$ dichloromethane and $20 \mathrm{~mL}$ were added, and then poured into a separatory for liquidliquid extraction. The organic layer was washed with 3 x $20 \mathrm{~mL}$ water. The organic extracts were dried over anhydrous sodium sulfate and concentrated to give a crude product which was purified by recrystallization in 15\% DCM / 85\% hexane as a white powder $(0.3 \mathrm{~g}, 72 \%)$ of compound. ${ }^{1} \mathrm{H}$ NMR $\left(\mathrm{CDCl}_{3}\right) \delta(\mathrm{ppm}): 7.16(1 \mathrm{H}, \mathrm{d}, \mathrm{J}=4.55), 7.68$ $(1 \mathrm{H}, \mathrm{d}, \mathrm{J}=8.09), 8.06(1 \mathrm{H}, \mathrm{d}, \mathrm{J}=5.890), 7.63(1 \mathrm{H}, \mathrm{d}, \mathrm{J}=8.09),, 3.32(2 \mathrm{H}, \mathrm{t}, \mathrm{J}=6.74), 7.57$ (1H, d, J=7.097), $1.81(14,2 \mathrm{H}, \mathrm{t}, \mathrm{J}=6.742), 2.60(15,2 \mathrm{H}, \mathrm{t}, \mathrm{J}=2.67), 2.46(2 \mathrm{H}, \mathrm{m}), 2.71$ (4H, m), $2.51(4 \mathrm{H}, \mathrm{m}), 8.22(1 \mathrm{H}, \mathrm{d}, \mathrm{J}=8.44), 7.71(1 \mathrm{H}, \mathrm{d}, \mathrm{J}=8.23), 8.94(1 \mathrm{H}, \mathrm{d}, \mathrm{J}=4.72)$, $8.19(1 \mathrm{H}, \mathrm{d}, \mathrm{J}=8.529), 8.13$ (d, J=8.23), $7.65(1 \mathrm{H}, \mathrm{t}, \mathrm{J}=8.53)$.

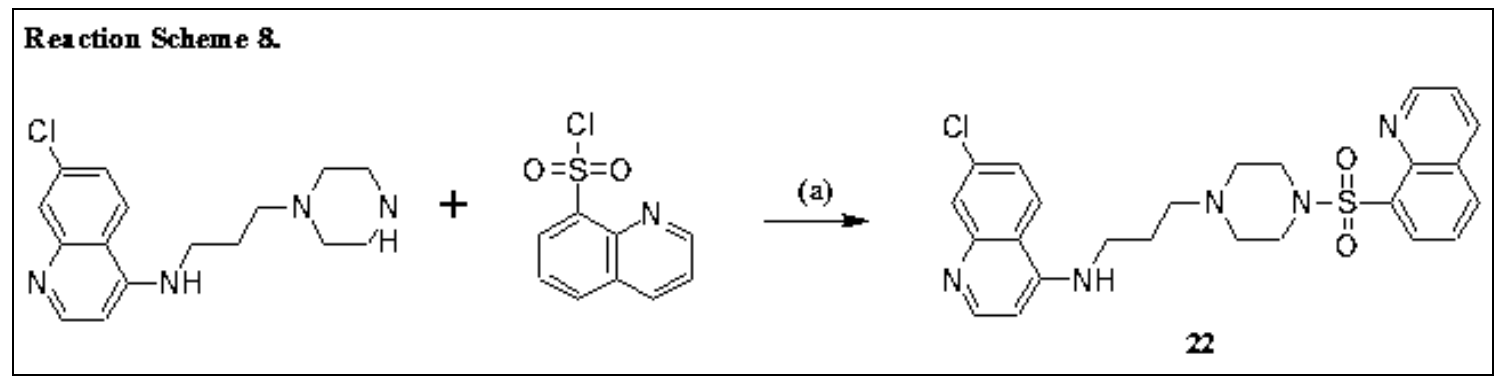

Figure 34. Reaction Scheme 8. (a) 1.25 eq Et $3 \mathrm{~N}, \mathrm{DCM}, 0{ }^{\circ} \mathrm{C}$.

3.2.24. N-(7-chloroquinolin-4-yl)propane-1,3-diamine (23) and N-(7-chloroquinolin-4yl)ethane-1,2-diamine (24). $3.0 \mathrm{~g}$ of 4,7-dichloroquinoline was dissolved in 12 molar equivalents of a diamine (ethylene or propylene). The reaction was run neat at reflux for $18 \mathrm{~h}$. The bulk of excess 
diamine was evaporated under heat and vacuum. The remaining waxy solid was suspended in $200 \mathrm{~mL}$ water, and stirred for $20 \mathrm{~min}$. The solid suspension was vacuum filtered to leave a pure white product. Yield $\sim 95 \% .23{ }^{1} \mathrm{H}$ NMR $\left(\mathrm{CDCl}_{3}\right) \delta(\mathrm{ppm}): 7.73$ $(1 \mathrm{H}, \mathrm{s}), 7.30(1 \mathrm{H}, \mathrm{d}, \mathrm{J}=8.257), 8.10(1 \mathrm{H}, \mathrm{d}, \mathrm{J}=8.25), 8.25(1 \mathrm{H}, \mathrm{d}, \mathrm{J}=4.581), 6.74(1 \mathrm{H}, \mathrm{d}$, $\mathrm{J}=4.58), 3.35(2 \mathrm{H}, \mathrm{t}, \mathrm{J}=6.58), 2.80(2 \mathrm{H}, \mathrm{t}, \mathrm{J}=6.58) .24{ }^{1} \mathrm{H} \mathrm{NMR}\left(\mathrm{CDCl}_{3}\right) \delta(\mathrm{ppm}): 7.74$ $(1 \mathrm{H}, \mathrm{s}), 7.30(1 \mathrm{H}, \mathrm{d}, \mathrm{J}=8.257), 8.10(1 \mathrm{H}, \mathrm{d}, \mathrm{J}=8.25), 8.25(1 \mathrm{H}, \mathrm{d}, \mathrm{J}=4.581), 6.74(1 \mathrm{H}, \mathrm{d}$, $\mathrm{J}=4.58), 3.32(2 \mathrm{H}, \mathrm{t}, \mathrm{J}=7.43), 1.70(2 \mathrm{H}, \mathrm{m}), 2.64(2 \mathrm{H}, \mathrm{t}, \mathrm{J}=7.25)$.

\subsubsection{6. $\mathrm{N}-\{2-[(7-$ chloroquinolin-4-yl)amino]ethyl $\}$ quinoline-8-sulfonamide (25) and} N-\{3-[(7-chloroquinolin-4-yl)amino]propyl $\} q u i n o l i n e-8$-sulfonamide (26). To a stirred solution of $\mathbf{2 3}$ or $\mathbf{2 4}(0.25 \mathrm{~g})$ in $8-10 \mathrm{~mL}$ of DCM at $0{ }^{\circ} \mathrm{C}$ was added triethylamine (1.25 molar equivalents). 1 molar equivalent ( $\sim .24 \mathrm{~g}$ ) of quinonyl-8sulfonyl chloride was added portionwise. The reaction was let warm to room temperature and stirred overnight. On reaction completion (TLC) $20 \mathrm{~mL}$ dichloromethane and $20 \mathrm{~mL}$ were added, and then poured into a separatory for liquid-liquid extraction. The organic layer was washed with $3 \times 20 \mathrm{~mL}$ water. The organic extracts were dried over anhydrous sodium sulfate and concentrated to give a crude product which was purified by recrystallization in 15\% DCM / 85\% hexane as a white powder ( $0.3 \mathrm{~g}, \sim 75 \%)$ of compound. $25{ }^{1} \mathrm{H}$ NMR $\left(\mathrm{CDCl}_{3}\right) \delta(\mathrm{ppm}): 7.73(1 \mathrm{H}, \mathrm{s}), 7.30(1 \mathrm{H}, \mathrm{d}, \mathrm{J}=8.257), 8.10(1 \mathrm{H}$, $\mathrm{d}, \mathrm{J}=8.25), 8.25(1 \mathrm{H}, \mathrm{d}, \mathrm{J}=4.581), 6.74(1 \mathrm{H}, \mathrm{d}, \mathrm{J}=4.58), 3.35(2 \mathrm{H}, \mathrm{t}, \mathrm{J}=6.58), 2.80(2 \mathrm{H}, \mathrm{t}$, $\mathrm{J}=6.58), 8.22(1 \mathrm{H}, \mathrm{d}, \mathrm{J}=8.44), 7.71(1 \mathrm{H}, \mathrm{d}, \mathrm{J}=8.23), 8.94(1 \mathrm{H}, \mathrm{d}, \mathrm{J}=4.72), 8.19(1 \mathrm{H}, \mathrm{d}$, $\mathrm{J}=8.529), 8.13(\mathrm{~d}, \mathrm{~J}=8.23), 7.65(1 \mathrm{H}, \mathrm{t}, \mathrm{J}=8.53) .26{ }^{1} \mathrm{H} \mathrm{NMR}\left(\mathrm{CDCl}_{3}\right) \delta(\mathrm{ppm}): 7.74(1 \mathrm{H}$, s), $7.30(1 \mathrm{H}, \mathrm{d}, \mathrm{J}=8.257), 8.10(1 \mathrm{H}, \mathrm{d}, \mathrm{J}=8.25), 8.25(1 \mathrm{H}, \mathrm{d}, \mathrm{J}=4.581), 6.74(1 \mathrm{H}, \mathrm{d}$, $\mathrm{J}=4.58), 3.32(2 \mathrm{H}, \mathrm{t}, \mathrm{J}=7.43), 1.70(2 \mathrm{H}, \mathrm{m}), 2.64(2 \mathrm{H}, \mathrm{t}, \mathrm{J}=7.25), 8.22(1 \mathrm{H}, \mathrm{d}, \mathrm{J}=8.44)$, 
$7.71(1 \mathrm{H}, \mathrm{d}, \mathrm{J}=8.23), 8.94(1 \mathrm{H}, \mathrm{d}, \mathrm{J}=4.72), 8.19$ (1H, d, J=8.529), 8.13 (d, J=8.23), 7.65 $(1 \mathrm{H}, \mathrm{t}, \mathrm{J}=8.53)$.

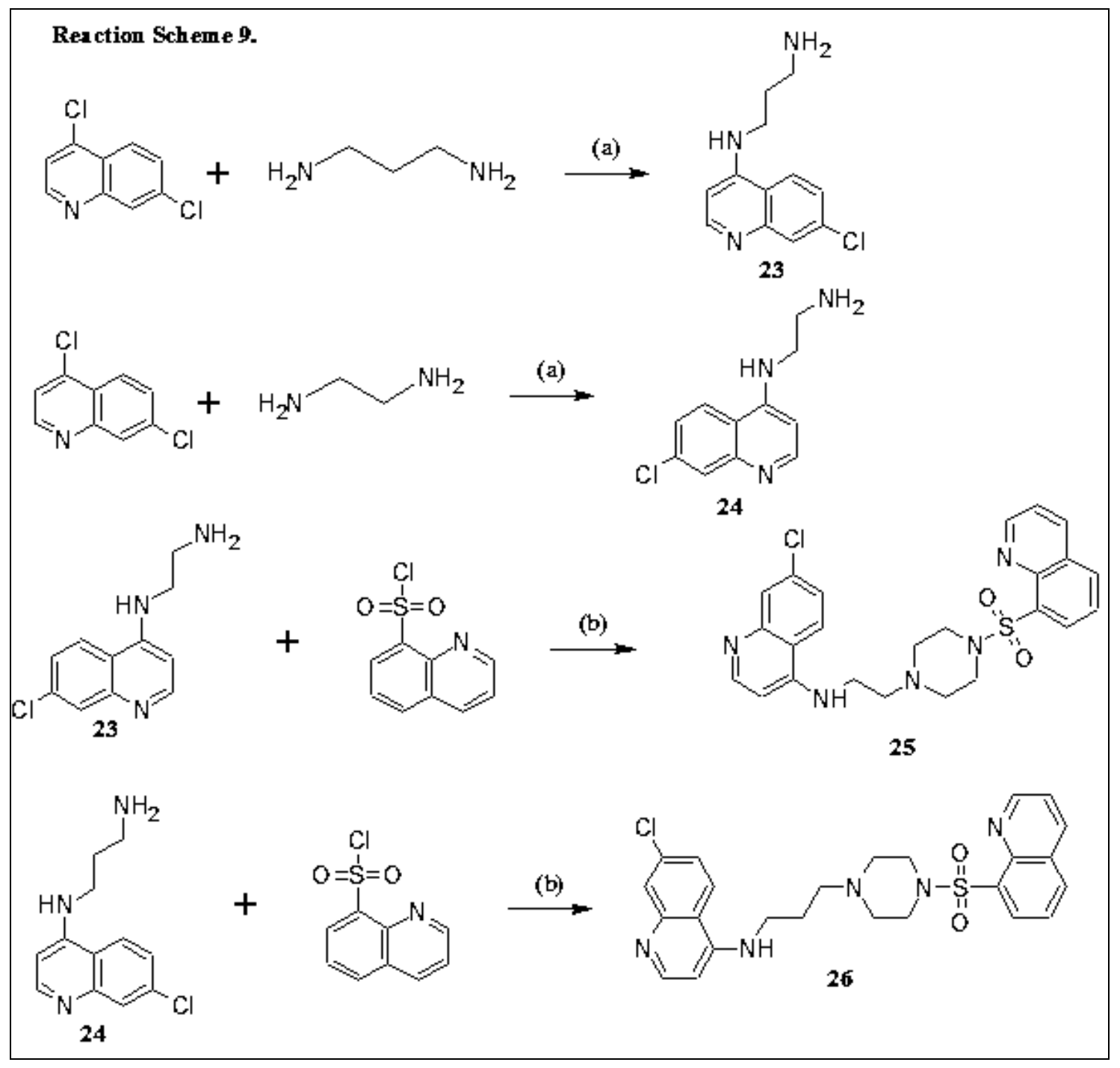

Figure 35. Reaction Scheme 9. (a) 12 molar equivalents of diamine; reflux 18 h. (b) $1.25 \mathrm{eq} \mathrm{Et}_{3} \mathrm{~N}, \mathrm{DCM}, 0$ ${ }^{\circ} \mathrm{C}$. 


\subsubsection{7-chloro-N-(3-\{4-[3-(trifluoromethyl)benzenesulfonyl]piperazin-1-yl\}-}

propyl)quinolin-4-amine (27):

To a solution of previously prepared and purified 7-chloro-N-[3-(piperazin-1-

yl)propyl]quinolin-4-amine (see 22) $(0.25 \mathrm{~g}, 1 \mathrm{mmol})$ in $8-10 \mathrm{~mL}$ of DCM at $0{ }^{\circ} \mathrm{C}$ was added triethylamine $(0.12 \mathrm{~mL}, 1.26 \mathrm{mmol}) .0 .19 \mathrm{~g}$ of quinonyl-8-sulfonyl chloride was added portionwise. The reaction was let warm to room temperature and stirred overnight. On reaction completion (TLC) $20 \mathrm{~mL}$ dichloromethane and $20 \mathrm{~mL}$ were added, and then poured into a separatory funnel for liquid-liquid extraction. The organic layer was washed with $3 \times 20 \mathrm{~mL}$ water. The organic extracts were dried over anhydrous sodium sulfate and concentrated to give a crude product which was purified by recrystallization in 15\% DCM / 85\% hexane as a white powder $(0.3 \mathrm{~g}, 72 \%)$ of compound. ${ }^{1} \mathrm{H}$ NMR $\left(\mathrm{CDCl}_{3}\right) \delta$ (ppm): $7.16(1 \mathrm{H}, \mathrm{d}, \mathrm{J}=4.55), 7.68(1 \mathrm{H}, \mathrm{d}, \mathrm{J}=8.09), 8.06(1 \mathrm{H}, \mathrm{d}, \mathrm{J}=5.890), 7.63(1 \mathrm{H}, \mathrm{d}$, $\mathrm{J}=8.09,), 3.32(2 \mathrm{H}, \mathrm{t}, \mathrm{J}=6.74), 7.57(1 \mathrm{H}, \mathrm{d}, \mathrm{J}=7.097), 1.81(14,2 \mathrm{H}, \mathrm{t}, \mathrm{J}=6.742), 2.60$ (15, $2 \mathrm{H}, \mathrm{t}, \mathrm{J}=2.67), 2.46(2 \mathrm{H}, \mathrm{m}), 2.71(4 \mathrm{H}, \mathrm{m}), 2.51(4 \mathrm{H}, \mathrm{m}), 7.82(\mathrm{H}, \mathrm{s}), 8.00(1 \mathrm{H}, \mathrm{d}$, $\mathrm{J}=7.93), 7.71(1 \mathrm{H}, \mathrm{d}, \mathrm{J}=7.93), 7.95(1 \mathrm{H}, \mathrm{d}, \mathrm{J}=7.74)$.

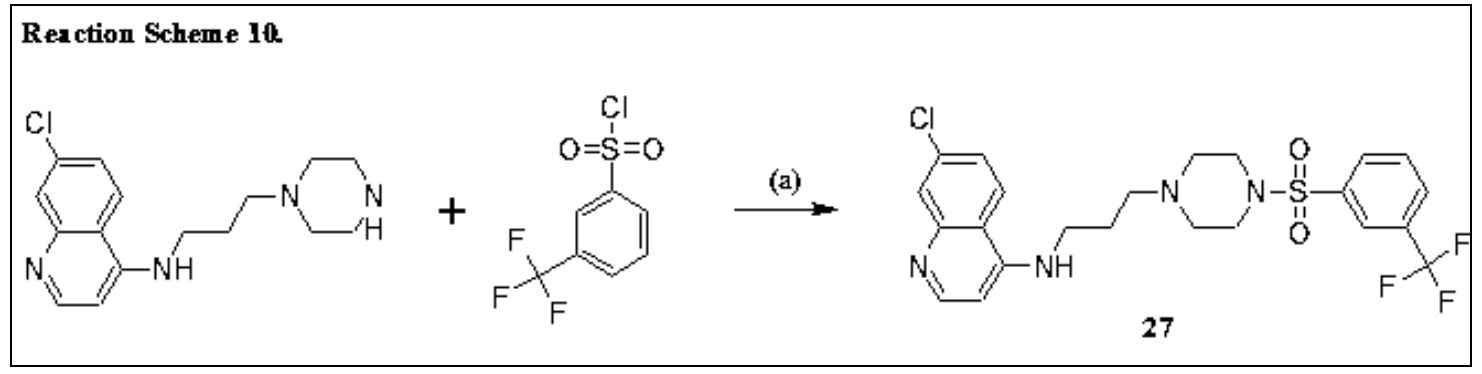

Figure 36. Reaction Scheme 10. (a) $1.25 \mathrm{eq} \mathrm{Et}_{3} \mathrm{~N}, \mathrm{DCM}, 0{ }^{\circ} \mathrm{C}$. 


\section{Chapter 4. Conclusions:}

Malaria is a devastating disease that has necessitated a pipeline of inexpensive chemotherapeutics in the face of the continual evolution of resistance mechanisms. A promising class of such treatments is the reversed chloroquine, first reported by the lab of David Peyton in 2006. The present thesis establishes the characteristics of several analogs of leading reversed chloroquine candidates that either a) maintain or improve drug potency, or b) impair the drug's function. The truncation of the 3-carbon linker in PL241 to two carbons does not affect drug efficacy, consistent with previous SAR studies on other RCQs of the effect of varying the aliphatic chain. A sulfonamide analog of RCQ retains high potency even in the absence of the standard reversal agent - that is, a diphenyl fragment or a quinoline. Substitution in a position other than 4 in the antimalarial portion of an RCQ impairs binding, particularly when substitution is in the third position.

An obvious deficiency of the thesis is that several of the completed molecules have yet to be subjected to pharmacological testing. Additional analytical methods need to be applied to the completed molecules, including high-performance liquid chromatography, mass spectrometry, elemental analysis, and ${ }^{13} \mathrm{C}$ NMR spectroscopy. Much work has to be done in the computational analyses. The transition state model must be refined to better reflect reaction conditions. Molecular dynamics with explicit solvent and full molecules are highly desirable.

Future work should consider alternative reaction conditions to permit the successful synthesis of those sulfonamide molecules that have so far proven intractable. 
As a particular form of sulfonamide analog is clarified, research can be dedicated to subtle alterations in the structure of this promising analog. 


\section{$\underline{\text { References: }}$}

Adam, M.E., El Fatih, E., Karim, A.Y., Ibrahim, K.E.E., Berger, B.J., Wiese, M., \& Babiker, H.A. (2004). "Imipramine induced complete reversal of chloroquine resistance in Plasmodium falciparum infections in Sudan." Saudi Pharmacology Journal. Vol. 12, pp. 130-135.

Bynum, B. (2008). "A history of malaria." The Lancet, Vol. 371, Iss. 9622, pp. 1407 1408.

Chai, A.C., Chevli, R., \& Fitch. C. (1980). "Ferriprotoporphyrin IX Fulfills the Criteria for Identification as the Chloroquine Receptor of Malaria Parasites." Biochemistry, Vol. 19, Iss. 8, pp. 1543 - 1549.

Cooper, R., Hartwig, C. \& Ferdig, M. (2005). "pfcrt is more than the Plasmodium falciparum chloroquine resistance gene: a functional and evolutionary perspective." Acta Trop. Vol. 94, Iss. 3, pp. 170-80.

Egan, T.J. (2008). "Haemozoin formation." Molecular and Biochemical Parasitology. Vol. 157, Iss. 2, pp. 127 - 136.

Feont Hall, B., \& Fauci, S. (2009). "Malaria Control, Elimination, and Eradication: The Role of the Evolving Biomedical Reseach Agenda." Journal of Infectious Diseases, vol. 200, Iss. 11, pp. 1639 - 1643/

Hashemi, N., Callon, L.M., \& Kumar, K.S. (2015). "Malaria retinopathy and cerebellitis in a 9-year-old boy in the United States." Journal of American Association for Pediatric Ophthalmology and Strabismus, Vol. 19, Iss. 1, pp. 87-89.

Hays, C.W. (2000). "The United States Army and malaria control in World War II." Parassitologia, Vol. 42, Iss. 2, pp. 47-52.

Khan, H.M., Shujatullah, F., Ashfaq, M., \& Raza A. (2011). "Changing trends in prevalence of different Plasmodium species with dominance of Plasmodium falciparum malaria infection in Aligarh (India)." Asian Pacific Journal of Tropical Medicine, Vol. 4, Iss. 1, pp. 64-66.

Krafts, K., Hempelmann, E., \& Skórska-Stania, A. (2012). "From methylene blue to chloroquine: a brief review of the development of an antimalarial therapy". Parasitol Res., Vol. 11, Iss. 1, pp. 1-6.

Kuhn, Y., Rohrbach, P. \& Lanzer, M.. (2007). "Quantitative pH Measurements in Plasmodium Falciparum-infected Erythrocytes Using PHluorin." Cellular Microbiology Vol. 9, Iss. 4, pp. 1004-013. 
Liu W., Li Y., Shaw K.S., Learn G.H., Plenderleith L.J., Malenke J.A., Sundararaman S.A., Ramirez M.A., Crystal P.A., Smith A.G., Bibollet-Ruche F.1, Ayouba A., Locatelli S., Esteban A., Mouacha F., Guichet E., Butel C., Ahuka-Mundeke S6, Inogwabini B.I., Mpoudi-Ngole E., Delaporte E., Carter R., Culleton R.L., Shaw G.M., Rayner J.C., Peeters M., Hahn B.H., \& Sharp PM32. (2014) "African origin of the malaria parasite Plasmodium vivax." Nat Commun. 5:3346.

Linscott, A.J. (2011). "Malaria in the United States - Past and Present" Clinical Microbiology, Vol. 33, Iss. 7, pp. 49 -52.

Mabaso, M.L.H., \& Ndlovu, N.C. (2012). "Critical review of research literature on climate-driven malaria epidemics in sub-Saharan Africa." Public Health, Vol. 126, Iss. 11, Pages 909-919.

Marciniec, K., \& Maslankiewqicz, A. (2009). "Action of NaSMe towards 4,7dichloroquinoline." Heterocycles, Vol. 42, Iss. 5, pp. 321 - 329.

Martin RE, Marchetti RV, Cowan AI et al.(September 2009). "Chloroquine transport via the malaria parasite's chloroquine resistance transporter". Science, Vol. 325, pp. 16801682:

Meshnick, S.R., \& Dobson, M.J. (2001). "The History of Antimalarial Drugs." Antimalarial Chemotherapy: Infectious Disease, pp. 15 - 25.

Moss, W.J., Shah, S.N., \& Morrow, R.H. (2013). "The History of Malaria and its Control." ref. in International Encyclopedia of Public Health, pp. 389-398.

Patrick, G.L. (1995). An Introduction to Medicinal Chemistry. New York: Oxford University Press.

Patz, J.A., et al. (2000). "Effects of environmental change on emerging parasitic diseases." Int Journal of Parasitology, Vol. 30, Iss. 12, pp. 1395-405.

Peyton, D.H. (2012). "Reversed Chloroquine Molecules as a Strategy to Overcome Resistance in Malaria." Current Topics in Medicinal Chemistry, Vol. 12, Iss. 5, pp. 400 407.

Pishchany, Gleb, and Eric P. Skaar. PLoS Pathogens "Taste for Blood: Hemoglobin as a Nutrient Source for Pathogens." Vol. 8, Iss. 3, E1002535.

Poser, C.M., \& Bruyn, G.W. (2000.) "An Illustrated History of Malaria." Parasitology Today, Vol. 16, Iss. 7, p. 314.

Ramos, W.M., Sardinha, J., Costa, M.R.F., Santana, M.S., Alecrim, M.G.C.,\& Lacerdo, M.V.G. (2010). "Clinical aspects of hemolysis in patients with P. vivax malaria treated 
with primaquine, in the Brazilian Amazon." The Brazilian Journal of Infectious Diseases, Vol. 14, Iss. 4, pp. 410-412.

Raynes, K. (1999). "Bisquinoline antimalarials: Their role in malarial chemotherapy." International Journal of Parasitology, Vol. 29, Iss. 3, pp. 367 - 369.

Roepe, P.D. (2009). "The Molecular and Physiological Basis of Quinoline Drug Resistance in P. falciparum Malaria." Future Microbiology Vol. 4, Iss. 4, pp. 441-455.

Sallaras, R., \& Gomzi, S. (1999). "Biomolecular archaeology of malaria." Ancient Biomolecules, Vol. 3, pp. $195-213$.

Sherman, I.W. (1998). Malaria: Parasite Biology, Pathogenesis, and Protection. ASM Press.

Sinton J.A., \& Ghosh, B.N. (1934). "Studies of malarial pigment (haemozoin). Part I. Investigation of the action of solvents on haemozoin and the spectroscopical appearances observed in the solutions". Records of the Malaria Survey of India. Vol. 4, pp. 15 - 42.

Wellems, T., \& Plowe, C. (2001). "Chloroquine-resistant Malaria." The Journal of Infectious Diseases, Vol. 184, pp. 770 - 776.

RTS,S Clinical Trials Partnership. "Effi cacy and safety of RTS,S/AS01 malaria vaccine with or without a booster dose in infants and children in Africa: final results of a phase 3 , individually randomised, controlled trial." The Lancet, April, 2015.

World Health Organization (WHO). WHO Report 2014. (accessed online, November 2014: http://www.who.int/malaria/publications/atoz/who-recommendation-managing-oldllins-mar2014.pdf?ua=1)).

"President's Malaria Iniative 2015 Ninth Annual Report to Congress" (access online, June 2, 2015: http://www.pmi.gov/docs/default-source/default-document-library/pmireports/pmi-ninth-annual-report-congress.pdf) 
Appendix A. Example NMR Spectra:

See next page. 


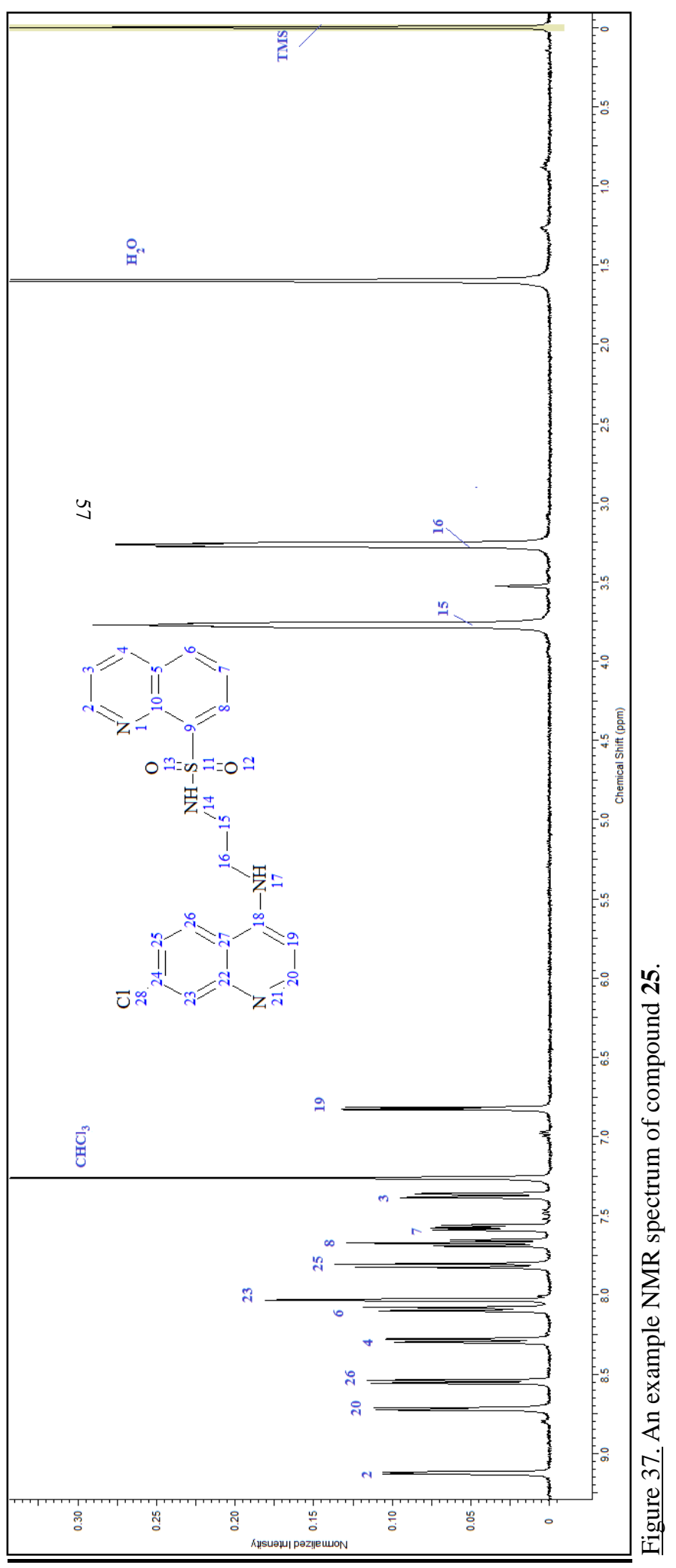


Appendix B. Example IC 50 Plot:

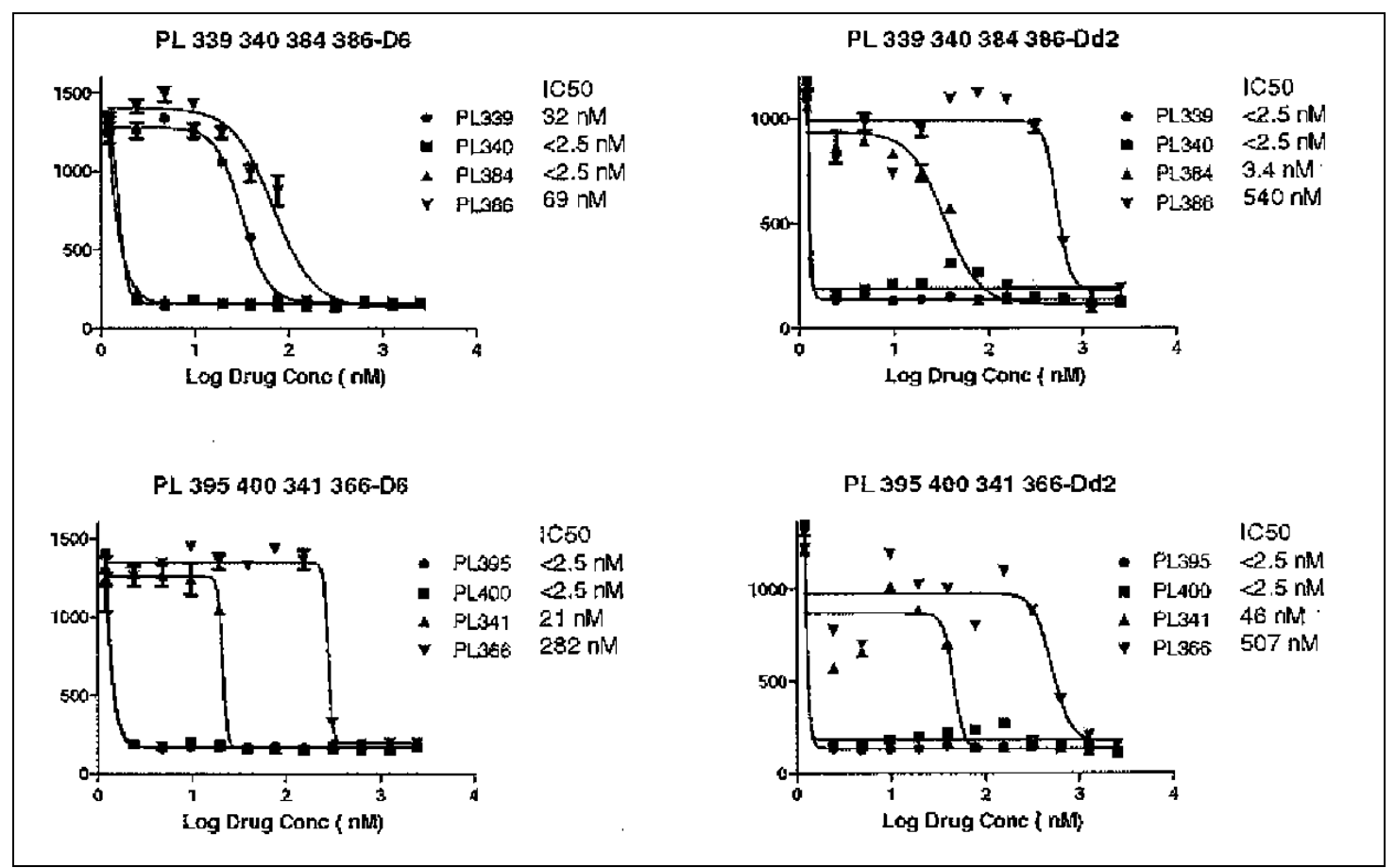

Figure 38. An example IC50 plot, the results of an in vitro test. Note that PL366 $=$ compound 3, PL400 = compound 20, PL395 = compound 16, and PL386 = compound 18. See Appendix F for structures. 


\section{Appendix C. Thermodynamics \& Kinetics via Spectroscopy:}

The efficacy of a drug is at least partially determined by its ability to bind the target molecule (receptor) which elicits a sequence of physiological events. This is usually measured by titration experiments to determine the binding affinity, $K_{a}$, the inverse of binding dissociation, $K_{d}$. Binding dissociation can be calculated by assuming the following simple stoichiometry:

$$
D+R=D R
$$

where $D$ is drug, $R$ is receptor, and $D R$ is the bound drug-receptor complex. When

$$
\frac{-d[D]}{d t}=\frac{-d[R]}{d t}=\frac{d[D K]}{d t}=0
$$

then

$$
K_{d}=K_{a}^{-1}=\frac{[D]+[R]}{[D K]}
$$

In UV-visible spectroscopy, a shift in absorption band reflects electron shifts corresponding to interactions between molecules. A titration of drug against a constant concentration of receptor will show shifts in electron excitation corresponding to such interactions. Assuming the presence of a chromophore in the ultraviolet-visible region of the electromagnetic spectrum, one can thereby equate electron excitation with the dissociation constant. For example, the binding of a drug to heme in solution induces a hypochromic shift of the absorption band corresponding to heme at about $400 \mathrm{~nm}$. If fraction of drug bound is $\Theta_{D}$, then

$$
\vartheta_{D}=\frac{[D R]}{[D]+[L R]}=\frac{1}{\frac{[D]}{[D R]}+1}=\frac{1}{\frac{K_{d}}{[R]}+1}=\frac{[R]}{K_{d}+[R]}
$$


It is easy to see from this expression that if $[R]=K_{d}$, then $\Theta_{D}=0.5$. Thus, half-maximal binding of $R$ occurs when the free $D$ concentration is equal to $K_{d}$, or when the $400 \mathrm{~nm}$ is reduced by $50 \%$.

In UV-visible spectroscopy, a shift in absorption band reflects electron shifts corresponding to interactions between molecules. A titration of drug against a constant concentration of receptor will show shifts in electron excitation corresponding to such interactions. Assuming the presence of a chromophore in the ultraviolet-visible region of the electromagnetic spectrum, one can thereby equate electron excitation with the dissociation constant.

Preliminary thermodynamic analyses by UV-visible spectroscopy give indication as to the binding energy of antimalarials to heme. This is determined by finding abscissa values corresponding to $50 \%$ of the ordinate maximum of a hyperbolic curve of concentration versus absorption band peak.

Heme chloride and the bisphosphate salt of chloroquine were purchased form Sigma-Aldrich. The experiment was performed on an Ocean Optics USB-2000 diode array spectrophotometer with 1-cm quartz cuvette. Data was directly exported to .xls format. The PL compounds were dissolved in distilled water after being converted to the dihydrochloride amine salts. The $\mathrm{pH}$ was controlled at 4.8 in all assays.

A $1 \mathrm{mM}$ stock solution of the CQ or PL compond was dissolved in distilled $60 \%$ aqueous buffer, $40 \%$ DMSO, and sonicated to ensure complete dissolution. A 4 mM stock solution of heme was prepared by dissolving $\mathrm{Heme}{ }^{*} \mathrm{Cl}$ in $0.1 \mathrm{mM} \mathrm{NaOH}$ by incubating at $37{ }^{\circ} \mathrm{C}$ for $30 \mathrm{~min}$. This solution was stored at $4{ }^{\circ} \mathrm{C}$ for up to $1 \mathrm{month}$. 
At the beginning of each experiment, stock heme was diluted to $4 \mu \mathrm{M}$ in phosphate buffer. The optical titration with each compound was performed by the successive addition of aliquots of its stock solution to $5 \mu \mathrm{M}$ heme solution. The equilibrium binding constants were determined by nonlinear least-squares analysis in Microsoft Excel. An example spectrum is shown in Figure 39, in which the heme absorption band is suppressed by increasing concentrations of PL241.

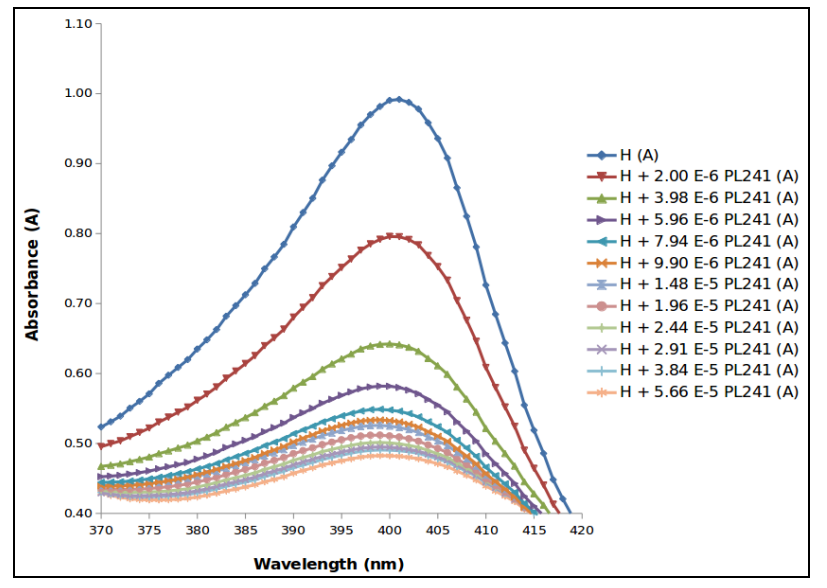

Figure 259. An example UV-Vis spectrum focusing on the absorption band (400 nm) measuring free heme.

An example plot of suppressed absorption of heme $(\alpha)$ against drug concentration is shown in figure 40 .

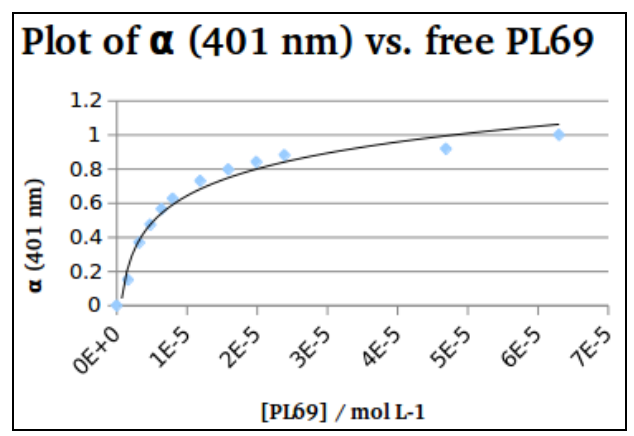

Figure 40. An example plot of suppressed absorption (at the absorption band measuring free heme) vs. drug concentration. Higher concentration of drug corresponds to greater suppression of the free heme absorption band. 


\begin{tabular}{|l|l|l|}
\hline Drug & $\mathbf{K}_{\mathbf{d}}(\boldsymbol{\mu M})$ & $\mathbf{\Delta} \mathbf{( k J ~ \mathbf { ~ m o l } ^ { - 1 } )}$ \\
\hline CQ & 4.44 & -30.5 \\
\hline PL69 & 3.35 & -31.2 \\
\hline PL241 & 3.29 & -31.3 \\
\hline
\end{tabular}

Table 1 . The primary results of the UV-visible spectroscopy thermodynamics analysis. The Gibbs free energy is proportional to the natural $\operatorname{logarithm}$ of $\mathrm{K}_{\mathrm{d}}$, as expressed in the equation $\Delta \mathrm{G}=-\underline{n} \mathrm{RT} * \ln (\mathrm{K})$.

As seen in Table 1, the indications thus far are that, while reversed chloroquines and bisquinolines generally do bind to heme with greater affinity, it is not on an order of magnitude consistent with the differential of efficacy extant in vivo. Perhaps, then, the pronounced efficacy of reversed chloroquines lie in a mechanism outside that of heme binding.

It is also possible to conduct kinetic studies by observing spectra of a solution over time. The kinetic analyses of this system are, at this stage, highly preliminary. By UV-visible spectroscopy, we have found that the instrument lacks the temporal resolution necessary to quantitate this rate of interaction; rather, it has only given a relative indication of the rate of association. These efforts to assess the rate of interaction between heme and a chloroquine-like molecule have indicated that the association happens as a function of a rate constant that is greater than $10 \mathrm{~s}^{-1}$. For very rapid kinetics, analyses will require stopped-flow techniques. 


\section{Appendix D. pKa Titration of a RCQ Lead:}

A detailed $\mathrm{pH}$ titration analysis was carried out to determine not merely the global $\mathrm{pKa}$, but the individual pKa's of protonatable nitrogens of a lead RCQ, PL69. The bisphosphate salt of PL69 was dissolved, to a final $1 \mathrm{mM}$ concentration, in $25 \mathrm{mM}$ sodium phosphate buffer of $90 \% \mathrm{H}_{2} \mathrm{O}$ and $10 \% \mathrm{D}_{2} \mathrm{O}$, and a trace of DSS reference, with $25 \mathrm{mM} \mathrm{KCl}$ for ionic buffering. Beginning at a $\mathrm{pH}$ of 2.00, prepared by dissolving 250 $\mathrm{mL}$ of a $2 \mathrm{X}$ stock with $0.21 \mathrm{~mL}$ conc. $\mathrm{HCl}$ and $250 \mathrm{~mL}$ distilled $\mathrm{H}_{2} \mathrm{O}$ the $\mathrm{pH}$ of the solution of a series of test tube samples was titrated with increasing volumes of $0.15 \mathrm{M}$ $\mathrm{NaOH}$ in steps of $0.5 \mathrm{pH}$ increments, monitoring with an electrode. These samples were subjected to ${ }^{1} \mathrm{H}$ NMR spectroscopy, yielding data such as shown in Figure 41. A small program was written in Python to carry out the data analysis on chemical shifts, including calculation of first derivatives to determine equivalence points. Plotted on a Cartesian axis of change in chemical shift vs. $\mathrm{pH}$, the data can be represented as depicted in Figure 42. The conclusions of this analysis are shown in Figure 43. The pKa of the quinoline ring $\mathrm{NH}^{+}$was lower than published reports of the chloroquine (CQ) equivalent, which has a pKa of approximately 8.5. The most notable difference between the structure of CQ and PL69 is the presence of a methyl group, in PL69, on the carbon alpha to the secondary amine at the 4-position of the quinoline ring. This may subtly influence the electron resonance between the $\mathrm{NH}^{+}$of the quinoline ring, and the $\mathrm{NH}$ at the 4-position, and thereby alter the $\mathrm{pKa}$ of the quinolone ring $\mathrm{NH}^{+}$. One would expect this lower $\mathrm{pKa}$ to attenuate the DV:cytosol concentration, because a larger concentration difference across the DV membrane is generally thought important for heme binding and, thereby, potency. 
But the $\mathrm{IC}_{50}$ of PL69 is lower than that of CQ, despite a smaller DV influx, suggesting that the mechanism for malaria resistance lies at least partially outside of the DV.

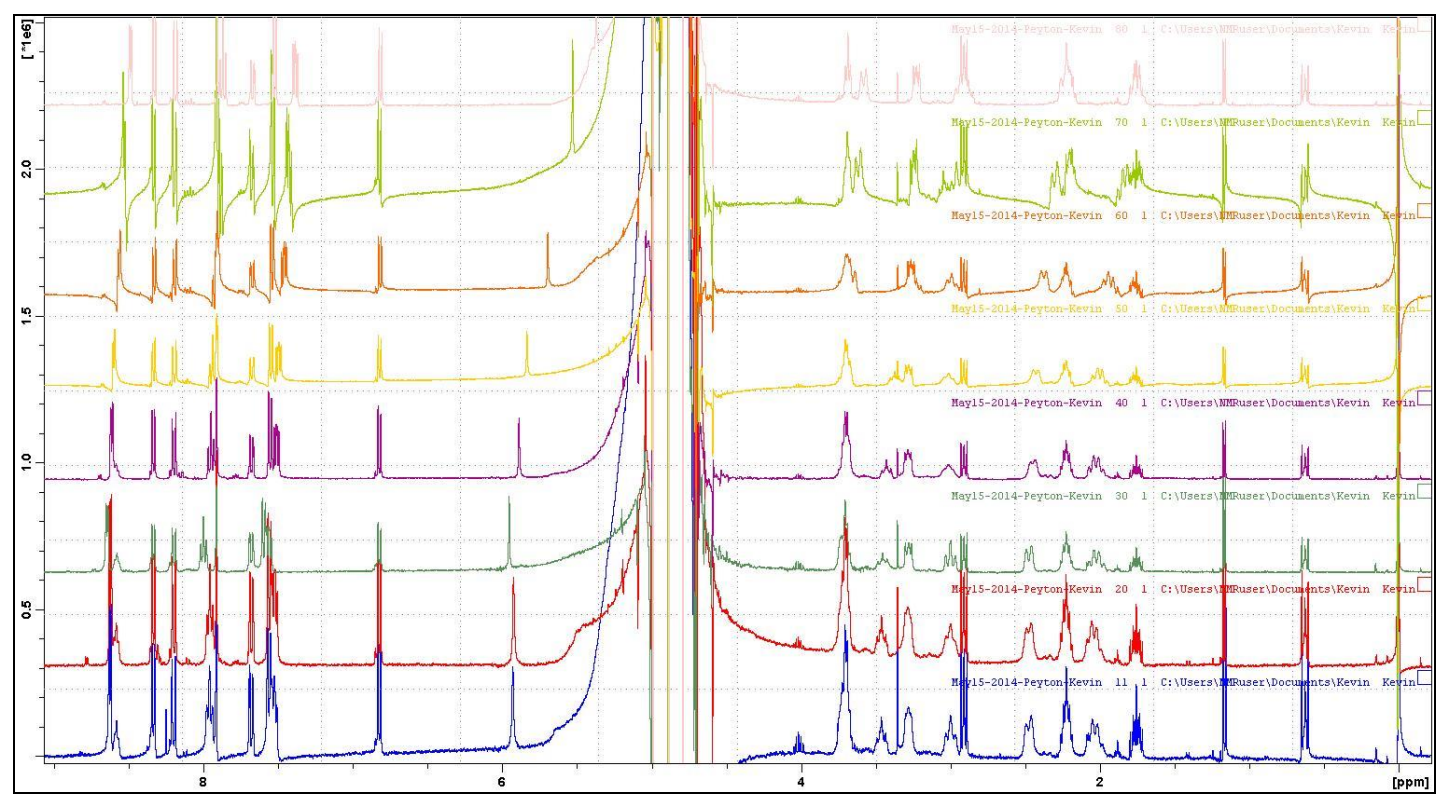

Figure 41. Stacked NMR spectra of PL69 samples at differing pH's. 


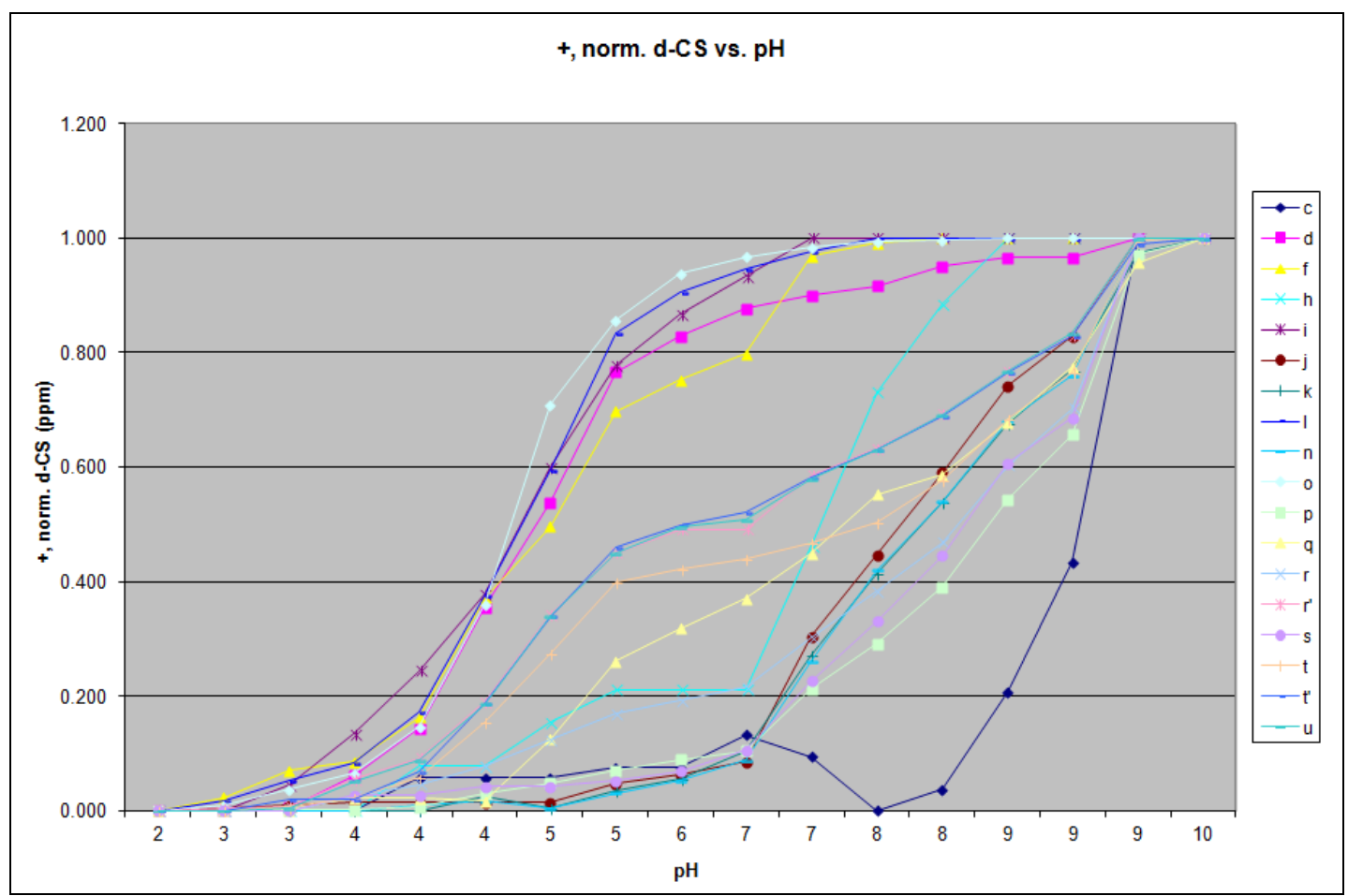

Figure 262. A plot of change in chemical shift vs. $\mathrm{pH}$.

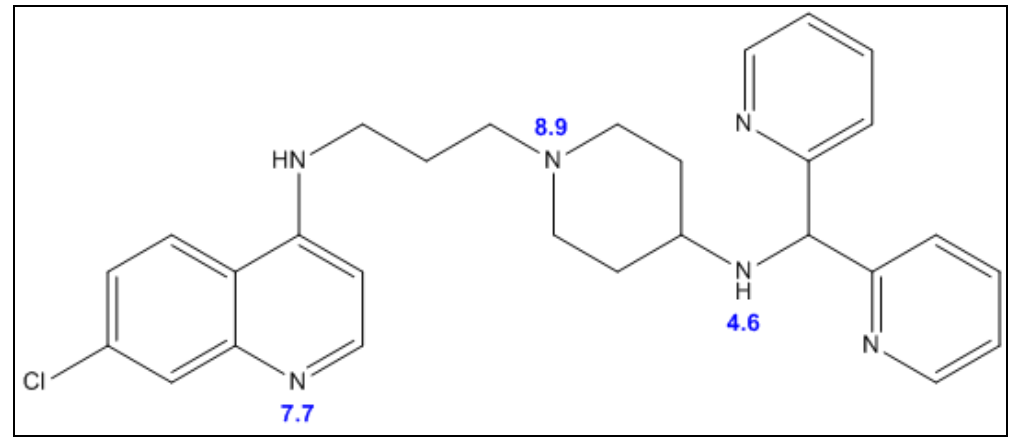

Figure 273. Measured pKas of protonatable nitrogens of the lead RCQ PL69. 


\section{Appendix E. Computational Analysis:}

Drug design relies enormously and increasingly upon computational modeling

(e.g., Durrant \& McCammon, 2011). These technologies make possible the elucidation of many aspects of pharmaceutical sciences that are critical to medicinal chemists:

molecular structures, prediction of drug-receptor interactions, and even transition state structures and the associated energetics for the reactions used by synthetic medicinal chemists to build new lead molecular structures.

Molecular mechanics (MM) simulations were performed using the Universal Force Field (UFF), the parameters of which include many transition metals. Aqueous solvent was modeled implicitly with the incorporation of the dielectric constant corresponding to water. Heme and the protonated form of PL69 was considered in two separate molecular modeling studies. A molecular electrostatic potential map of PL69, based on semi-empirical calculations, show the quinoline and one ring of the reversal agent as the highest electronic density regions. The HOMO orbitals are concentrated on these electron-rich heterocyclic regions. The LUMO distribution centers around the charged nitrogen atom of the reversal agent. These electronic features suggest that both moieties of a RCQ may interact with the heme group since, in the case of chloroquine, such interaction is believed to occur through a co-facial $\pi-\pi$ complex.

Figure 44 shows the result of a MM calculation of CQ in the presence of heme. Depicted is the atomic structure as ball-and-stick, as well as VdW spheres to approximately depict the spatial dimensions of the atoms' electrons with respect to each other. The geometry is consistent with reports that chloroquine binds cofacially to unligated faces of heme via $\pi-\pi$ stacking. Chloroquine-like molecules complex by a non- 
covalent mode with iron protoporphyrin IX. CQ is planar to the iron-porphyrin system, with the quinoline moiety orientated toward the planar and electron-rich periphery region of heme. In addition, the nitrogen atom of the secondary amine is orientated toward the iron atom, establishing an electron transfer interaction, while the side-chain interacts by attractive vdW forces with the porphyrin system.

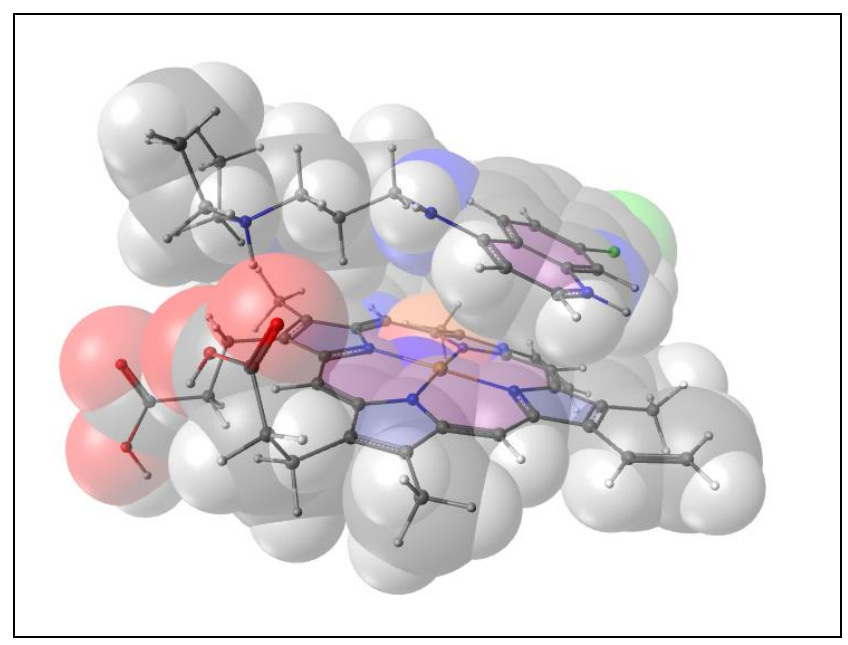

Figure 284. CQ complexed non-covalently with heme.

Quantum chemical calculations were performed to build on earlier work by Bhattacharjee $(2000 ; 2001)$ exploring the nature of non-covalent interactions between the quinoline ring of a drug and fragments of heme. These calculations were performed using the $6-31 \mathrm{G}^{* *}$ basis as implemented in the PSI4 package. The basis set is constructed by a set of six second-order (d-type) gaussian primitives to the split-valence 6-31G basis set description of each heavy non-hydrogen atom together with a single set of gaussian ptype functions to each hydrogen and helium atom. The method employed was the unrestricted Hartree-Fock method and Moller-Plesset perturbation theory, the MP2 variant, for electron correlation.cAn understanding of the weak noncovalent interaction is 
crucial to a large number of biological processes. In particular, the participation of metal ions in biological processes is well documented. For instance, cation- $\pi$ type noncovalent interactions play a major role in macromolecular organization. In the context of an antimalarial mechanism, it is speculated that iron, while possibly contributing relatively little to the binding affinity of a drug, plays an important role in longer-distance electrostatic interactions - i.e., initial recognition. Molecular electrostatic potential profiles may provide a convenient qualitative guide to track the quantitative binding energies of a cation in a complex as well as the strength of the pi electrons in aromatic systems.

Figure 45 shows the result of a geometry optimization experiment, visualized with a ball-and-stick model and vdW spheres, between 4-amino-7-chloroquinoline and a sodium cation. Figure 45 also shows the highest occupied molecular orbitals of this calculation from two angles. This line of research remains highly preliminary.

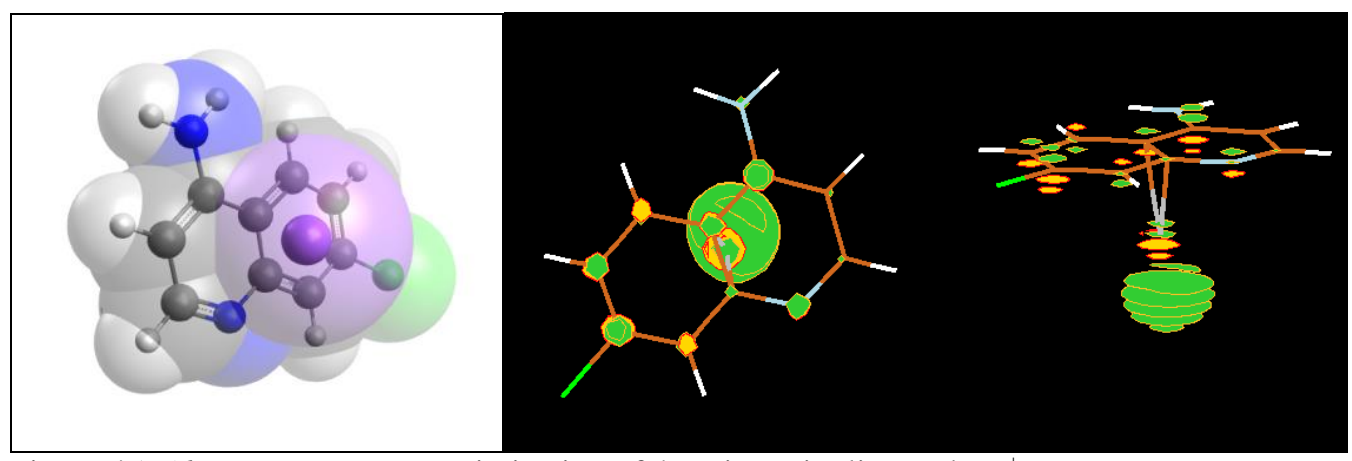

Figure 45. Ab initio geometry optimization of 4-aminoquinoline and $\mathrm{Na}^{+}$.

In addition to interaction studies, transition state calculations were executed to explore the challenges associated with reaction scheme 6 . The analysis was necessarily a simplified model. Consistent with most simple computational Menshutkin-type $\mathrm{S}_{\mathrm{N}} 2$ 
reactions, a clear transition state, as an imaginary frequency or negative eigenvalue of the Hessian matrix, was converged upon (see Figure 46). Further computational exploration will be necessary to elucidate the complex characteristics of this particular reaction system. It is anticipated that refinement of such calculations will serve as a useful tool for predicting the viability of proposed reactions by synthetic chemists.

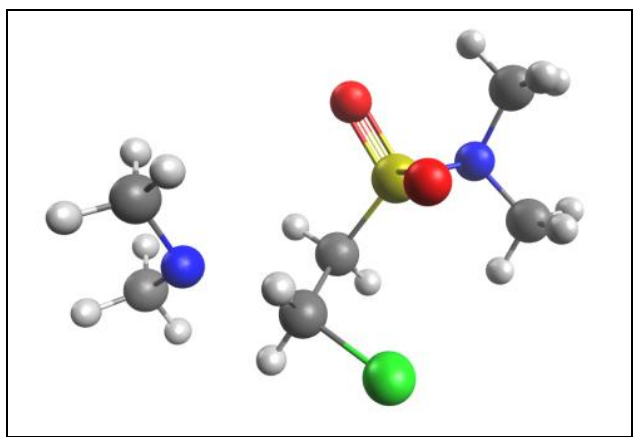

Figure 296. The transition state of a model of the $\mathrm{S}_{\mathrm{N}} 2$ reaction in Reaction Scheme 6. 
Appendix F. Summary of Results,

and Corresponding Thesis Structures to the Peyton Lab (PL) Compound Database:

\begin{tabular}{|c|c|c|c|}
\hline Compound & PL & $\mathrm{CQ}^{\mathrm{R}} \mathrm{IC}_{50}(\mathrm{nM})$ & Structure \\
\hline 3 & 366 & 507 & \\
\hline 16 & 395 & $<2.5$ & \\
\hline 18 & 386 & 540 & \\
\hline 20 & 400 & $<2.5$ & \\
\hline 21 & 455 & 211 & $\mathrm{Cl}$ \\
\hline 22 & 451 & $>250$ & \\
\hline
\end{tabular}




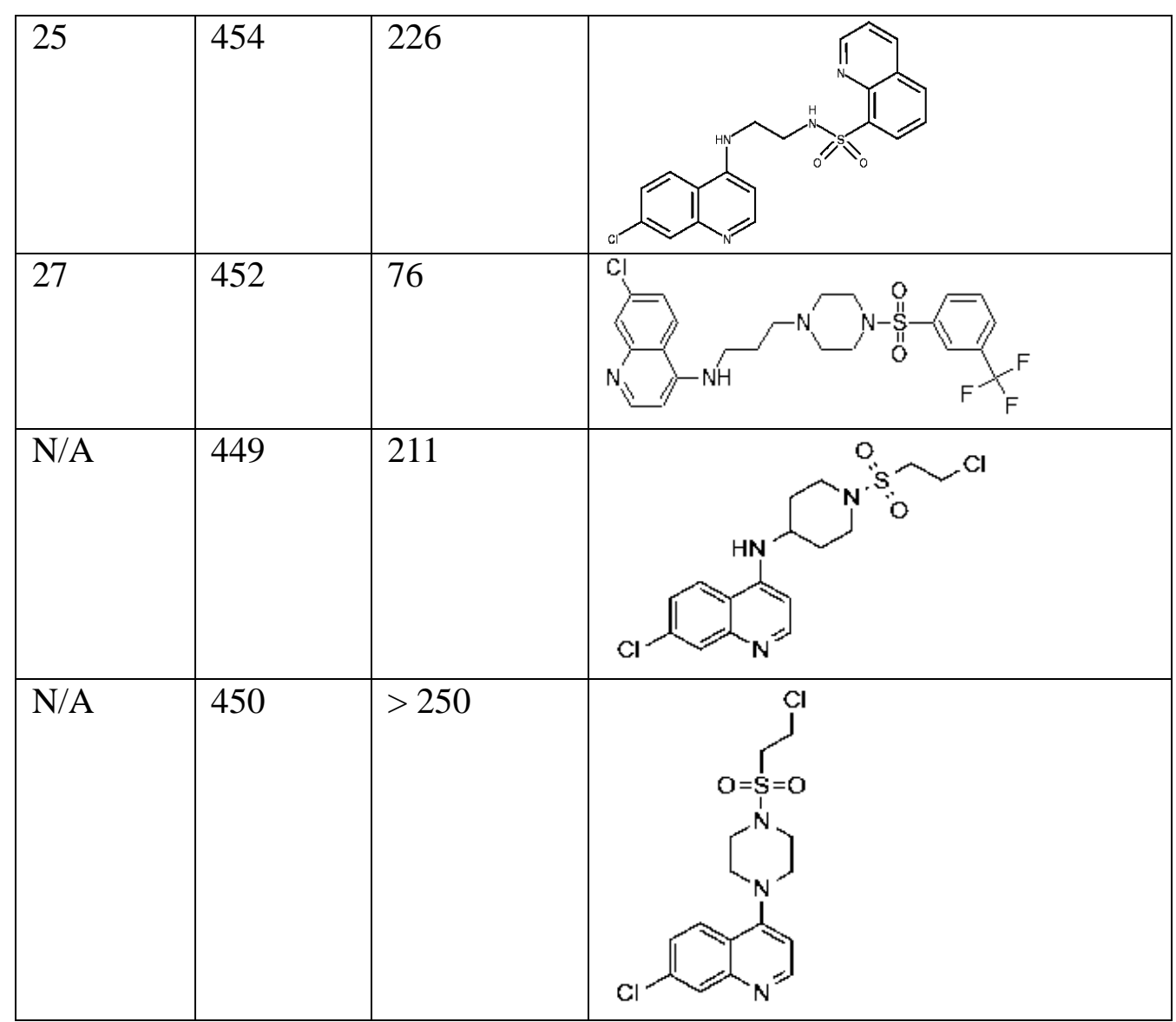

Table 2. Summary of results. 